Supporting Information for

\title{
Oxygen Atom Transfer as Key to Reverse Regioselectivity in the Gold(I)- Catalyzed Generation of Aminooxazoles from Ynamides
}

Dmitry P. Zimin, ${ }^{a}$ Dmitry V. Dar'in, ${ }^{a}$ Vadim Yu. Kukushkin,* a,b and Alexey Yu. Dubovtsev*a

${ }^{a}$ Saint Petersburg State University, Universitetskaya Nab. 7/9, 199034 Saint Petersburg, Russian Federation

${ }^{b}$ South Ural State University, 76, Lenin Av., Chelyabinsk 454080, Russian Federation

E-mails: v.kukushkin@spbu.ru (V.Yu.K.); a.dubovtsev@spbu.ru (A.Yu.D.)

Copies of ${ }^{1} \mathrm{H}$ and ${ }^{13} \mathrm{C}\{1 \mathrm{H}\}$ NMR spectra and XRD data 
${ }^{1} \mathrm{H}$ NMR $\left(400 \mathrm{MHz}, \mathrm{CDCl}_{3}\right)$
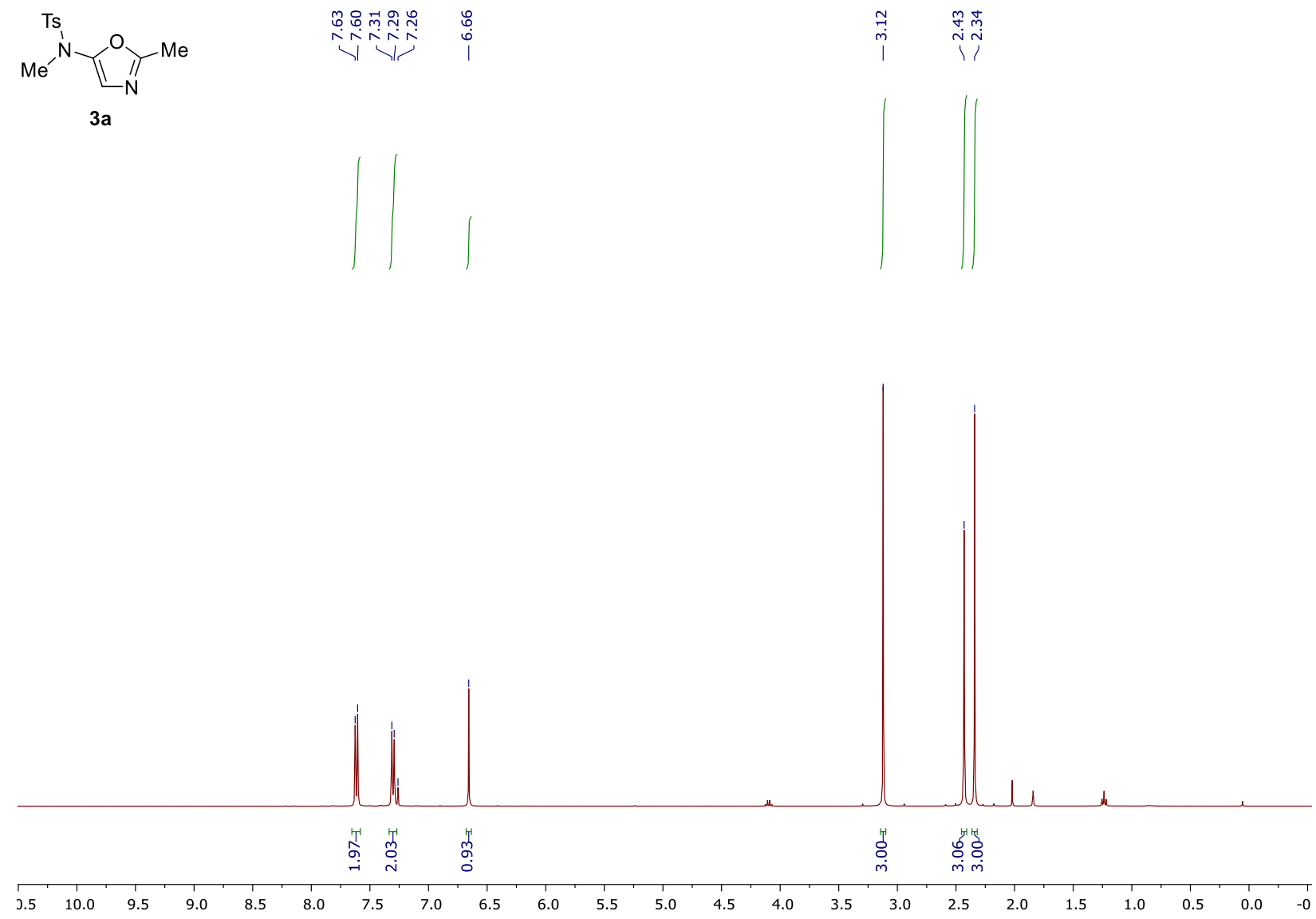

${ }^{13} \mathrm{C}\left\{{ }^{1} \mathrm{H}\right\} \mathrm{NMR}\left(100 \mathrm{MHz}, \mathrm{CDCl}_{3}\right)$

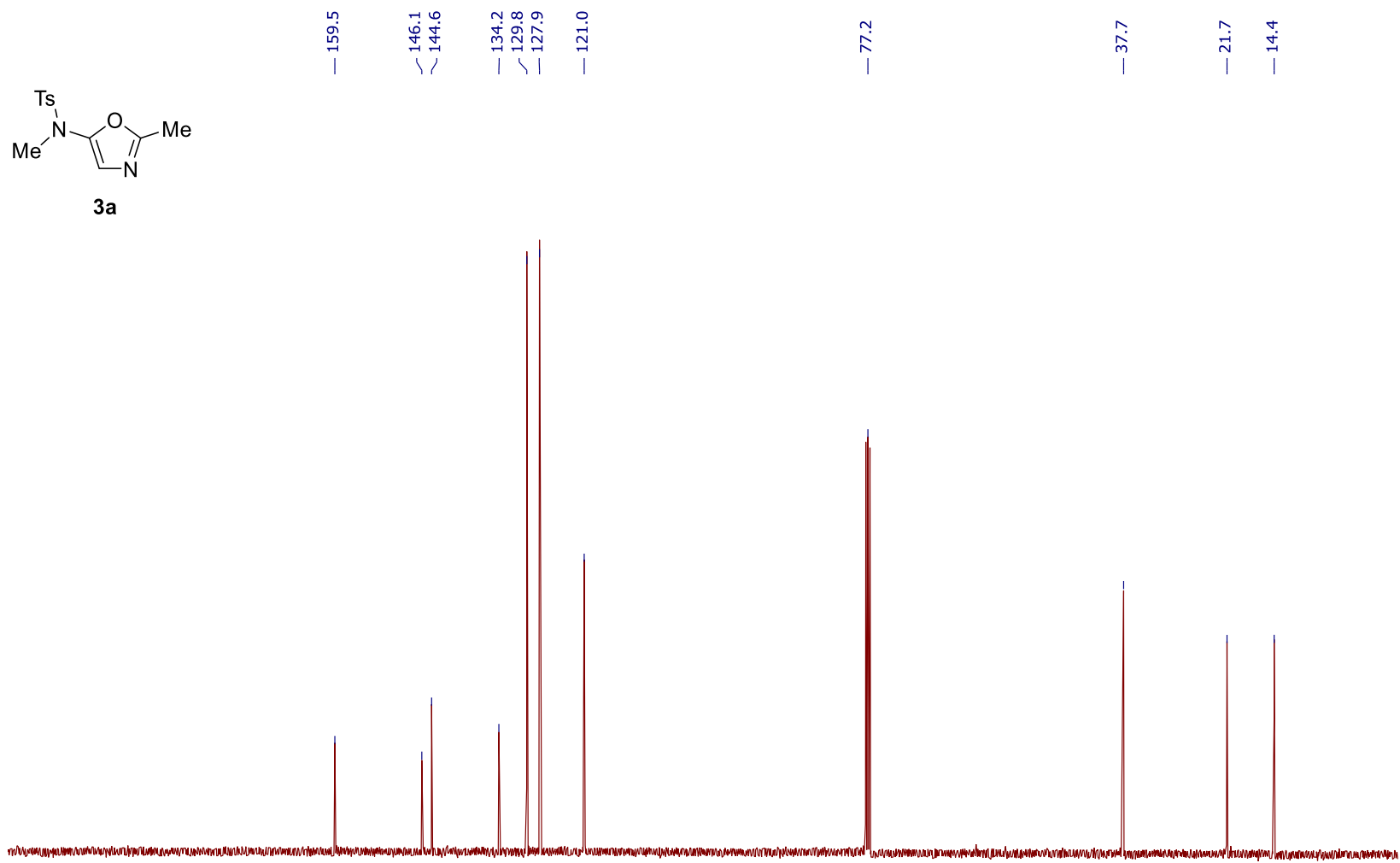

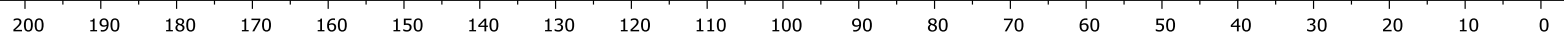


${ }^{1} \mathrm{H}$ NMR (400 MHz, $\left.\mathrm{CDCl}_{3}\right)$
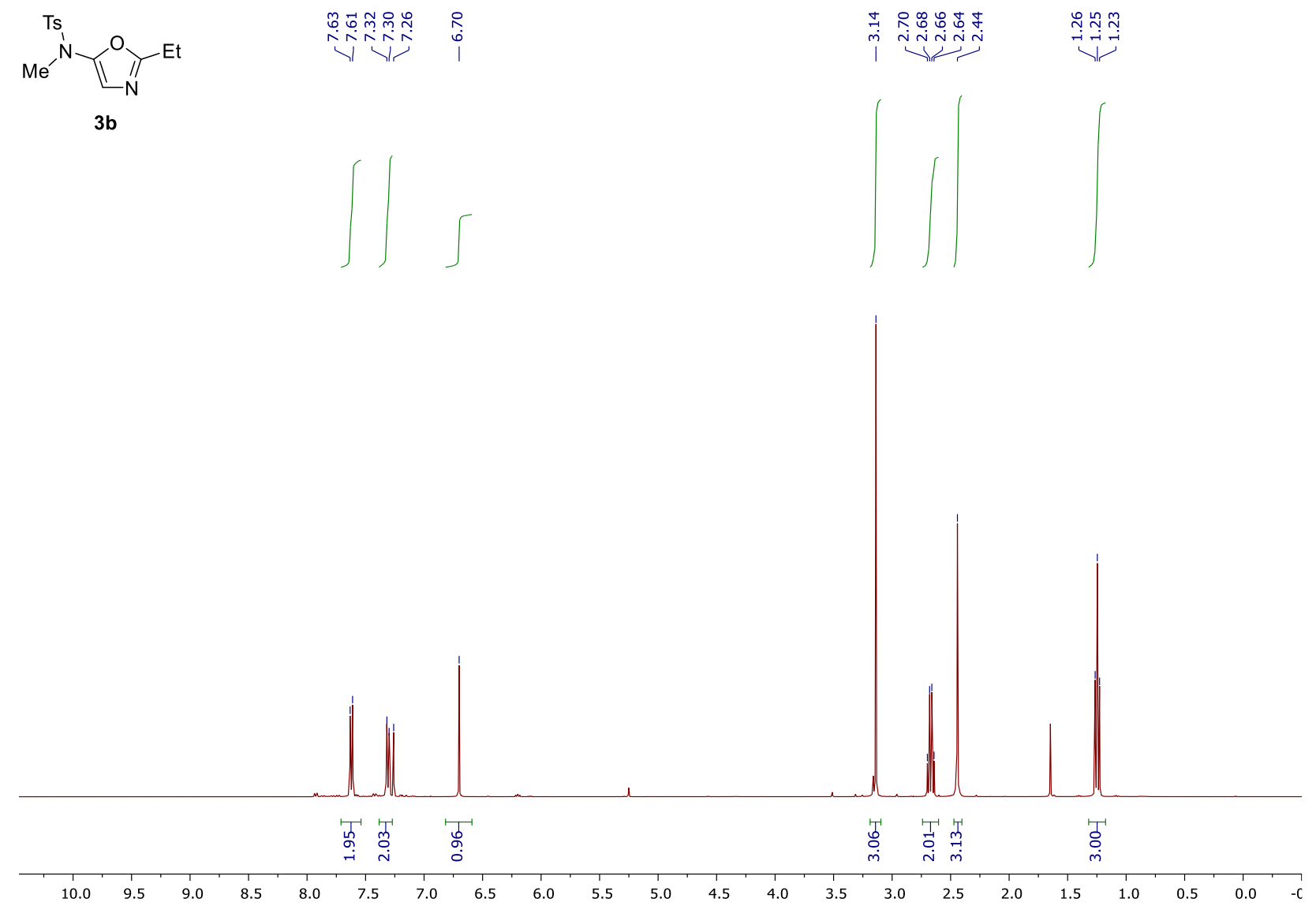

${ }^{13} \mathrm{C}\left\{{ }^{1} \mathrm{H}\right\} \mathrm{NMR}\left(100 \mathrm{MHz}, \mathrm{CDCl}_{3}\right)$

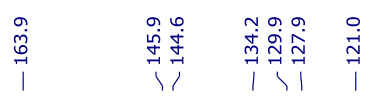

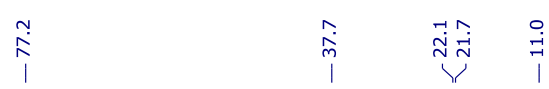

$\mathrm{Me}^{\mathrm{N}} \mathrm{T}_{\mathrm{N}}^{\mathrm{T}} \mathrm{T}^{\mathrm{Et}}$

3b

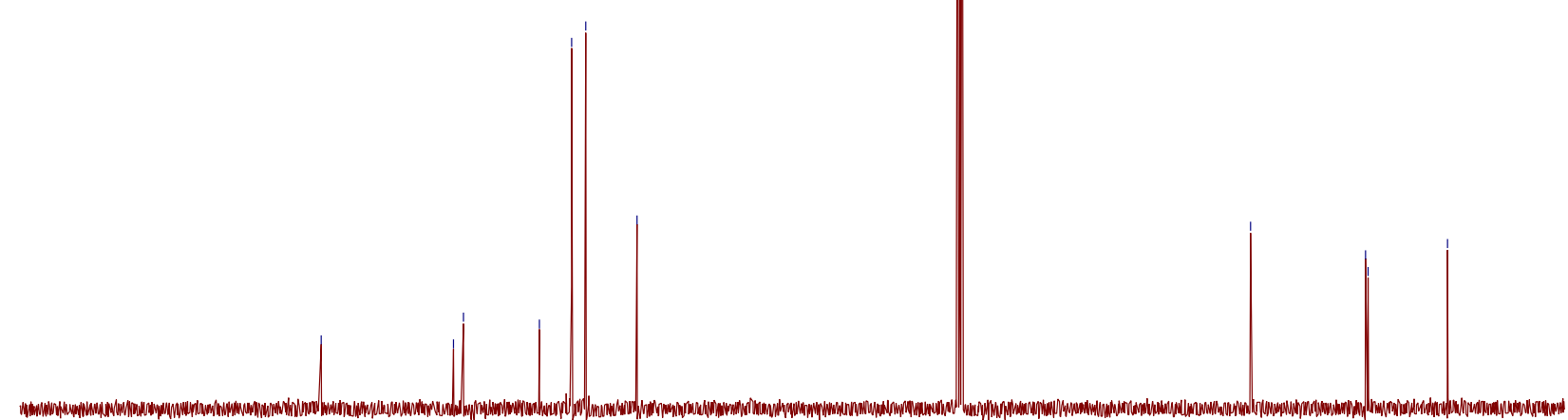

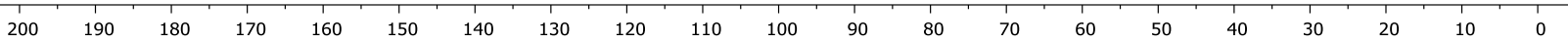


${ }^{1} \mathrm{H}$ NMR (400 MHz, $\left.\mathrm{CDCl}_{3}\right)$
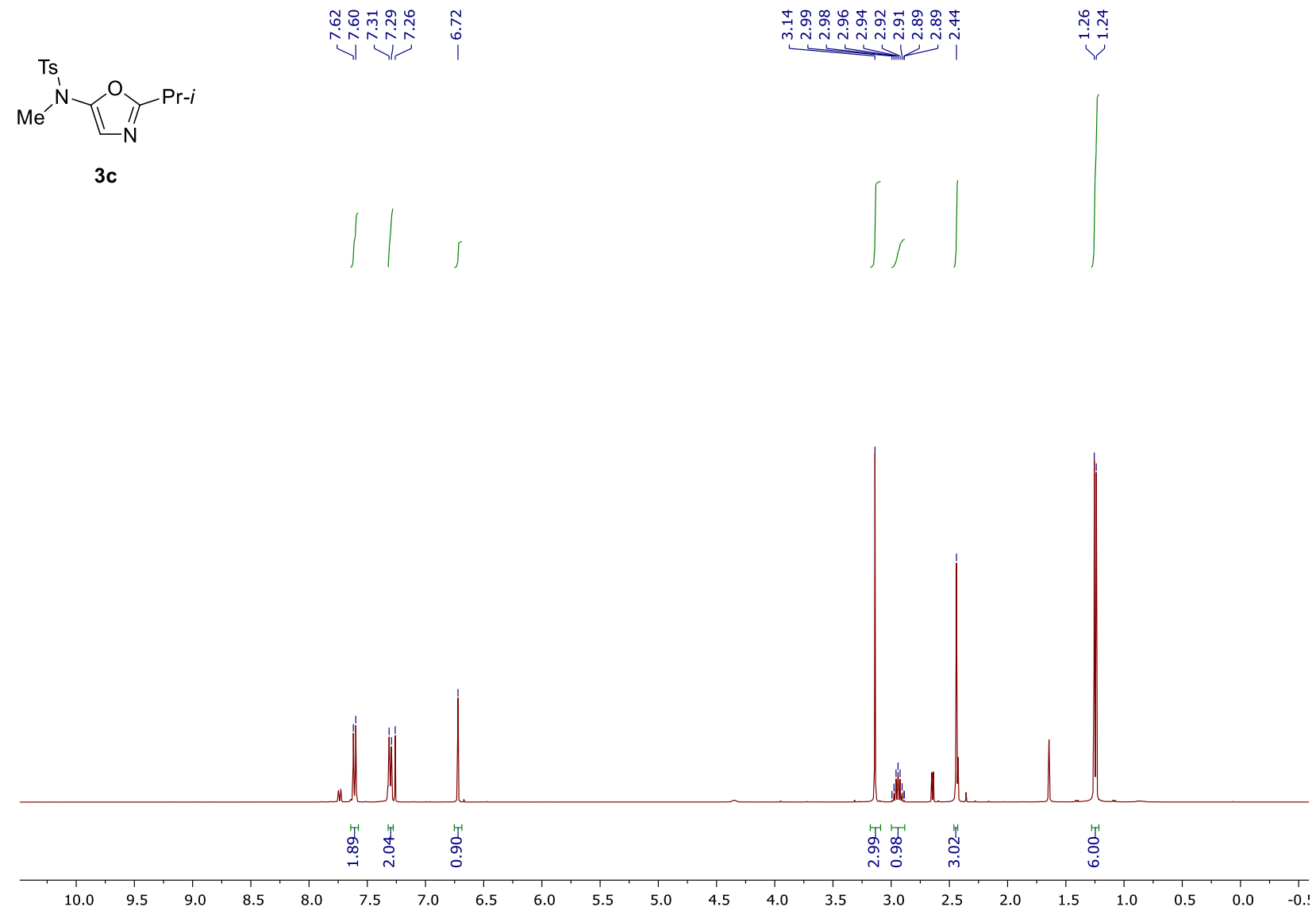

${ }^{13} \mathrm{C}\left\{{ }^{1} \mathrm{H}\right\}$ NMR (100 MHz, $\left.\mathrm{CDCl}_{3}\right)$
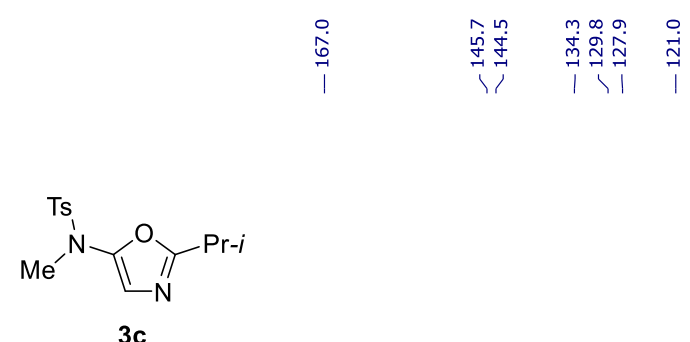

$3 c$

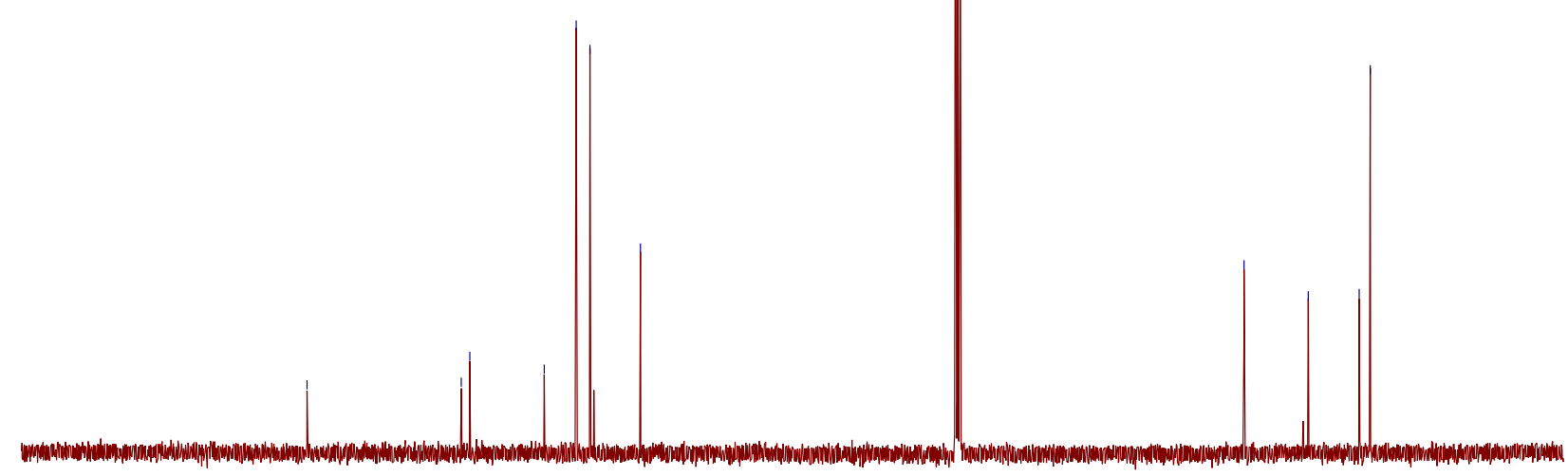

$\begin{array}{lllllllllllllllllllll}200 & 190 & 180 & 170 & 160 & 150 & 140 & 130 & 120 & 110 & 100 & 90 & 80 & 70 & 60 & 50 & 40 & 30 & 20 & 10 & 0\end{array}$ 
${ }^{1} \mathrm{H}$ NMR $\left(400 \mathrm{MHz}, \mathrm{CDCl}_{3}\right)$

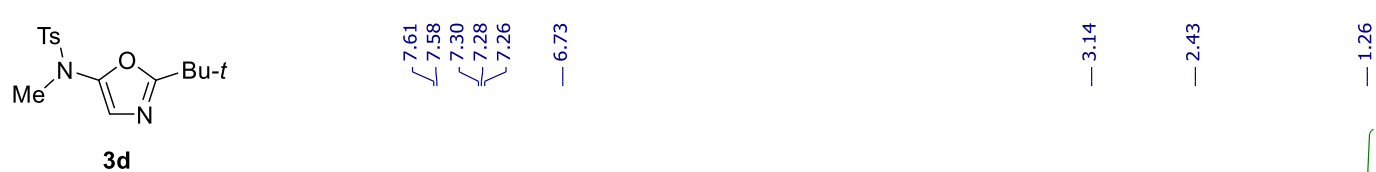

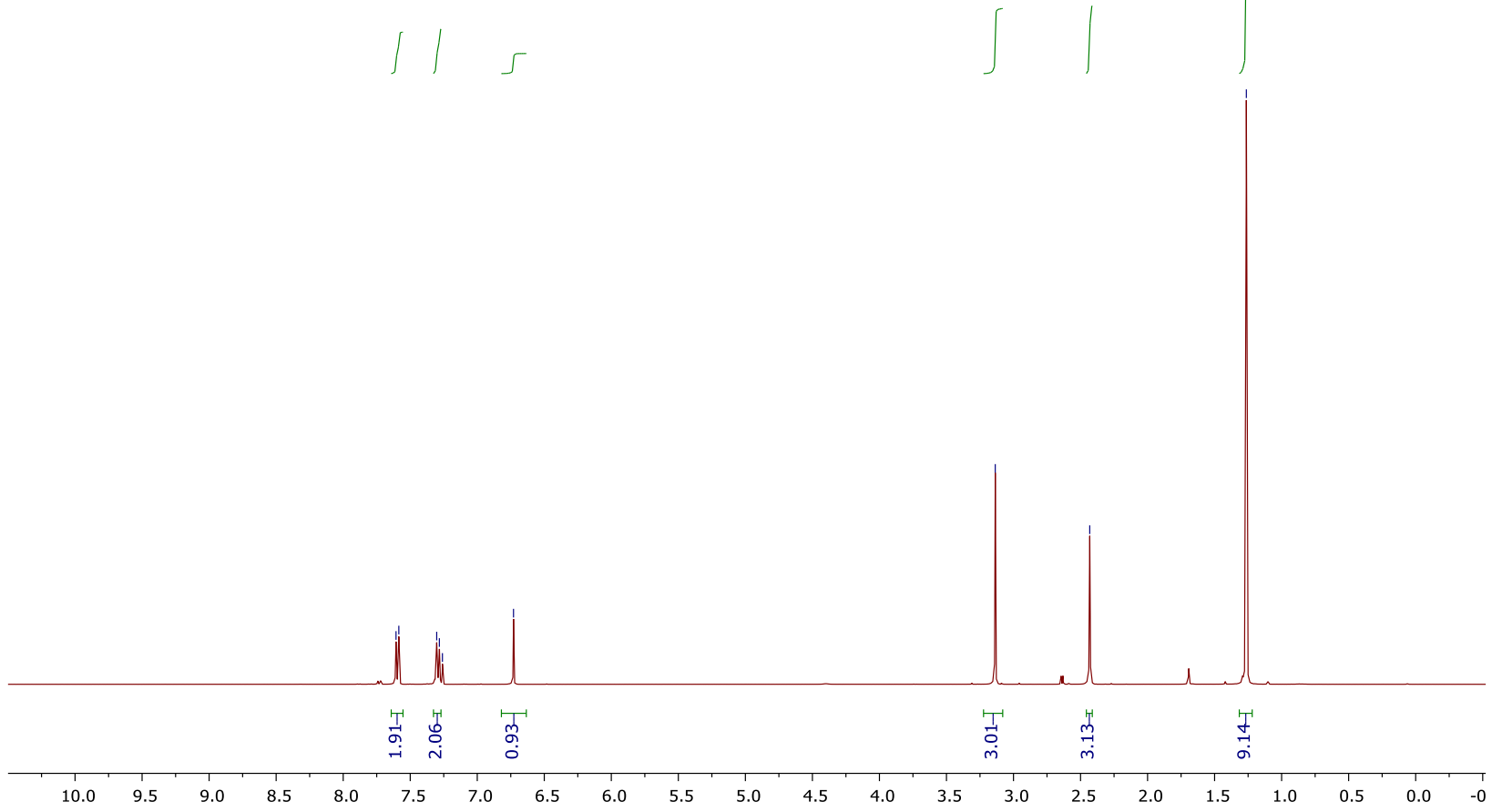

${ }^{13} \mathrm{C}\left\{{ }^{1} \mathrm{H}\right\} \mathrm{NMR}\left(100 \mathrm{MHz}, \mathrm{CDCl}_{3}\right)$

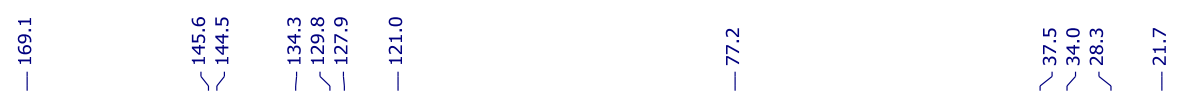

$\left.\mathrm{Me}^{\mathrm{T}} \mathrm{I}^{\mathrm{T}} \prod_{\mathrm{N}}^{\mathrm{O}}\right\rangle^{\mathrm{Bu}-\mathrm{t}}$

3d

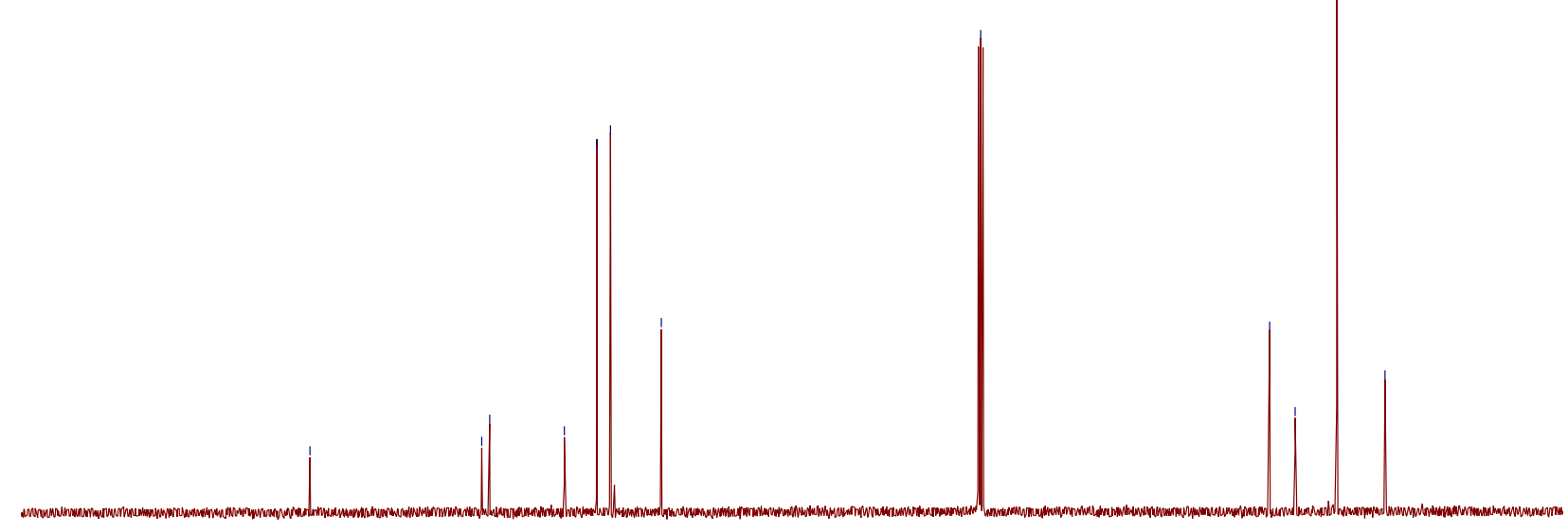

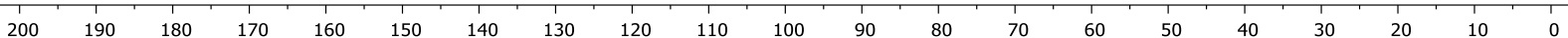


${ }^{1} \mathrm{H}$ NMR (400 MHz, $\left.\mathrm{CDCl}_{3}\right)$

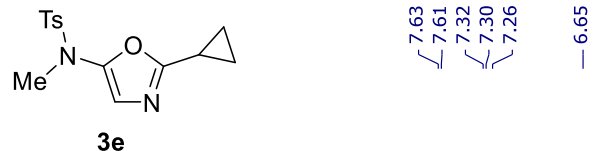

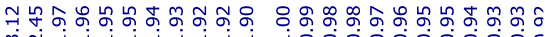

U

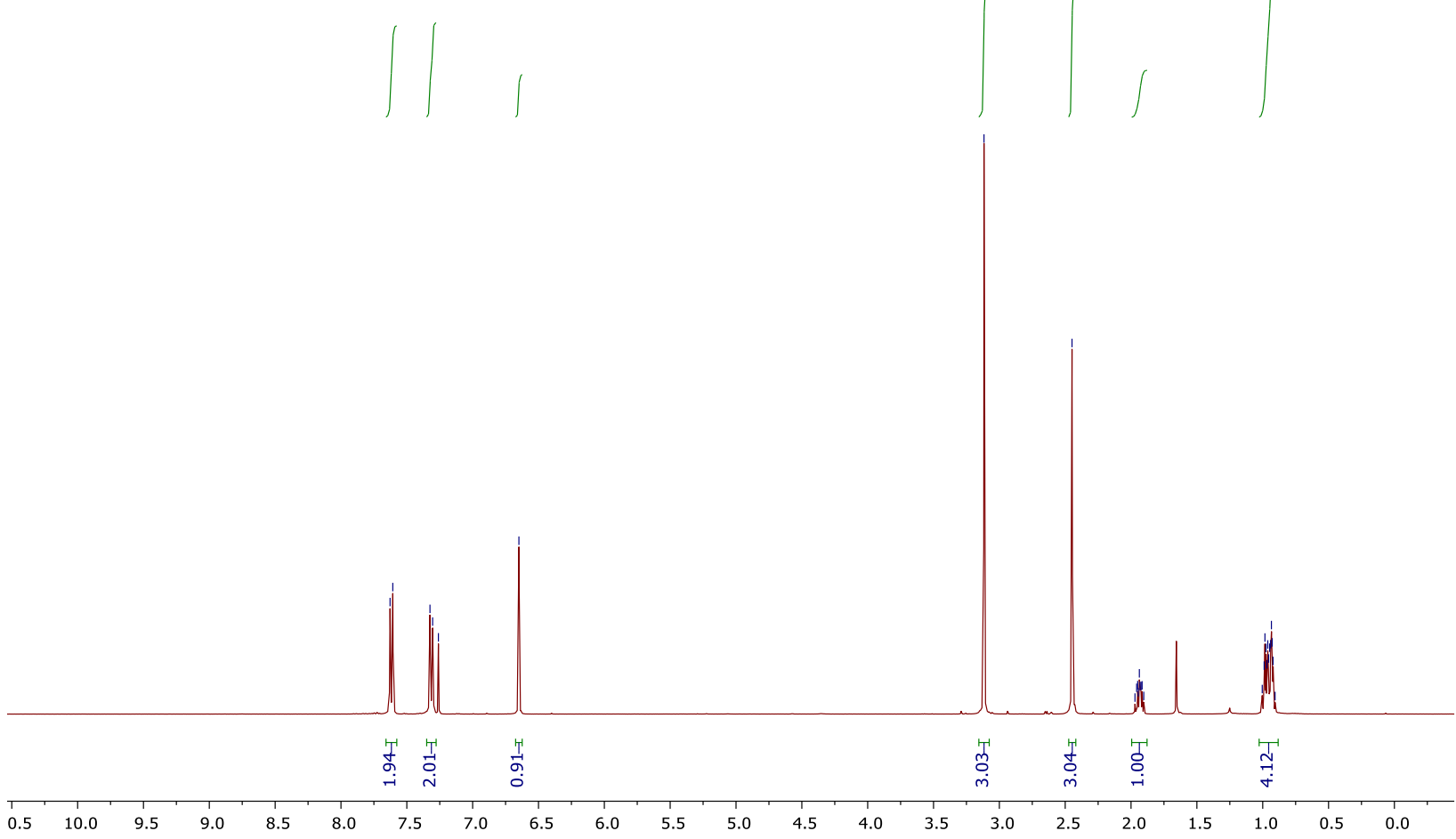

${ }^{13} \mathrm{C}\left\{{ }^{1} \mathrm{H}\right\} \mathrm{NMR}\left(100 \mathrm{MHz}, \mathrm{CDCl}_{3}\right)$<smiles>[Y5]N([Y5])c1cnc(C2CC2)o1</smiles>

3e

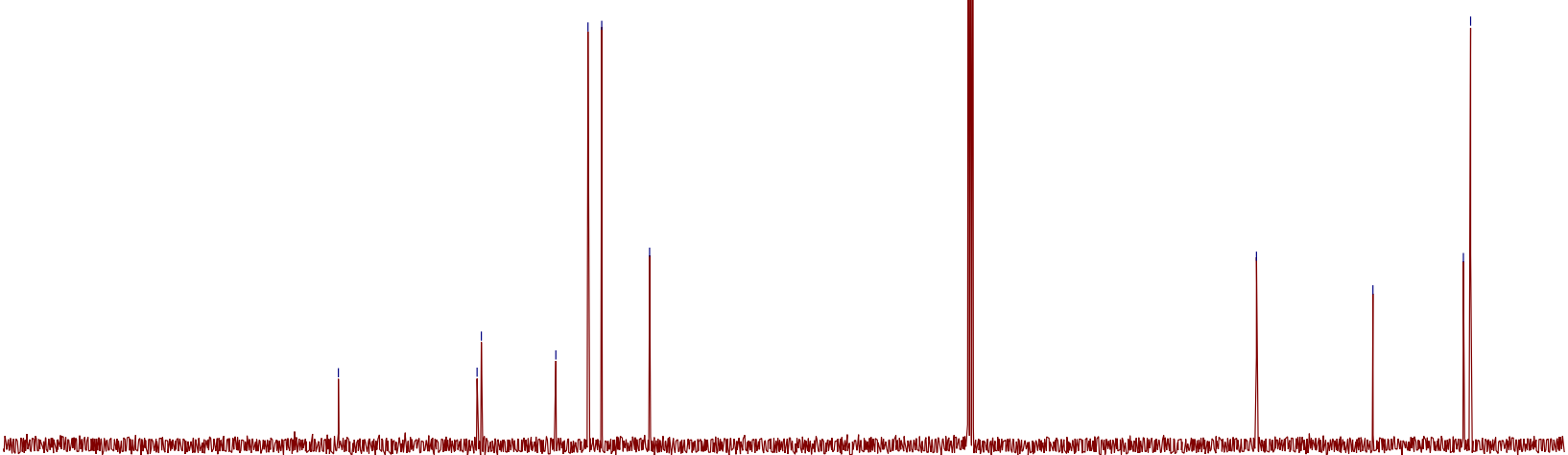

10 $\begin{array}{llllll}200 & 190 & 180 & 170 & 160 & 150\end{array}$ $140 \quad 130 \quad 120$ 
${ }^{1} \mathrm{H}$ NMR (400 MHz, $\left.\mathrm{CDCl}_{3}\right)$

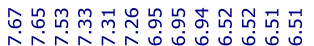

मूरो

$\stackrel{\substack{n \\ i}}{i}$

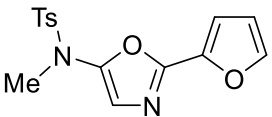

$3 f$
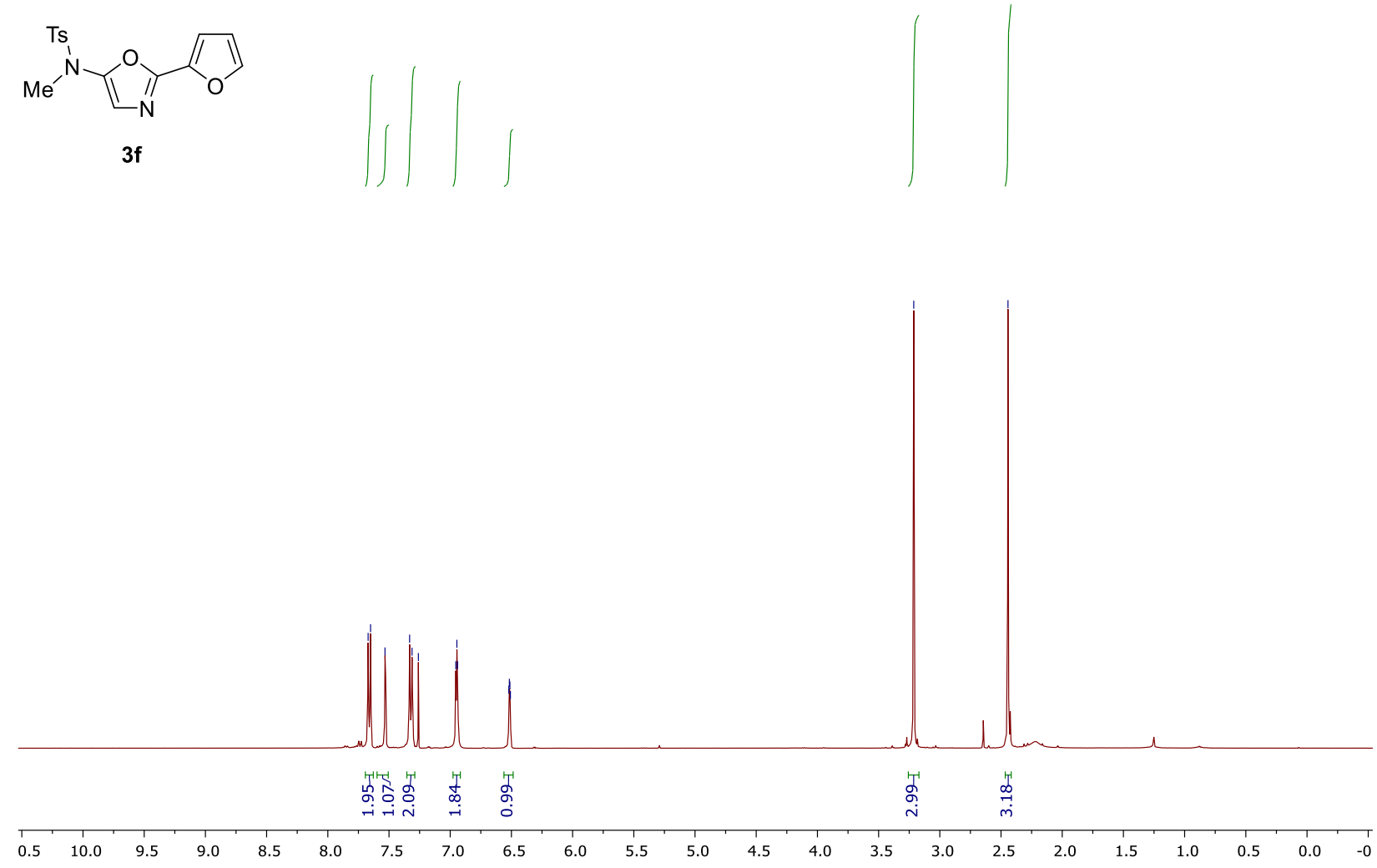

${ }^{13} \mathrm{C}\left\{{ }^{1} \mathrm{H}\right\}$ NMR $\left(100 \mathrm{MHz}, \mathrm{CDCl}_{3}\right)$

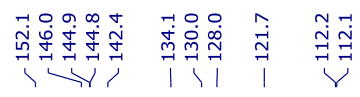

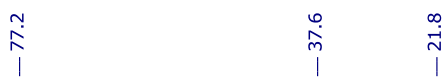

$\mathrm{Me}^{\mathrm{Ts}} \|_{\mathrm{N}}^{\mathrm{O}}$

$3 f$

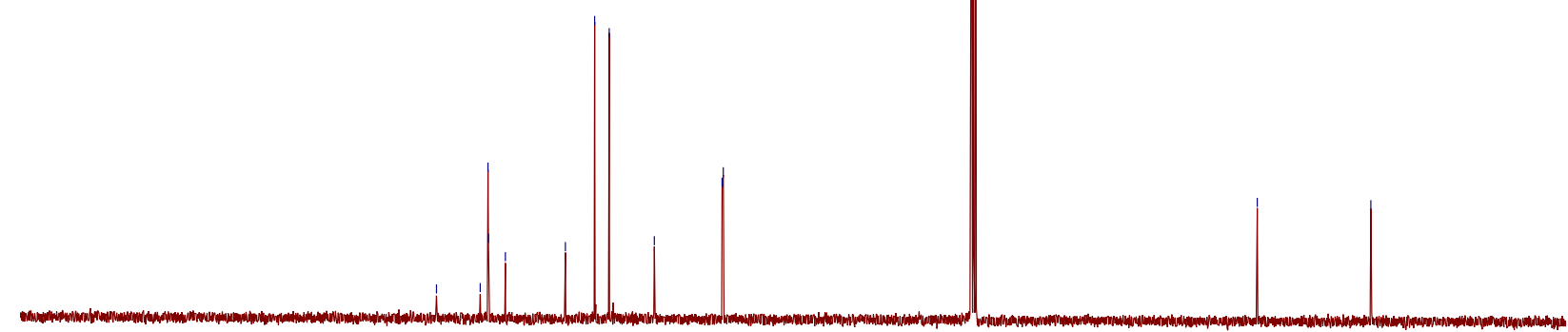

10

$\begin{array}{llllll}200 & 190 & 180 & 170 & 160 & 150\end{array}$

$\begin{array}{llll}130 & 120 & 110 & 100\end{array}$

90

80

60

40 
${ }^{1} \mathrm{H}$ NMR $\left(400 \mathrm{MHz}, \mathrm{CDCl}_{3}\right)$

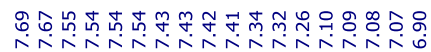

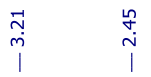

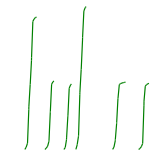

$\mathrm{Me}^{\mathrm{N}} \mathrm{s}_{\mathrm{N}}^{\mathrm{T}}$

$3 g$

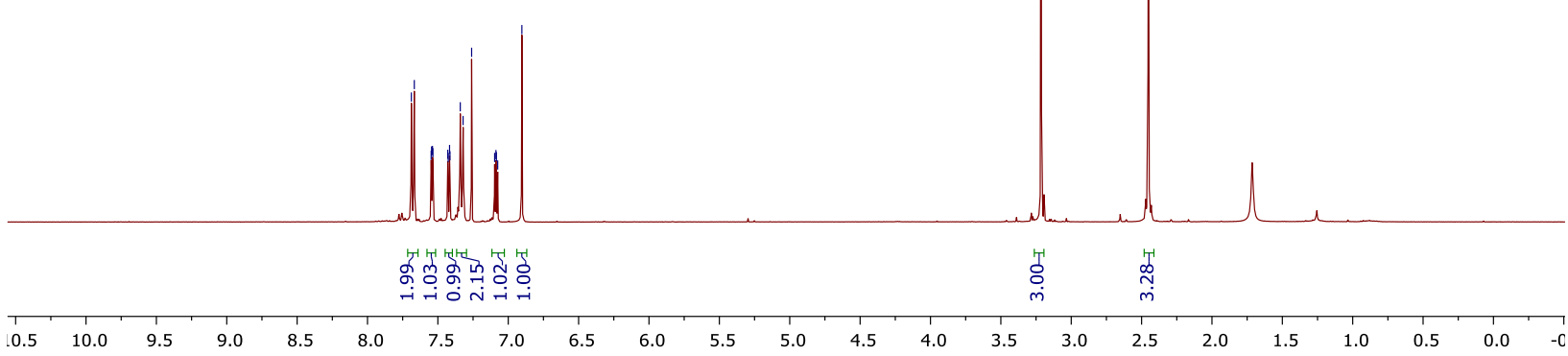

${ }^{13} \mathrm{C}\left\{{ }^{1} \mathrm{H}\right\}$ NMR $\left(100 \mathrm{MHz}, \mathrm{CDCl}_{3}\right)$

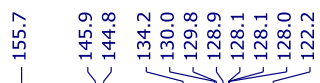

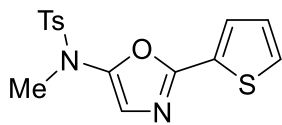

$3 g$

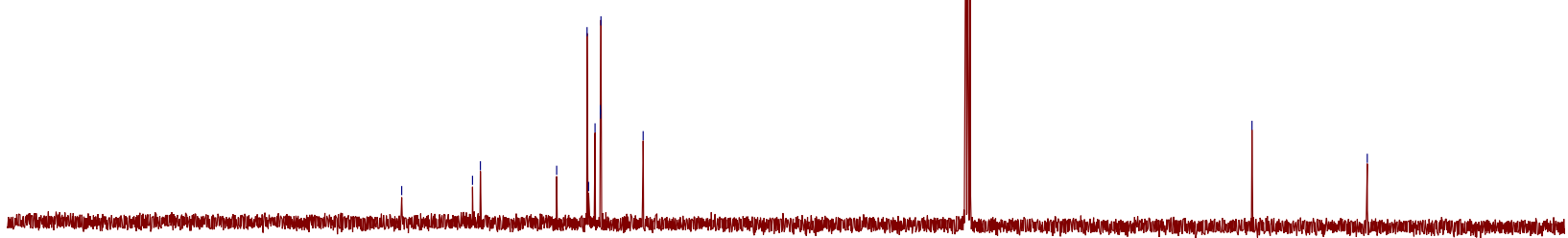


${ }^{1} \mathrm{H}$ NMR $\left(400 \mathrm{MHz}, \mathrm{CDCl}_{3}\right)$

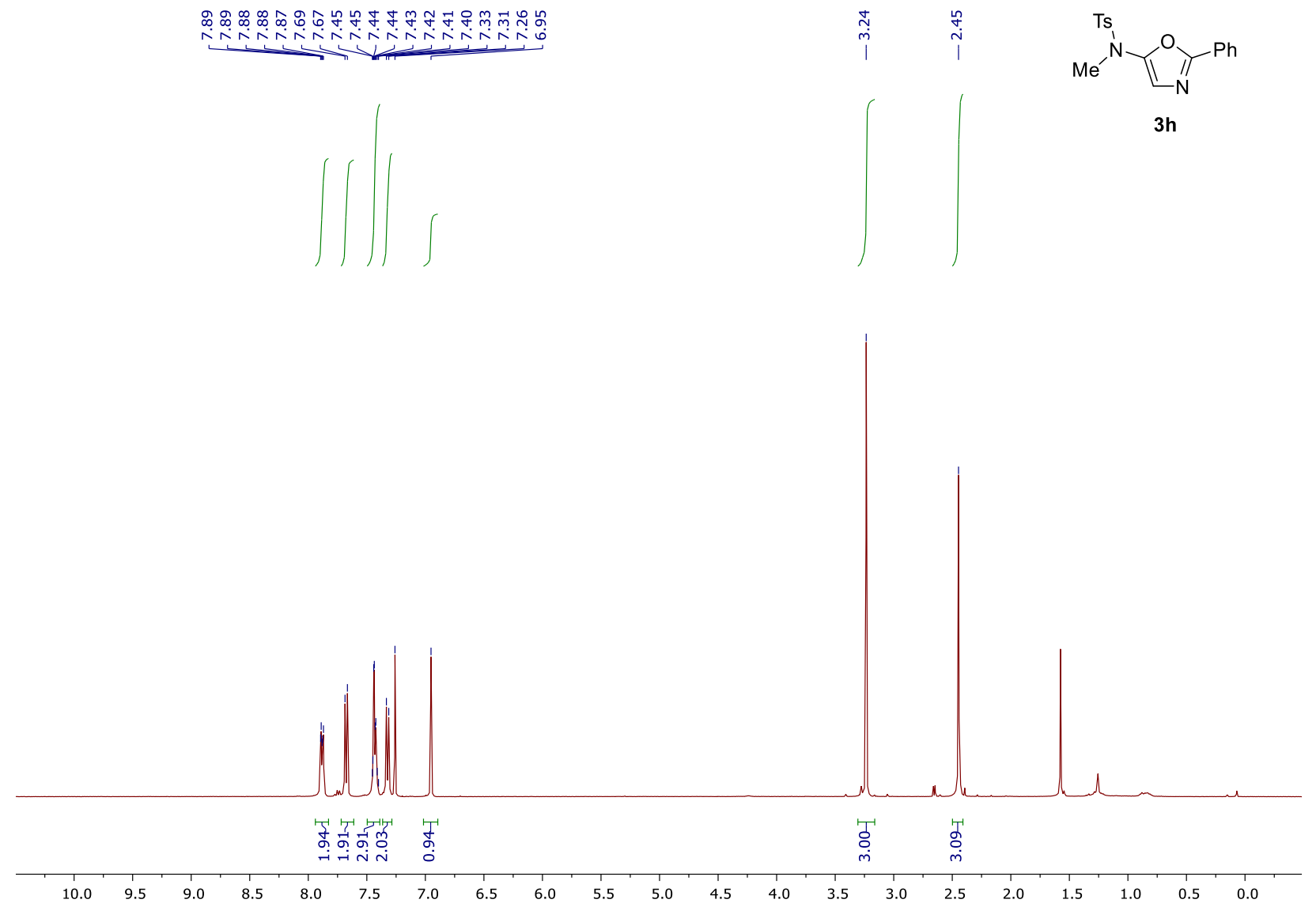

${ }^{13} \mathrm{C}\left\{{ }^{1} \mathrm{H}\right\}$ NMR $\left(100 \mathrm{MHz}, \mathrm{CDCl}_{3}\right)$

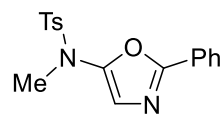

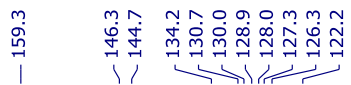

$3 \mathrm{~h}$

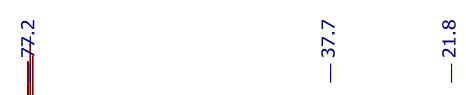

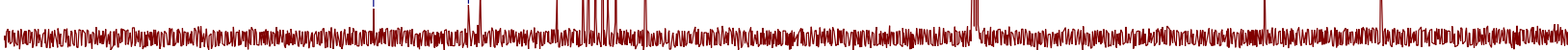

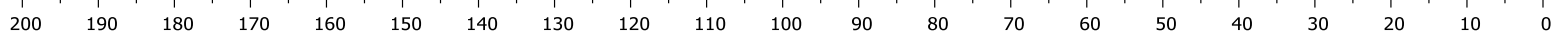


${ }^{1} \mathrm{H}$ NMR $\left(400 \mathrm{MHz}, \mathrm{CDCl}_{3}\right)$

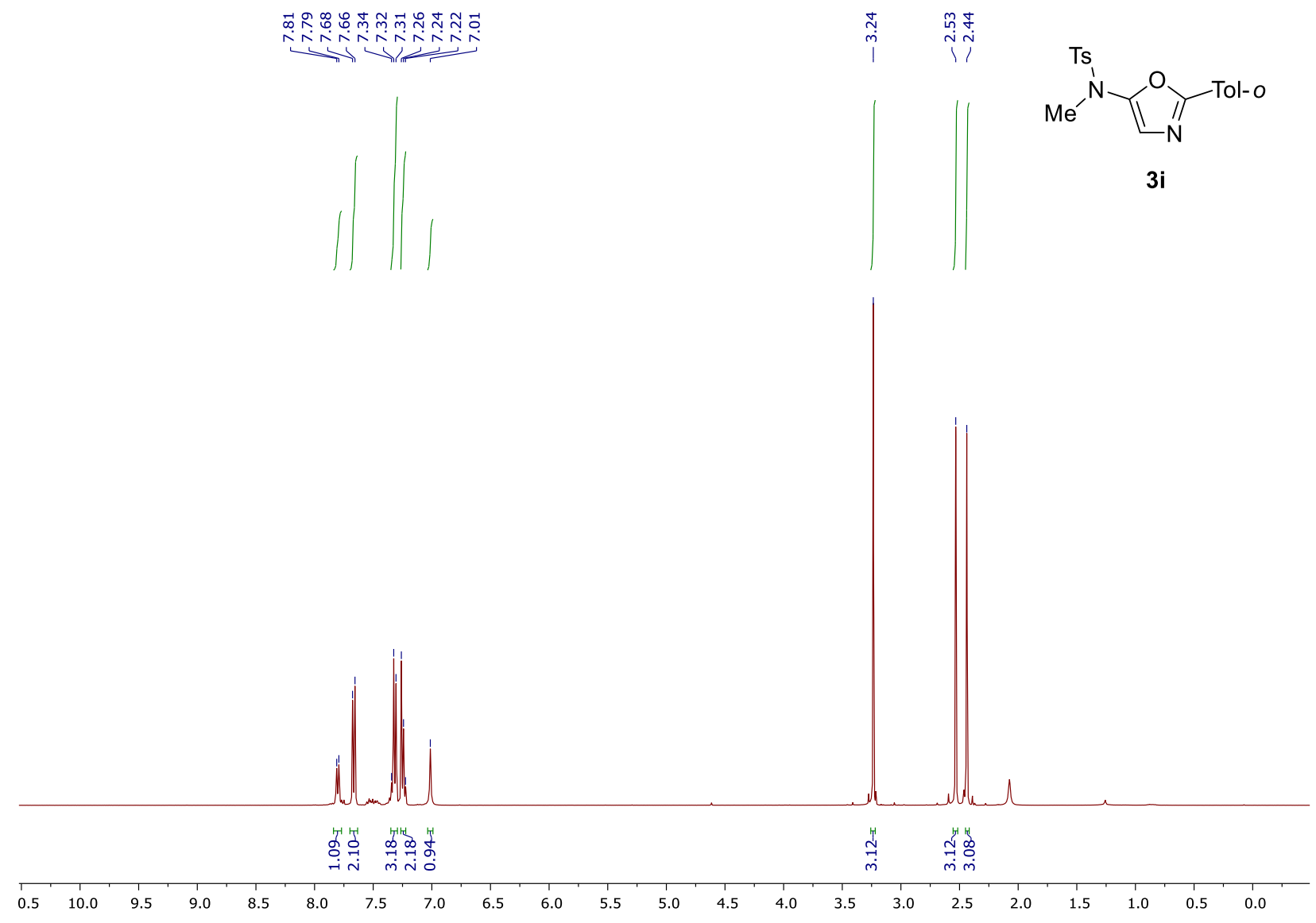

${ }^{13} \mathrm{C}\left\{{ }^{1} \mathrm{H}\right\} \mathrm{NMR}\left(100 \mathrm{MHz}, \mathrm{CDCl}_{3}\right)$

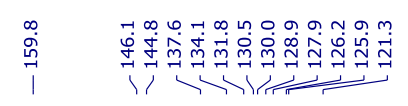

$\mathrm{Me}^{\mathrm{Ts}} \|_{\mathrm{N}}^{\mathrm{T}}$

3i

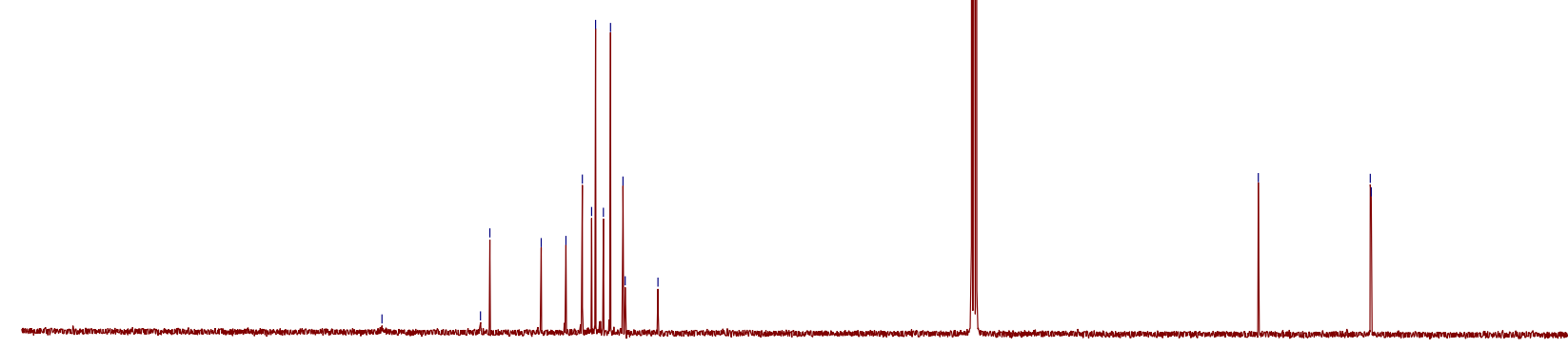

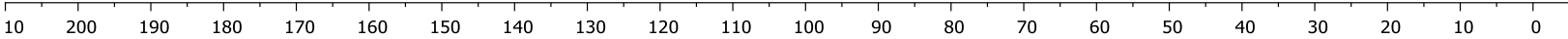


${ }^{1} \mathrm{H}$ NMR (400 MHz, $\left.\mathrm{CDCl}_{3}\right)$

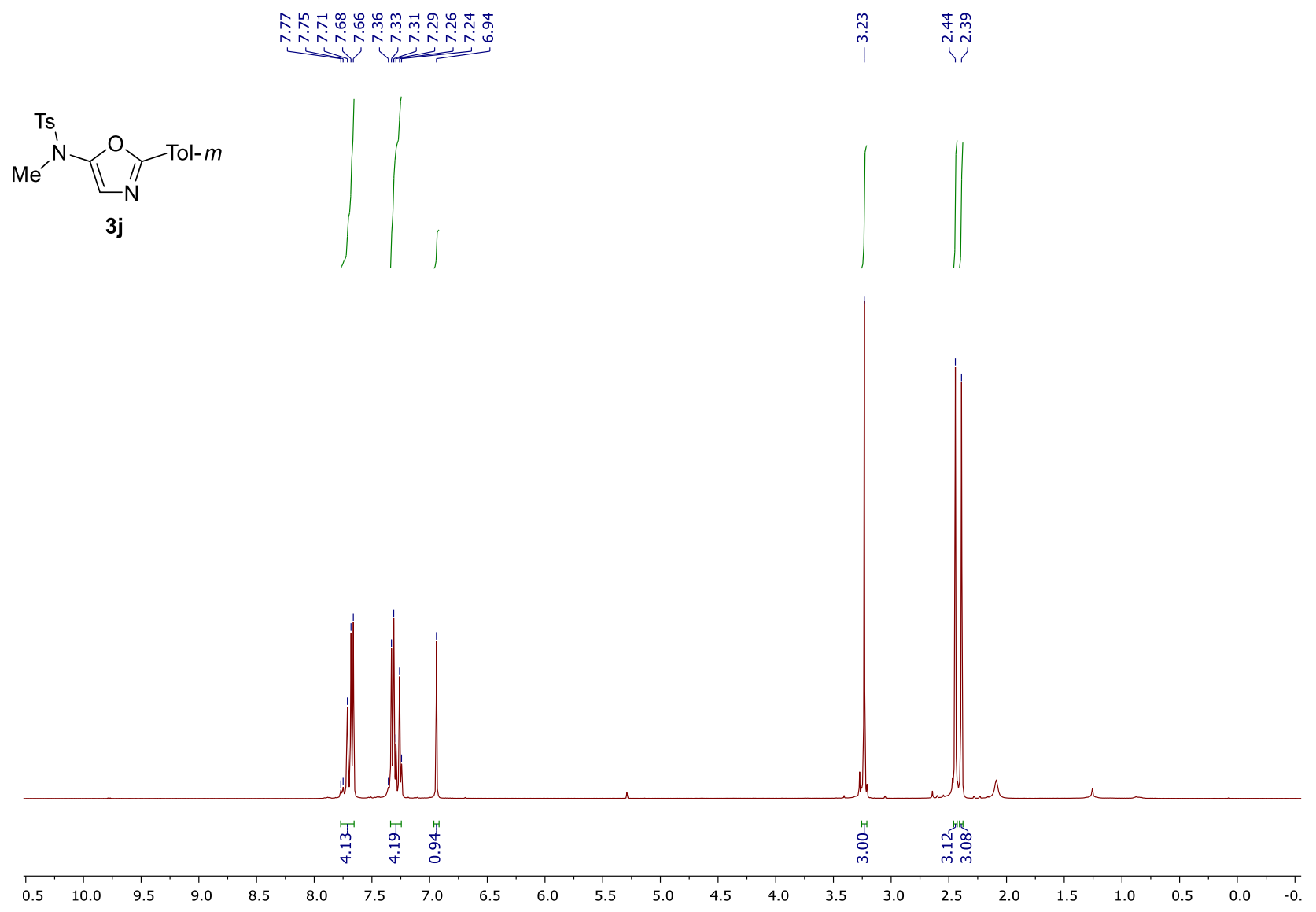

${ }^{13} \mathrm{C}\left\{{ }^{1} \mathrm{H}\right\} \mathrm{NMR}\left(100 \mathrm{MHz}, \mathrm{CDCl}_{3}\right)$
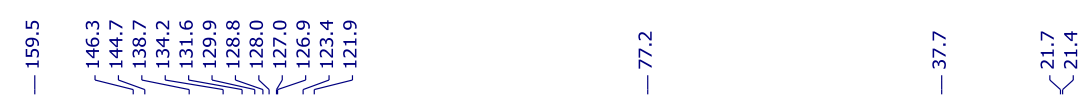

$\mathrm{Me}^{\mathrm{T}} \mathrm{U}_{\mathrm{N}}^{\mathrm{T}} \mathrm{Tol}-\mathrm{m}$

3j
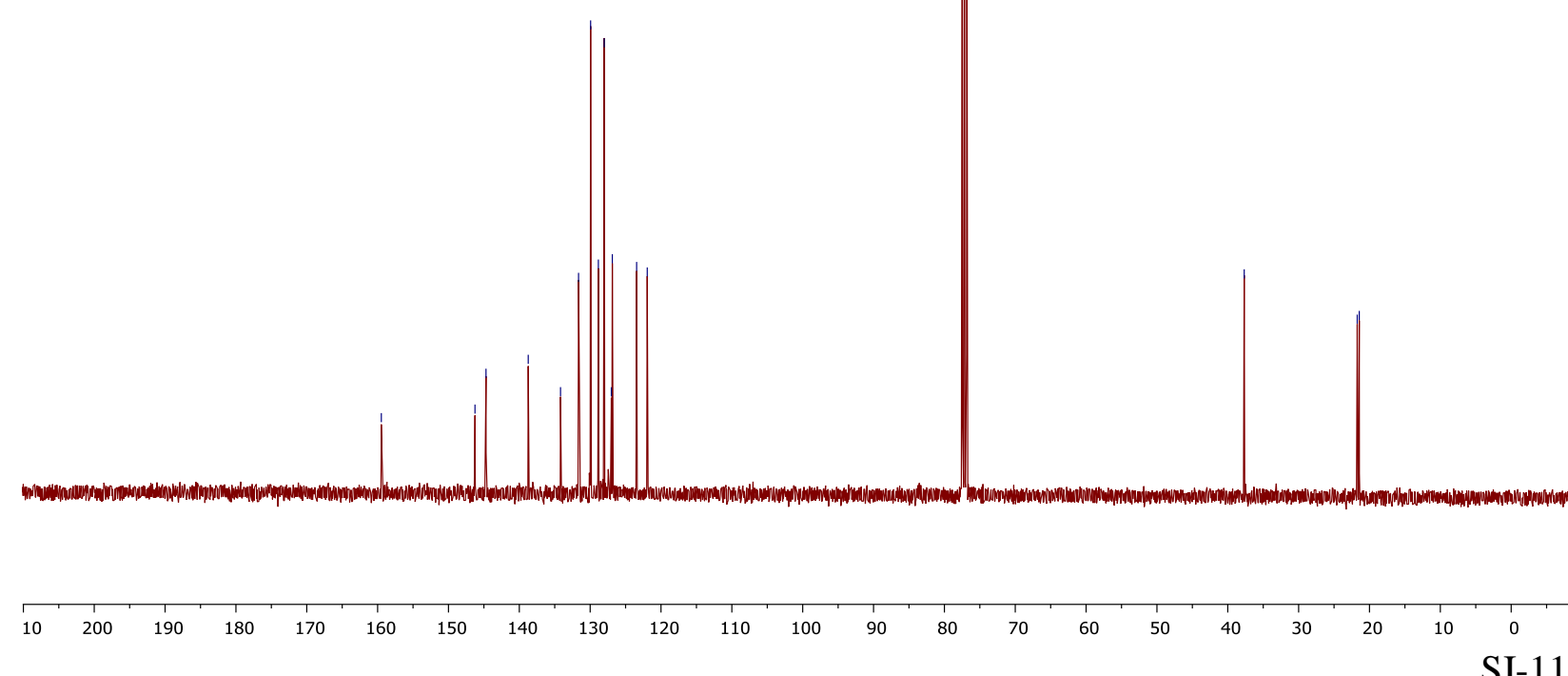
${ }^{1} \mathrm{H}$ NMR (400 MHz, $\left.\mathrm{CDCl}_{3}\right)$

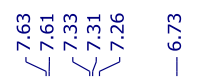

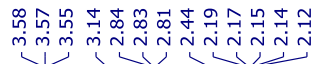

$\mathrm{Me}^{\mathrm{TS}} \mathrm{L}_{\mathrm{N}}^{\mathrm{N}}$

3k
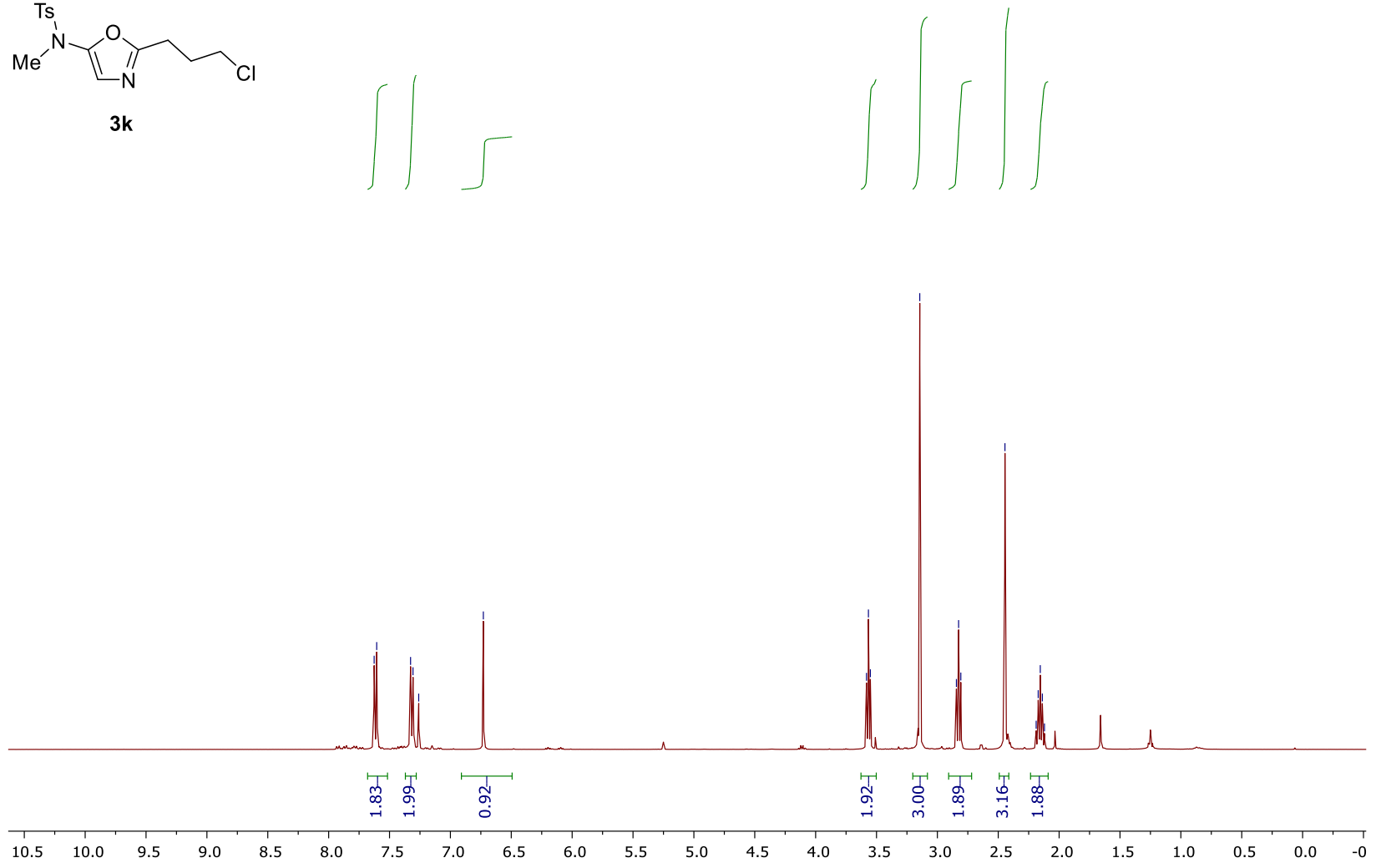

${ }^{13} \mathrm{C}\left\{{ }^{1} \mathrm{H}\right\}$ NMR $\left(100 \mathrm{MHz}, \mathrm{CDCl}_{3}\right)$

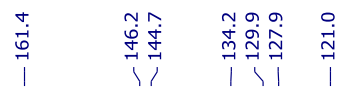

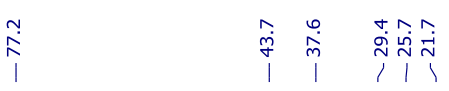<smiles>[13CH3]N([13CH3])c1cnc(CCCCl)o1</smiles>

$3 \mathbf{k}$

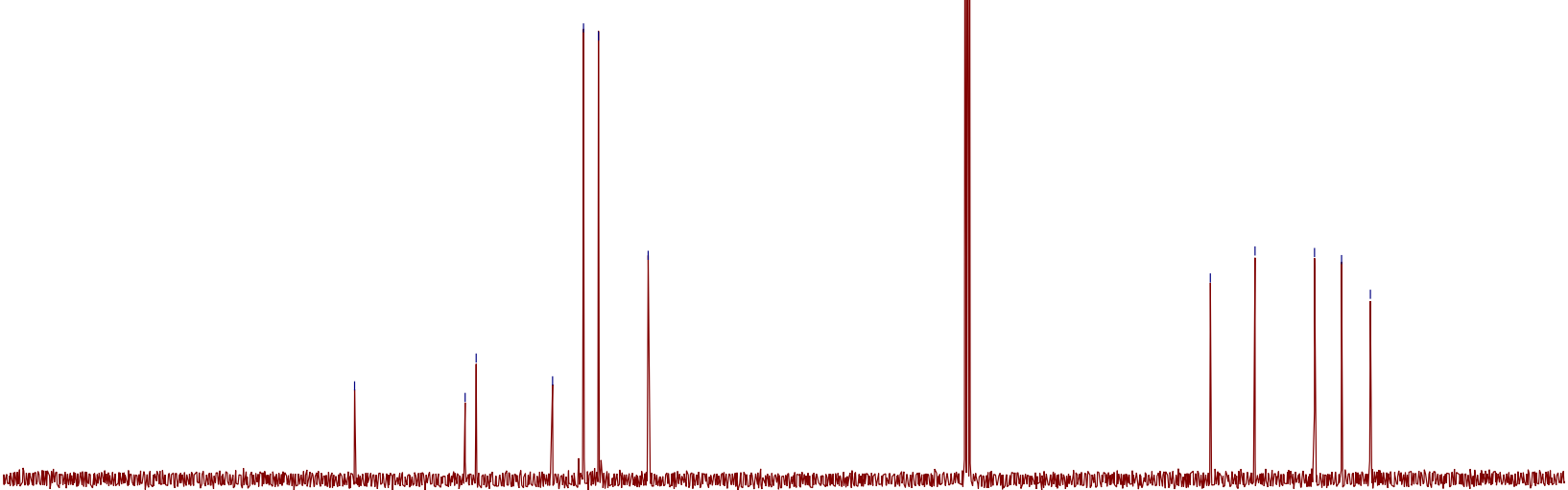


${ }^{1} \mathrm{H}$ NMR (400 MHz, $\left.\mathrm{CDCl}_{3}\right)$

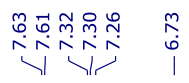

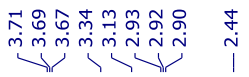
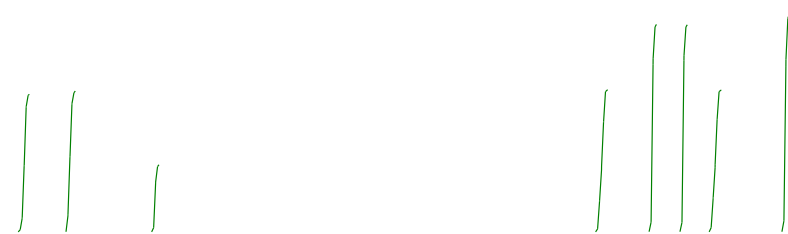

$\mathrm{Me}^{\mathrm{TS}} \overbrace{\mathrm{N}}^{\mathrm{O}} \mathrm{N}_{\mathrm{OMe}}$

3I
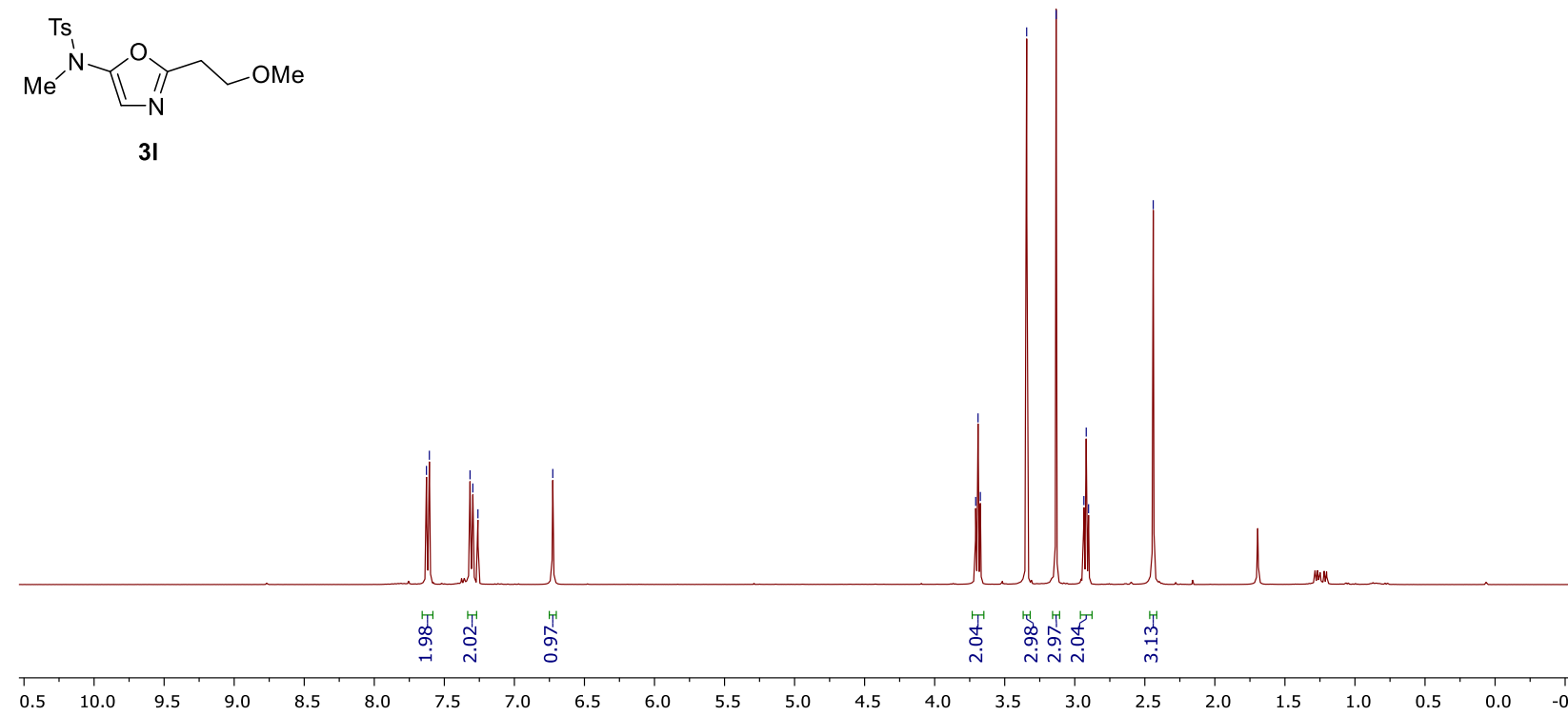

${ }^{13} \mathrm{C}\left\{{ }^{1} \mathrm{H}\right\} \mathrm{NMR}\left(100 \mathrm{MHz}, \mathrm{CDCl}_{3}\right)$

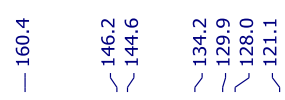

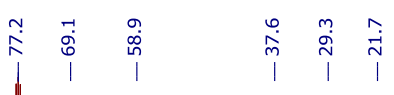

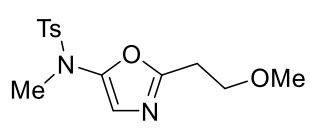

31

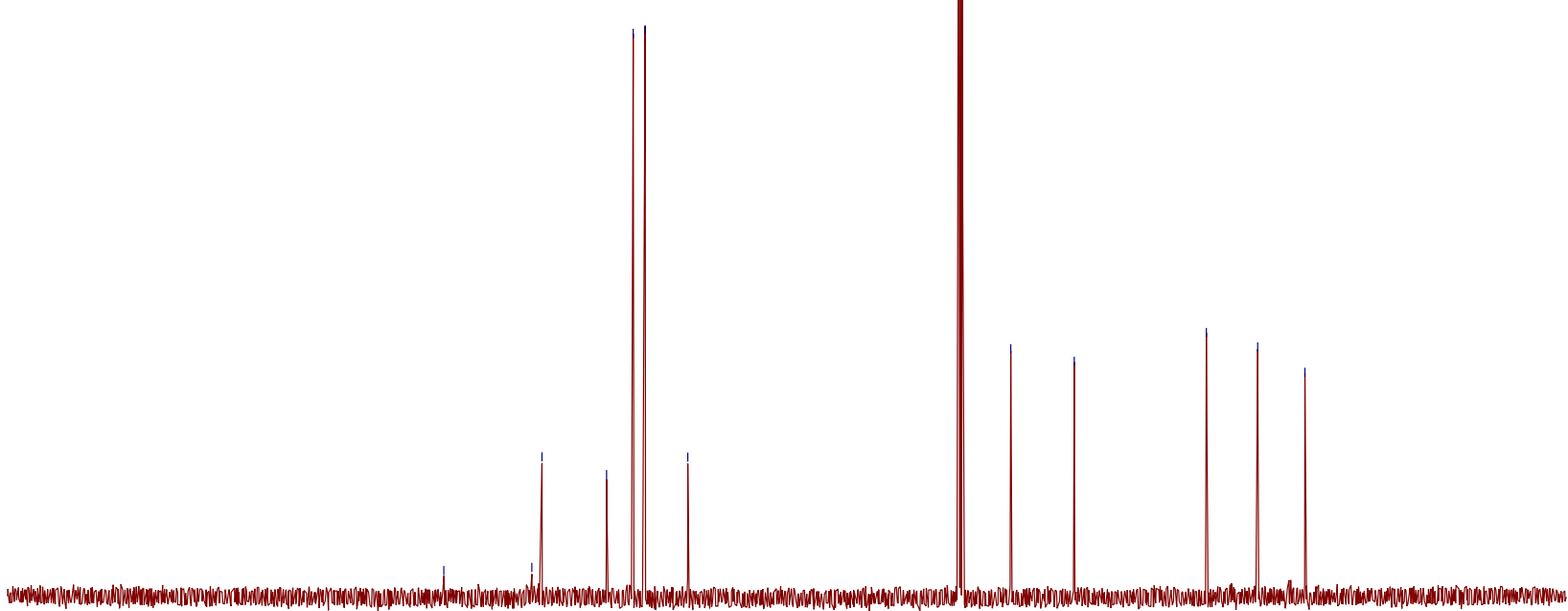

$\begin{array}{llllllllllllllllllllllllll}30 & 220 & 210 & 200 & 190 & 180 & 170 & 160 & 150 & 140 & 130 & 120 & 110 & 100 & 90 & 80 & 70 & 60 & 50 & 40 & 30 & 20 & 10 & 0 & -10 & -2\end{array}$ 
${ }^{1} \mathrm{H}$ NMR $\left(400 \mathrm{MHz}, \mathrm{CDCl}_{3}\right)$

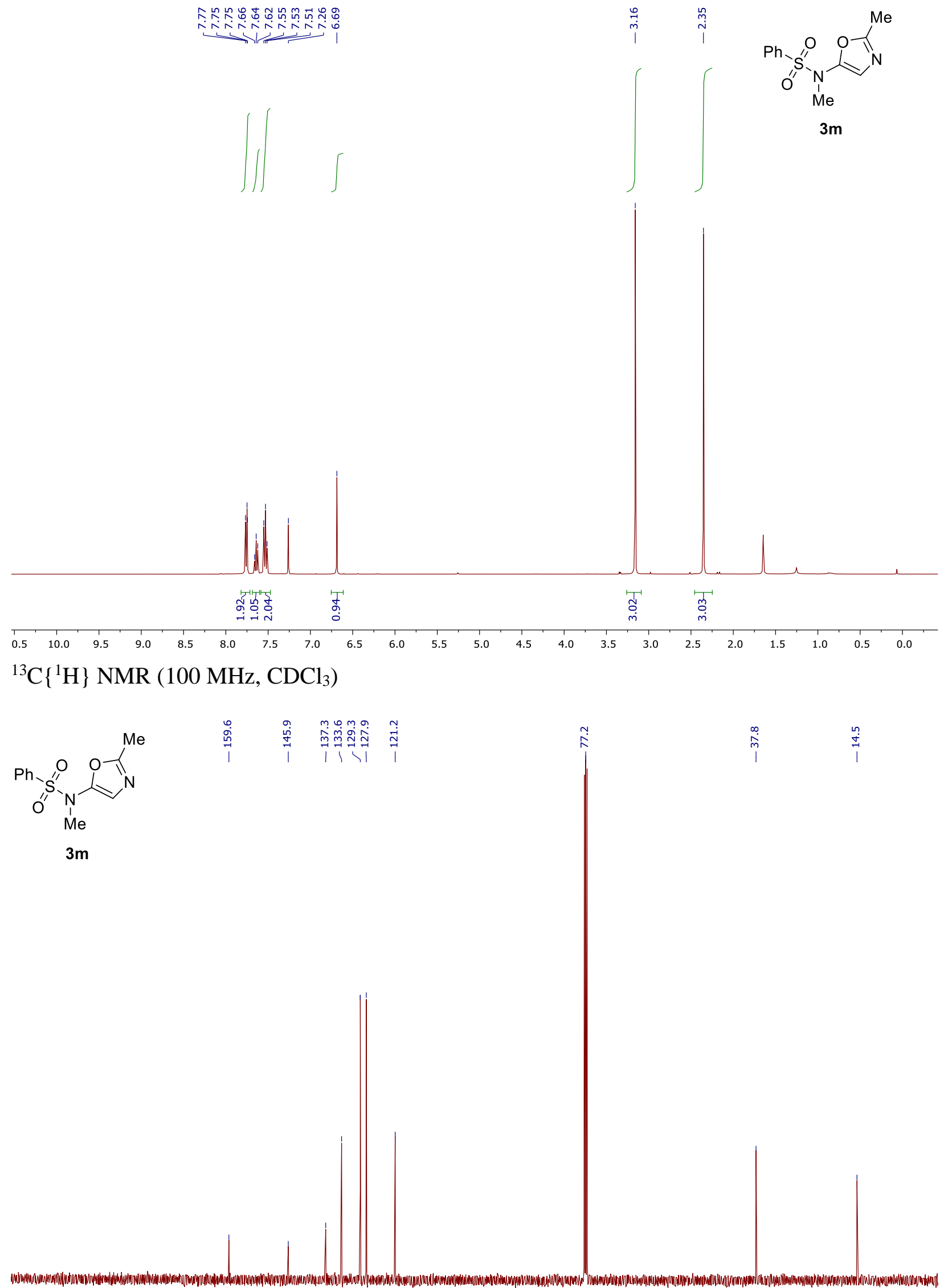

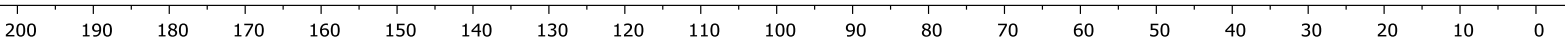


${ }^{1} \mathrm{H}$ NMR (400 MHz, $\mathrm{CDCl}_{3}$ )

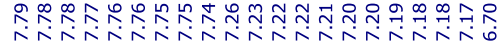

管

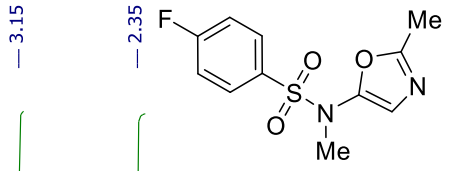

$3 n$

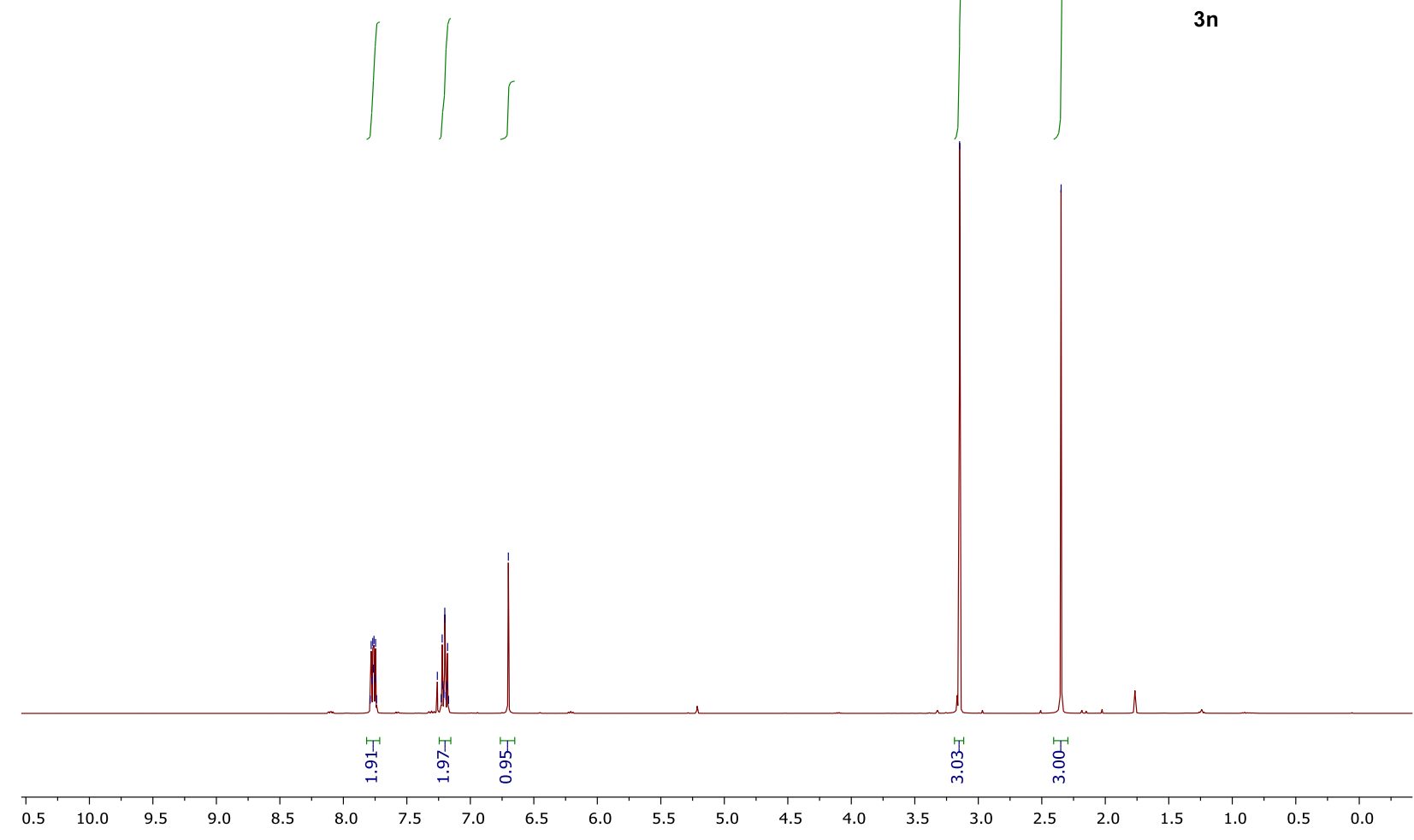

${ }^{13} \mathrm{C}\left\{{ }^{1} \mathrm{H}\right\}$ NMR $\left(100 \mathrm{MHz}, \mathrm{CDCl}_{3}\right)$

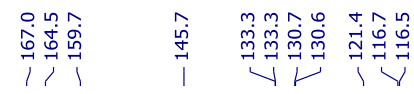

$\stackrel{\substack{n \\ i}}{\stackrel{2}{2}}$

$\stackrel{\substack{\infty \\ i}}{i}$

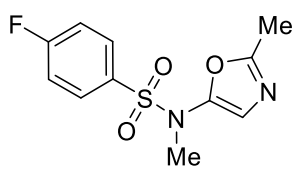

$3 n$

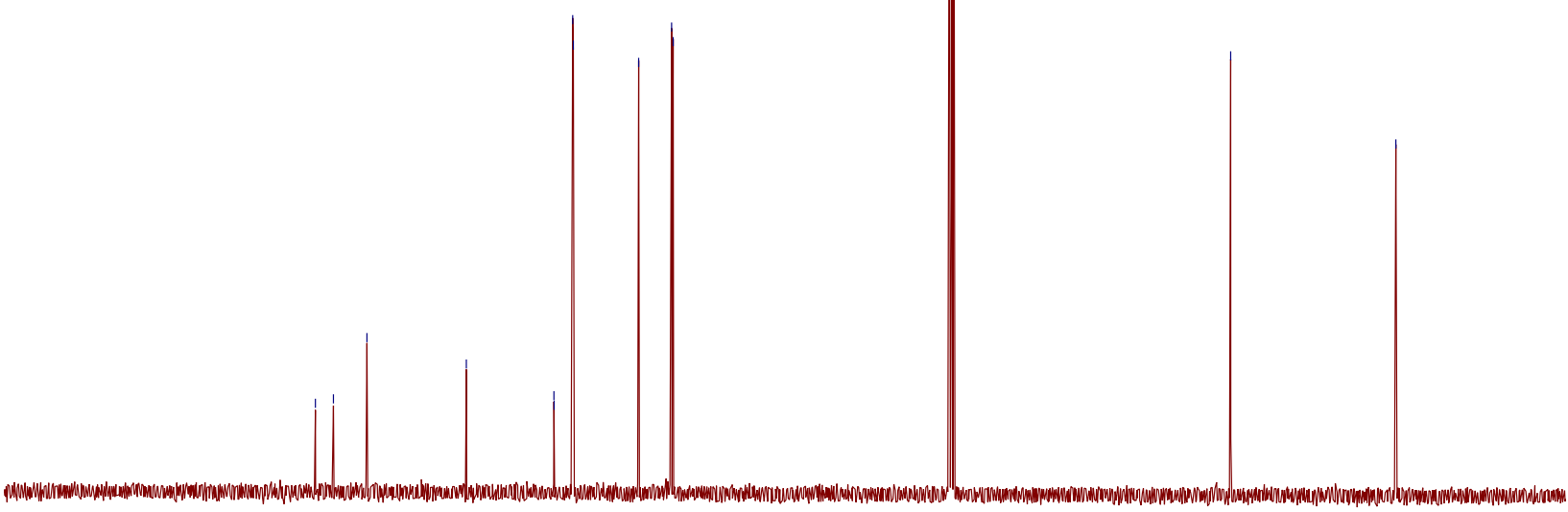

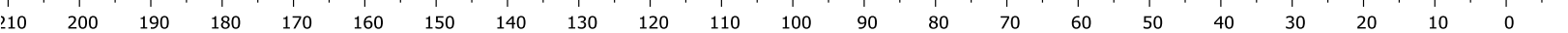


${ }^{1} \mathrm{H}$ NMR (400 MHz, $\mathrm{CDCl}_{3}$ )

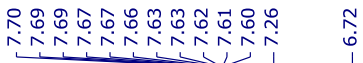

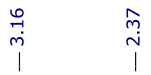

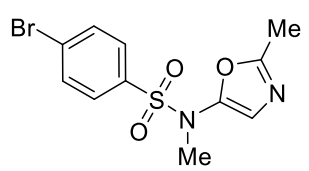

30

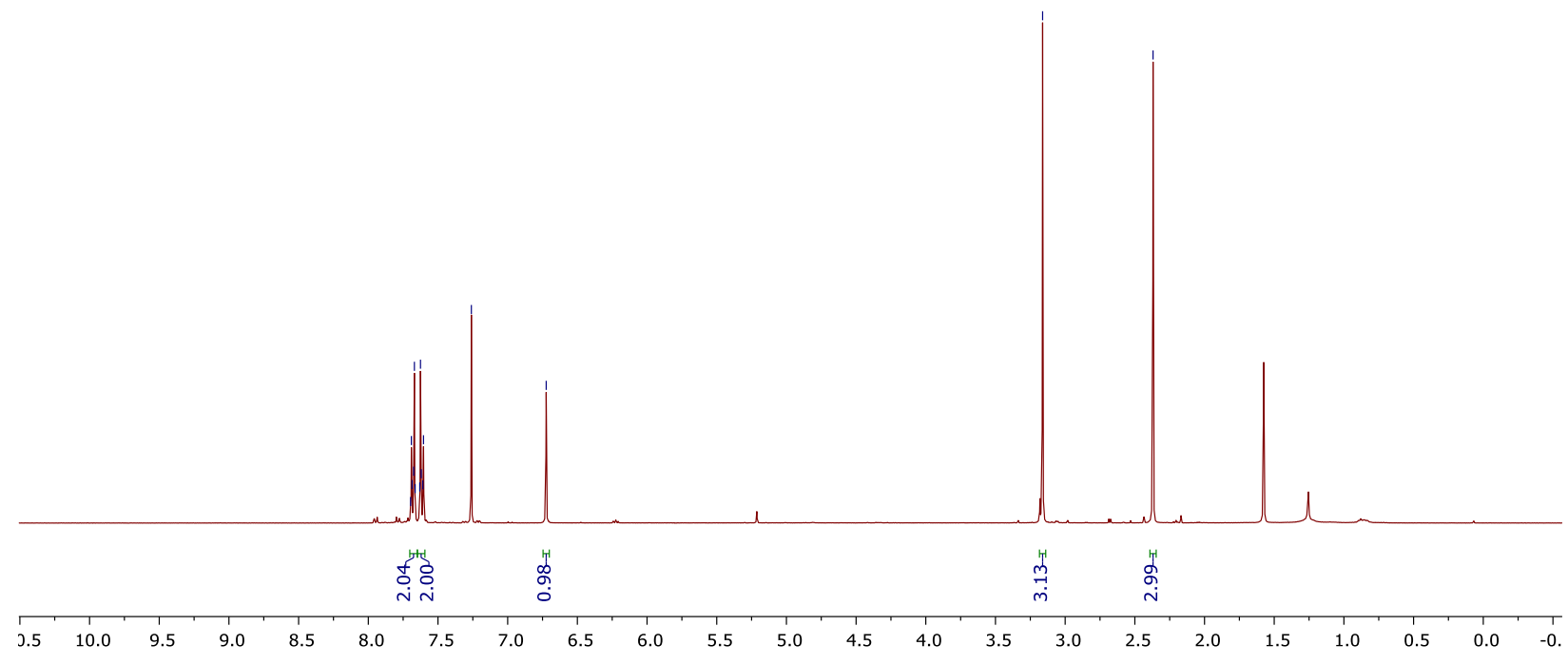

${ }^{13} \mathrm{C}\left\{{ }^{1} \mathrm{H}\right\} \mathrm{NMR}\left(100 \mathrm{MHz}, \mathrm{CDCl}_{3}\right)$

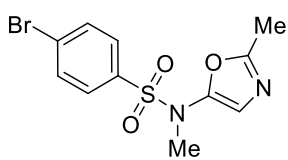

3o

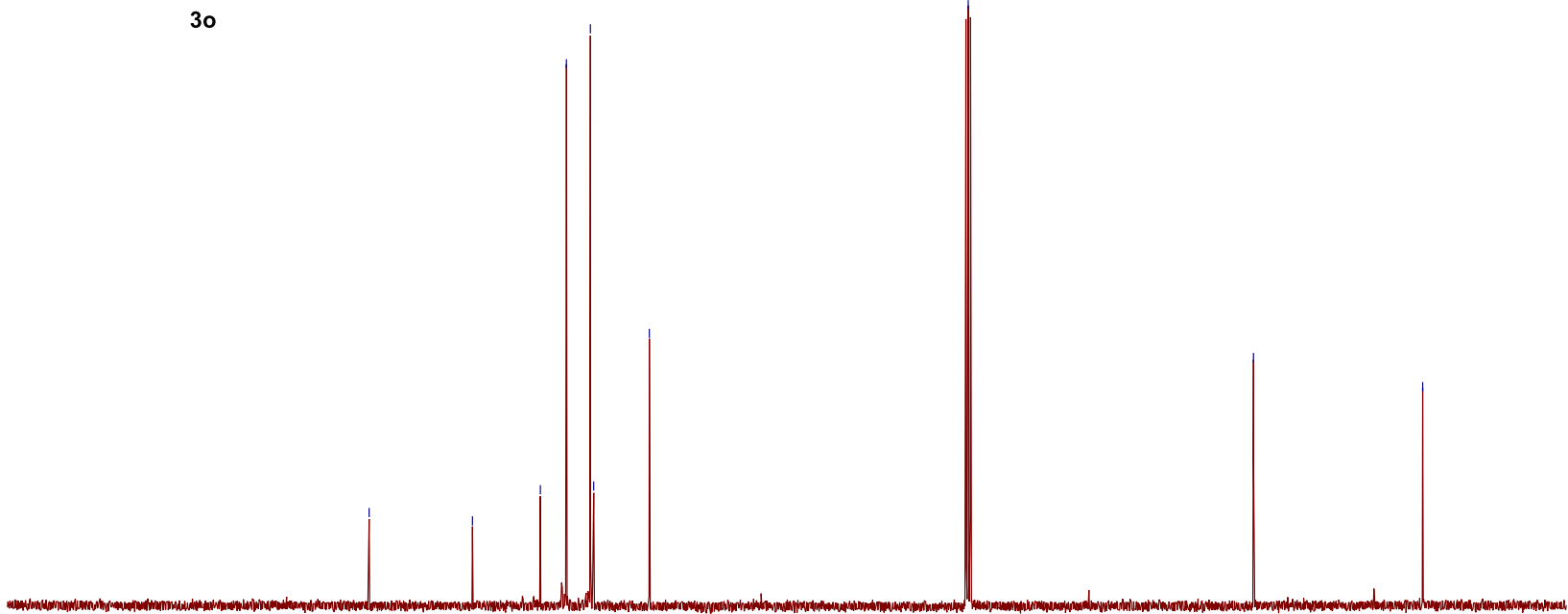

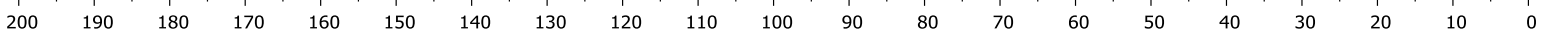


${ }^{1} \mathrm{H}$ NMR $\left(400 \mathrm{MHz}, \mathrm{CDCl}_{3}\right)$
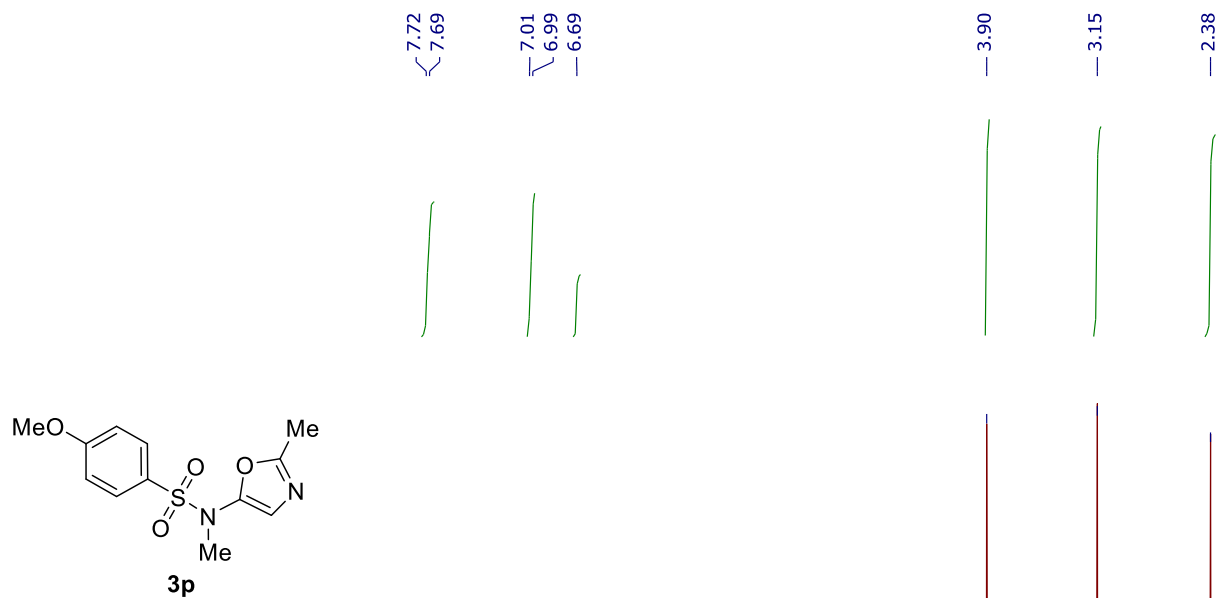

$3 p$

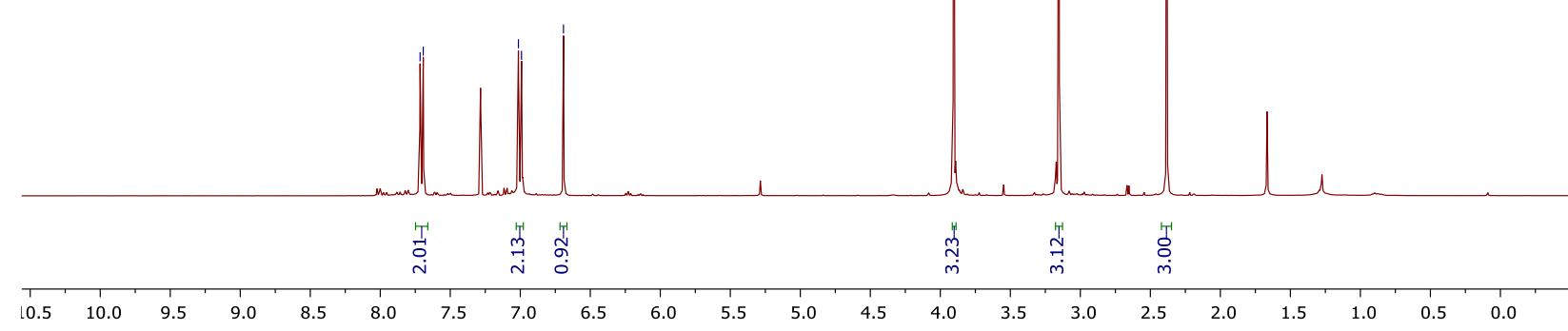

${ }^{13} \mathrm{C}\left\{{ }^{1} \mathrm{H}\right\}$ NMR $\left(100 \mathrm{MHz}, \mathrm{CDCl}_{3}\right)$

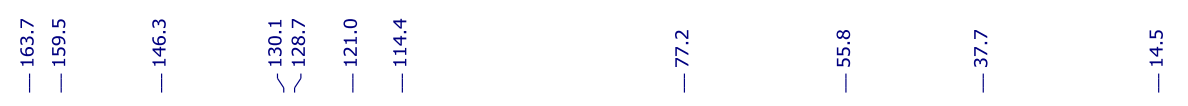

MeO

$3 p$

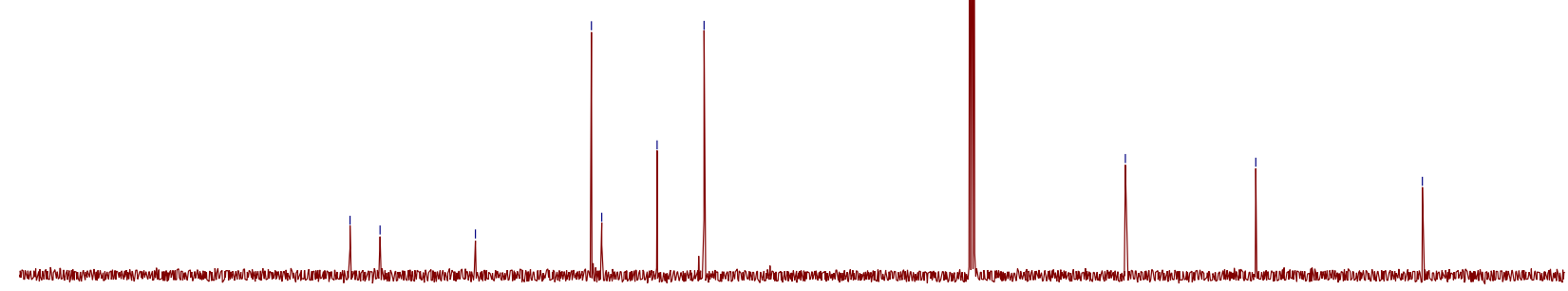

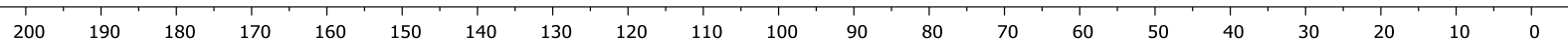


${ }^{1} \mathrm{H}$ NMR (400 MHz, $\mathrm{CDCl}_{3}$ )
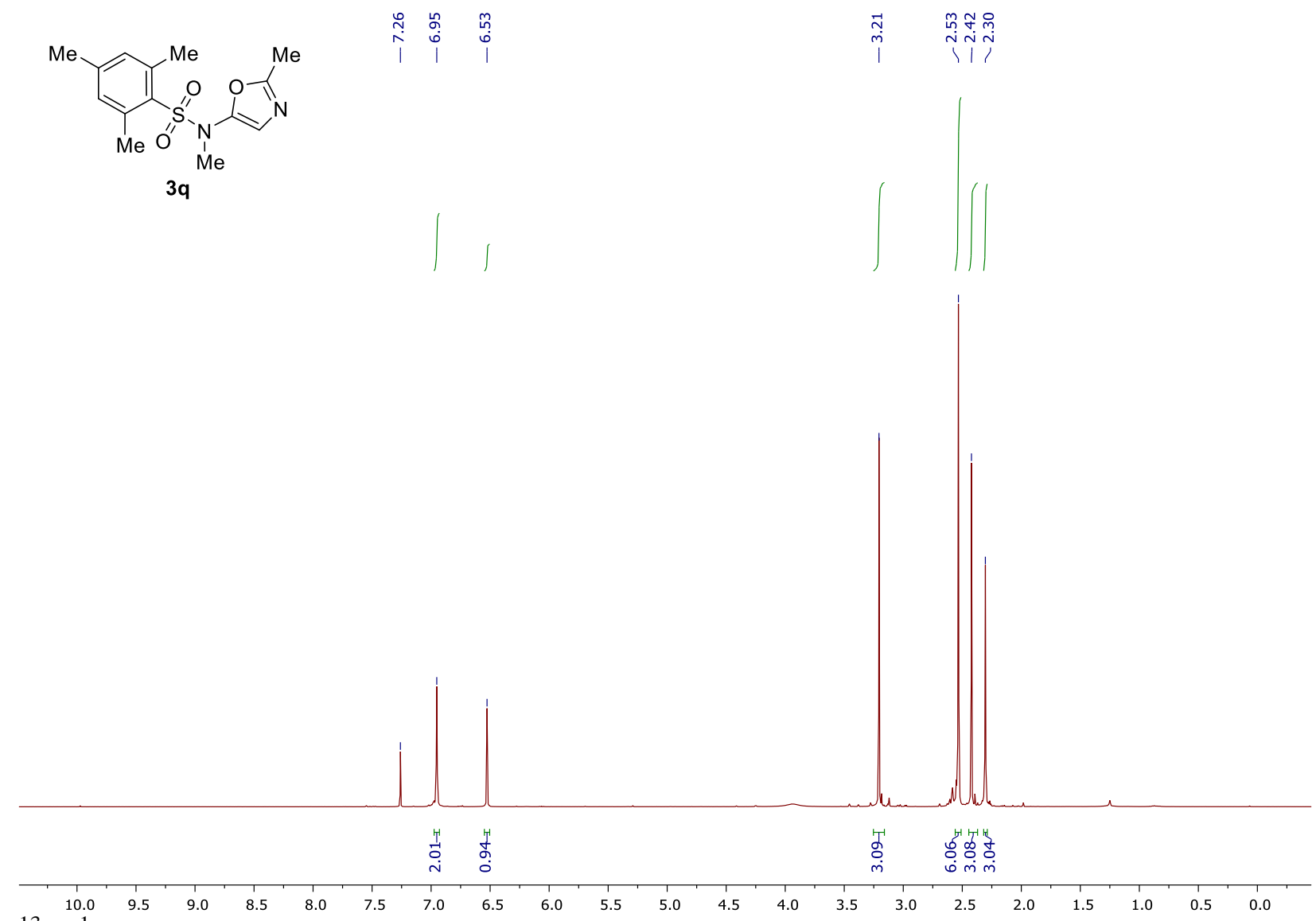

${ }^{13} \mathrm{C}\left\{{ }^{1} \mathrm{H}\right\}$ NMR $\left(100 \mathrm{MHz}, \mathrm{CDCl}_{3}\right)$

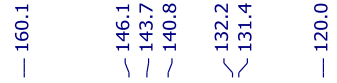
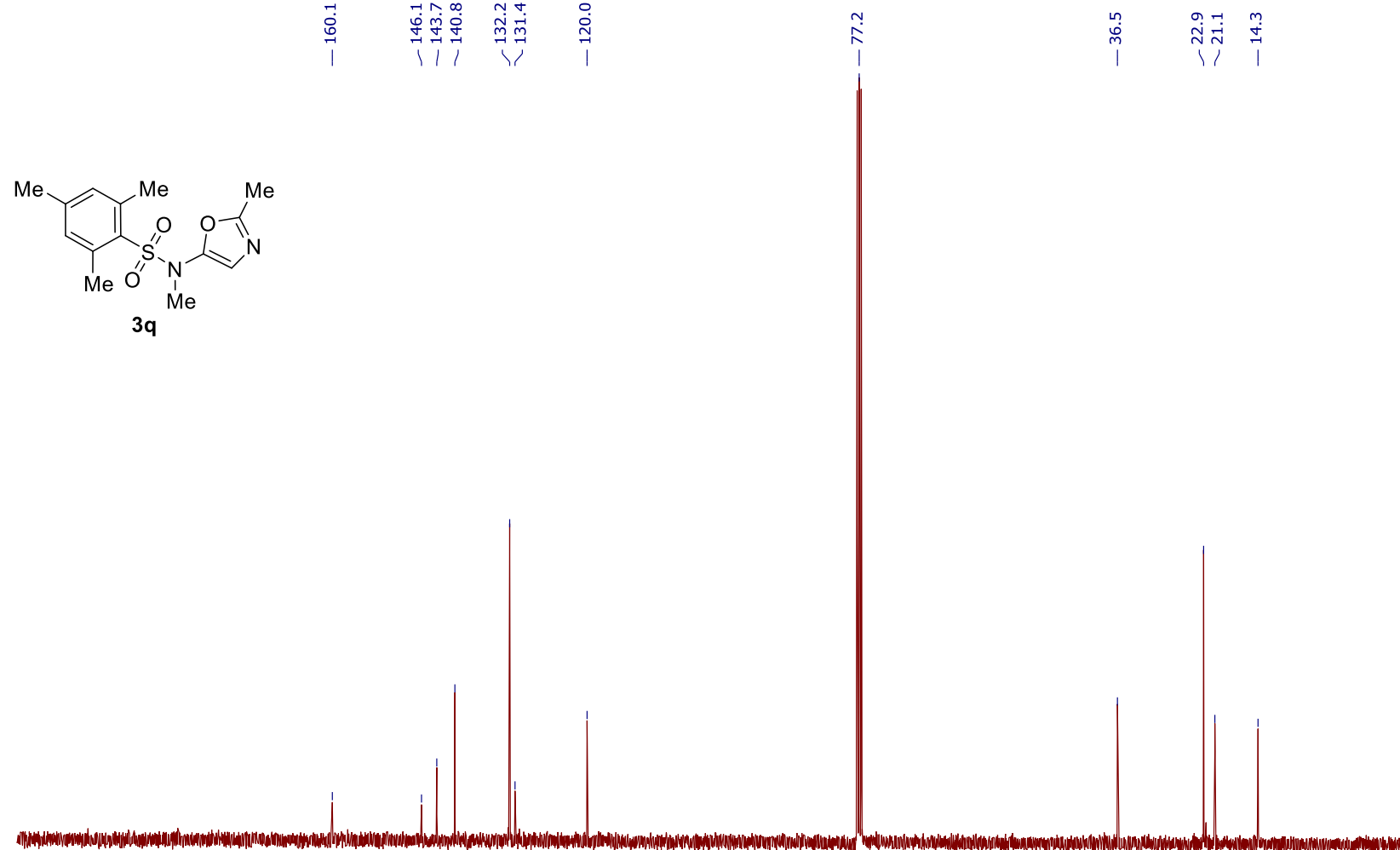

200
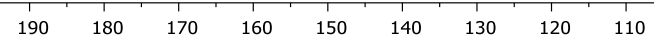

100 
${ }^{1} \mathrm{H}$ NMR (400 MHz, $\left.\mathrm{CDCl}_{3}\right)$

年

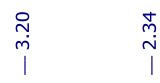

(Mr
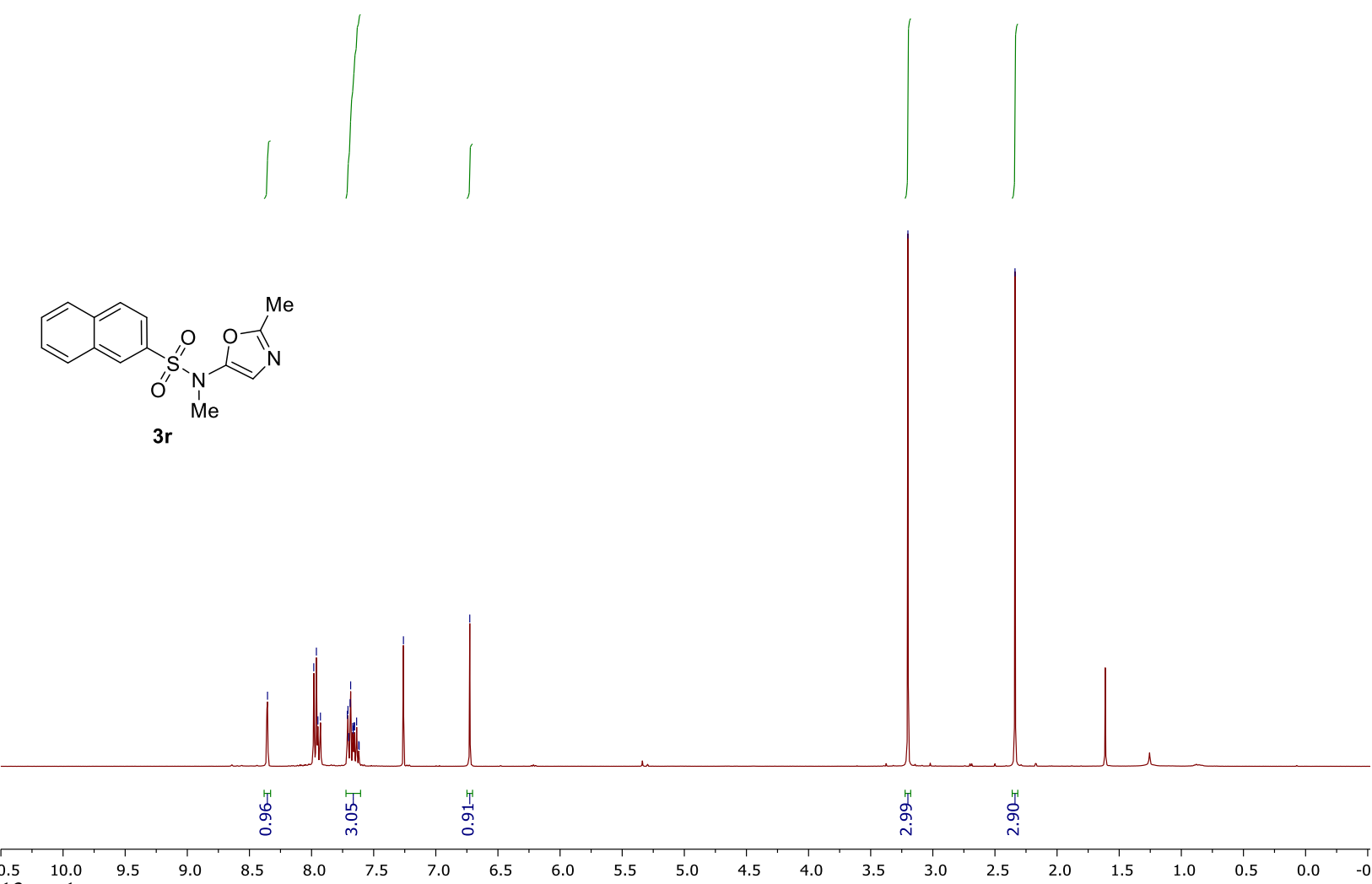

${ }^{13} \mathrm{C}\left\{{ }^{1} \mathrm{H}\right\}$ NMR (100 MHz, $\left.\mathrm{CDCl}_{3}\right)$

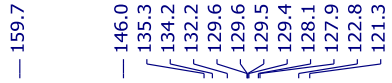

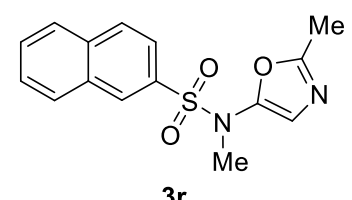

$3 r$
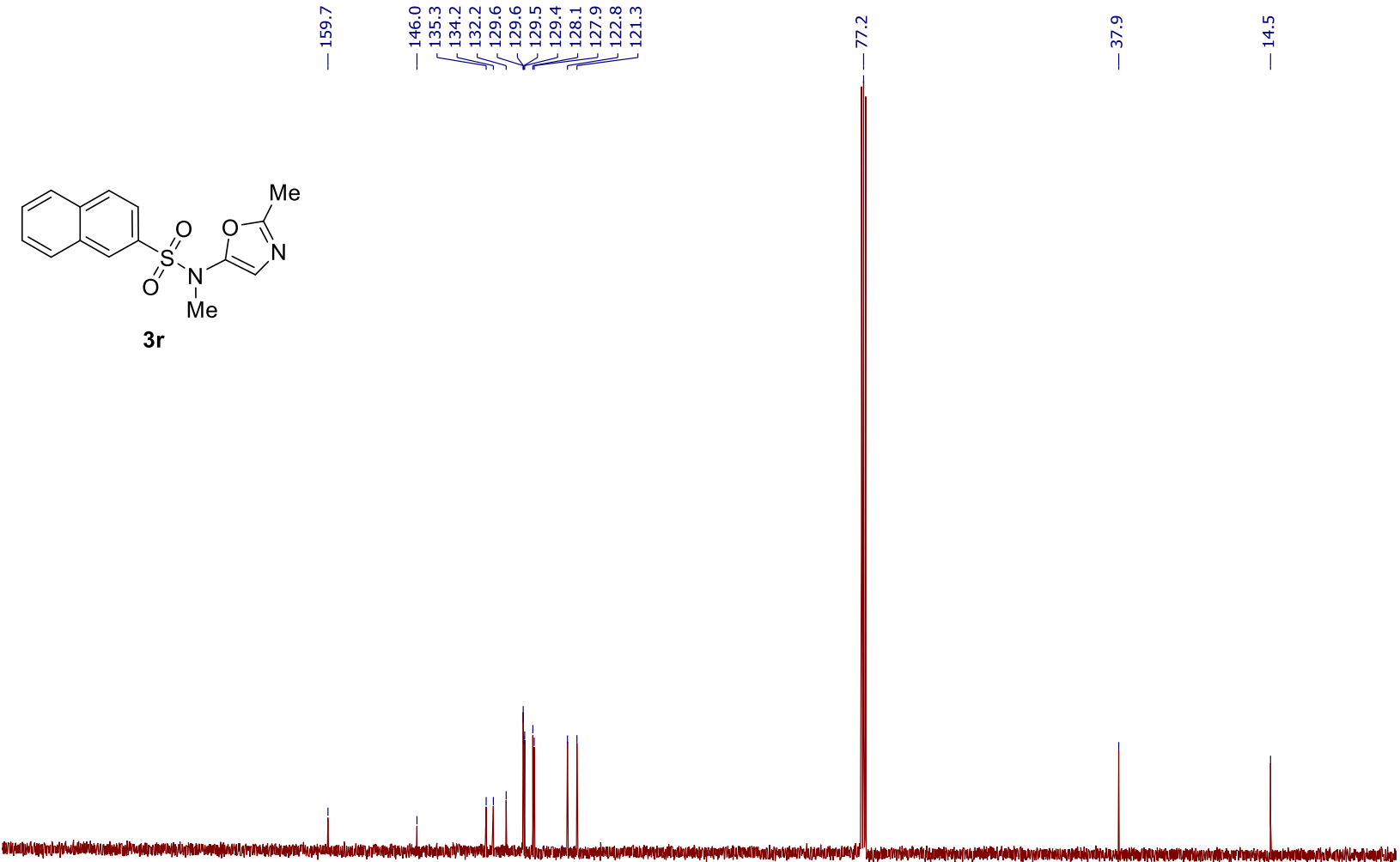

200

190

$180 \quad 170$

150

$130 \quad 120$

$\begin{array}{lll}110 & 100 & 90\end{array}$

8070

60

$\begin{array}{lllll}40 & 30 & 20 & 10 & 0\end{array}$ 
${ }^{1} \mathrm{H}$ NMR (400 MHz, $\mathrm{CDCl}_{3}$ )

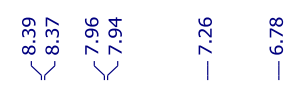

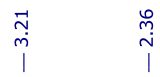

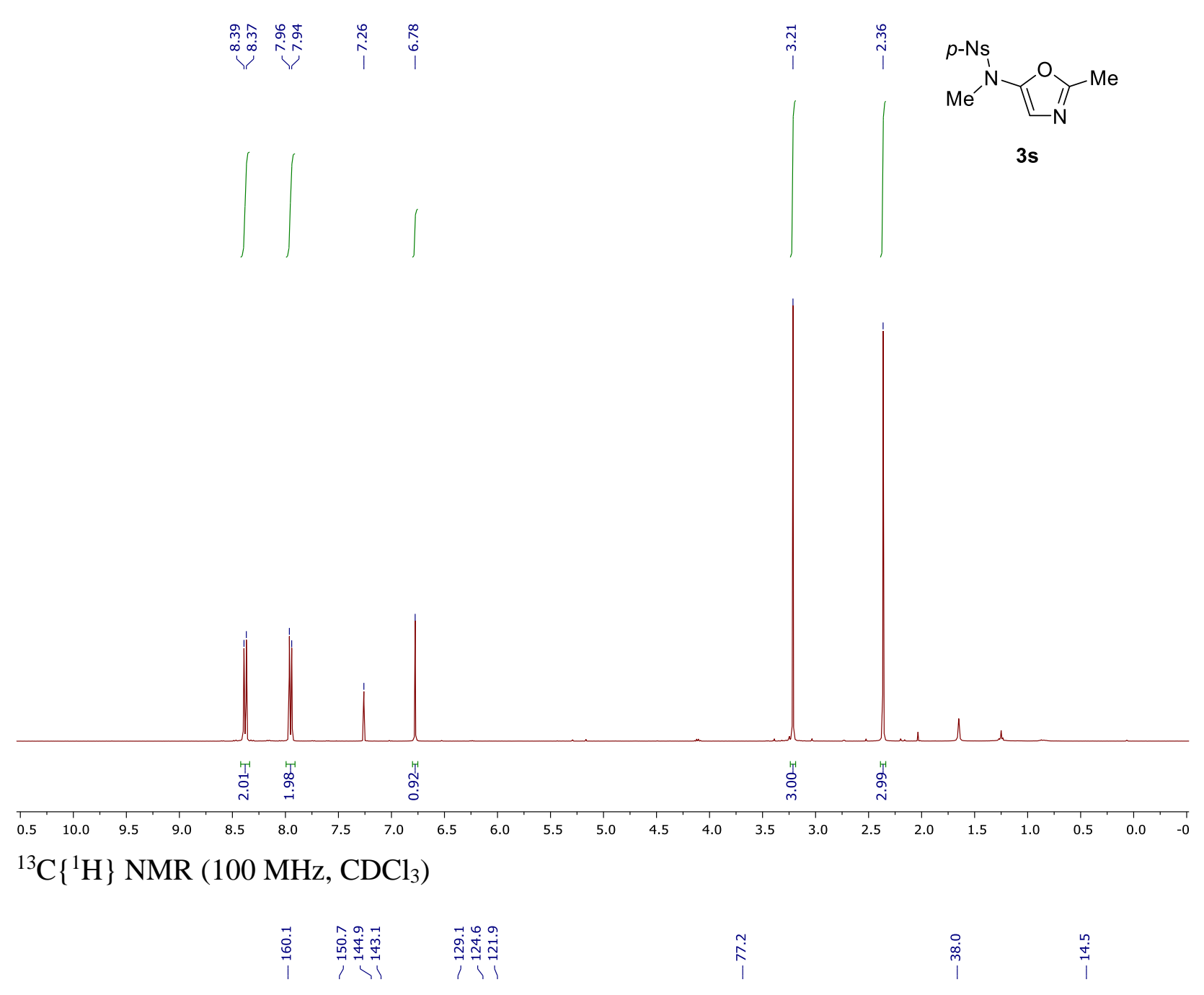

$3 s$
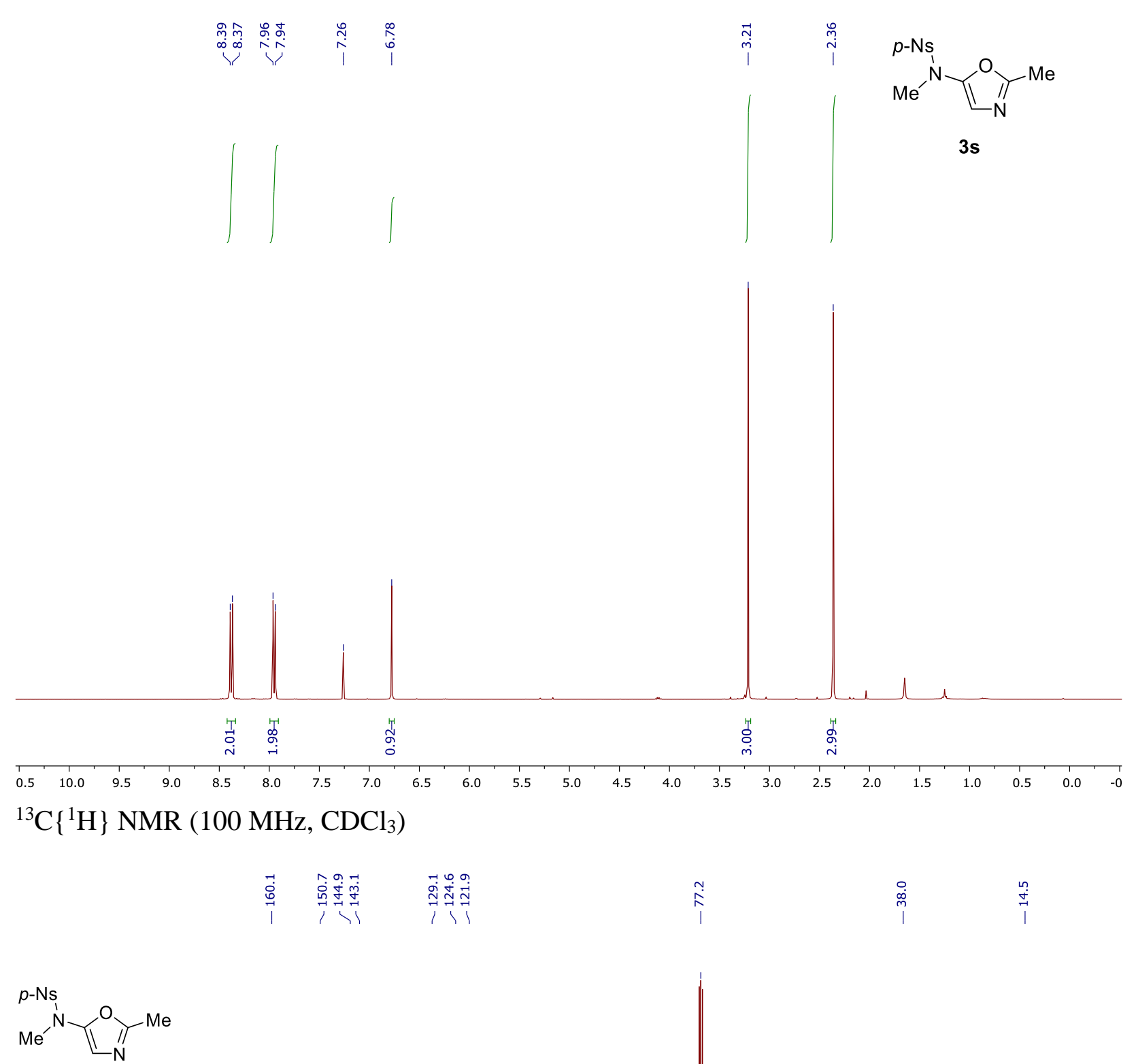

3s

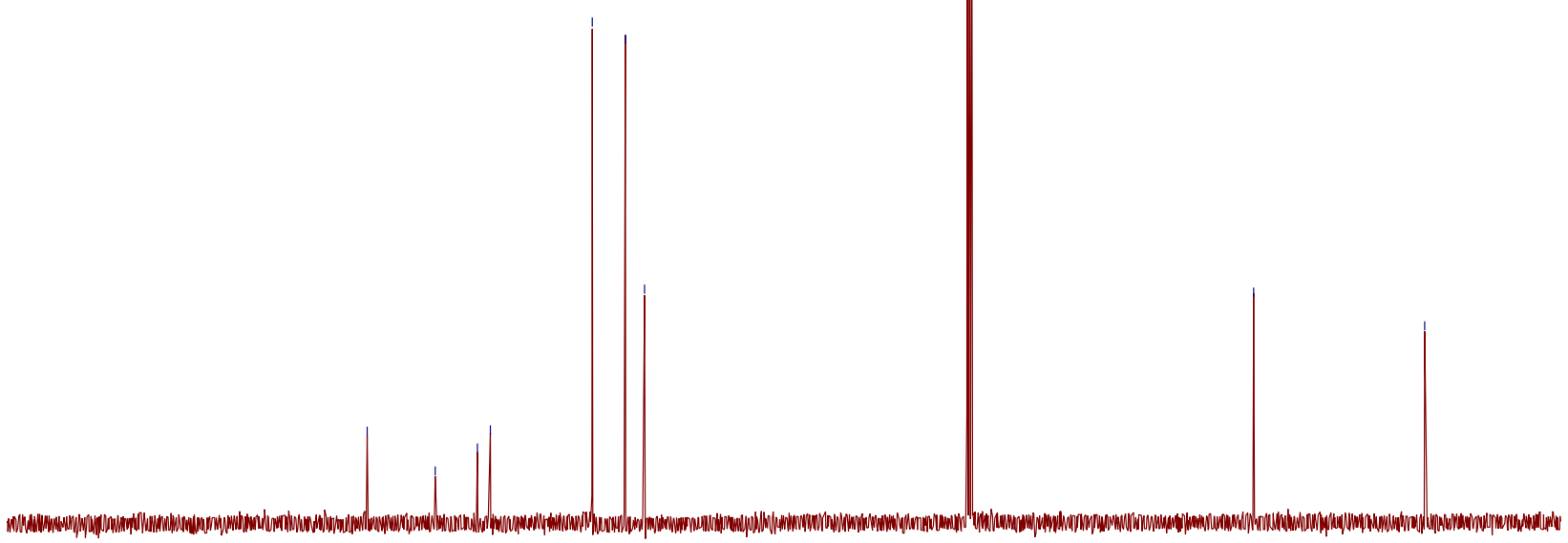

$\begin{array}{lllllllllllllllllllllll} & 1 & 190 & 180 & 170 & 160 & 150 & 140 & 130 & 120 & 110 & 100 & 90 & 80 & 70 & 60 & 50 & 40 & 30 & 20 & 10 & 0\end{array}$ 
${ }^{1} \mathrm{H}$ NMR $\left(400 \mathrm{MHz}, \mathrm{CDCl}_{3}\right)$

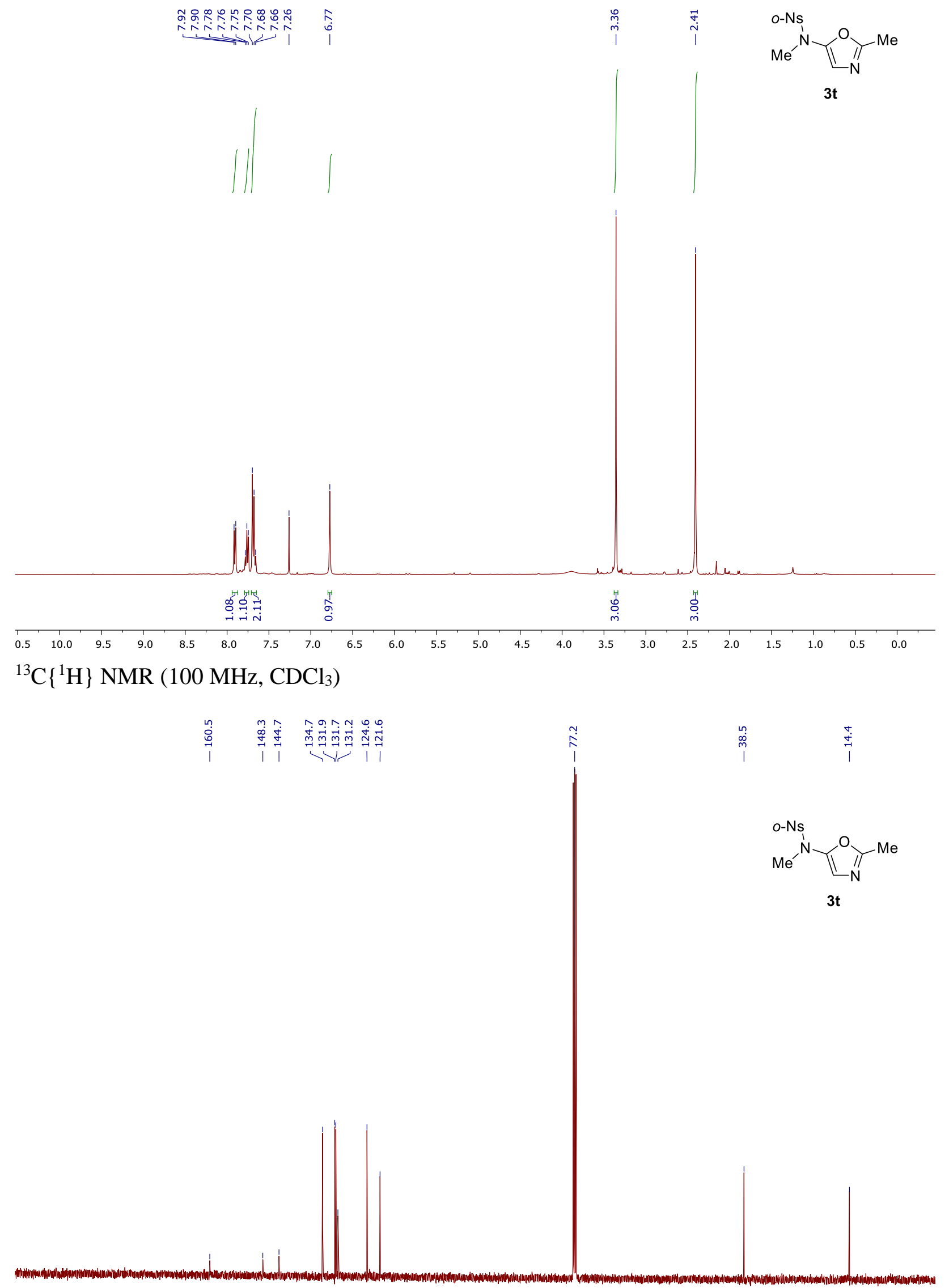

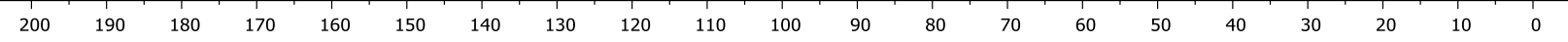


${ }^{1} \mathrm{H}$ NMR (400 MHz, $\left.\mathrm{CDCl}_{3}\right)$

$n_{n-u^{N}}^{T s} \prod_{N}^{-M e}$

$3 u$

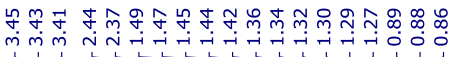

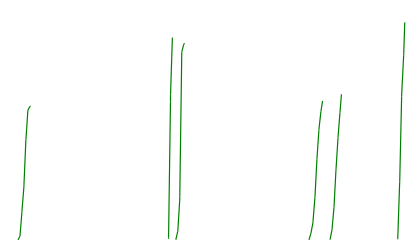

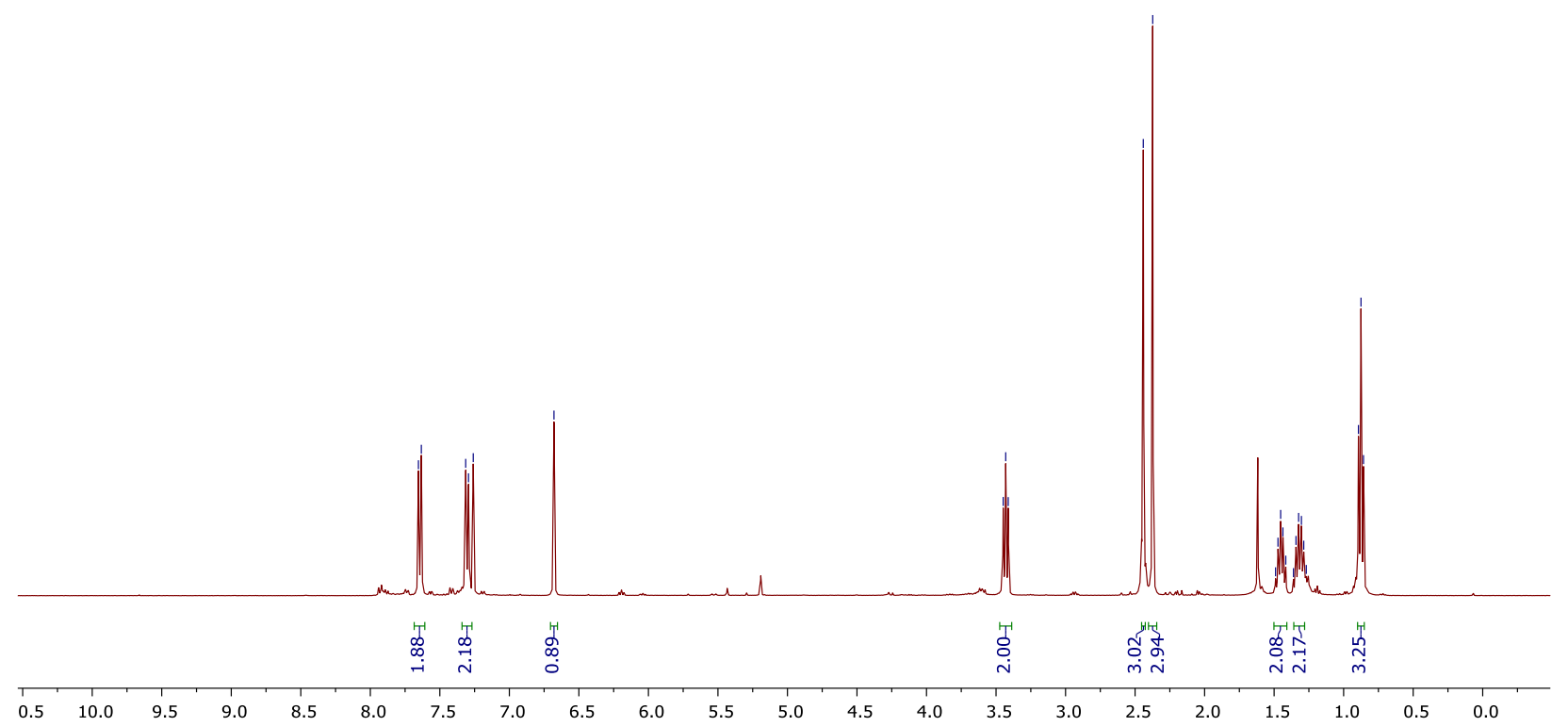

${ }^{13} \mathrm{C}\left\{{ }^{1} \mathrm{H}\right\}$ NMR $\left(100 \mathrm{MHz}, \mathrm{CDCl}_{3}\right)$

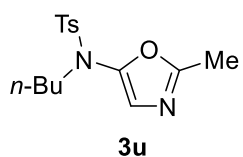

3u

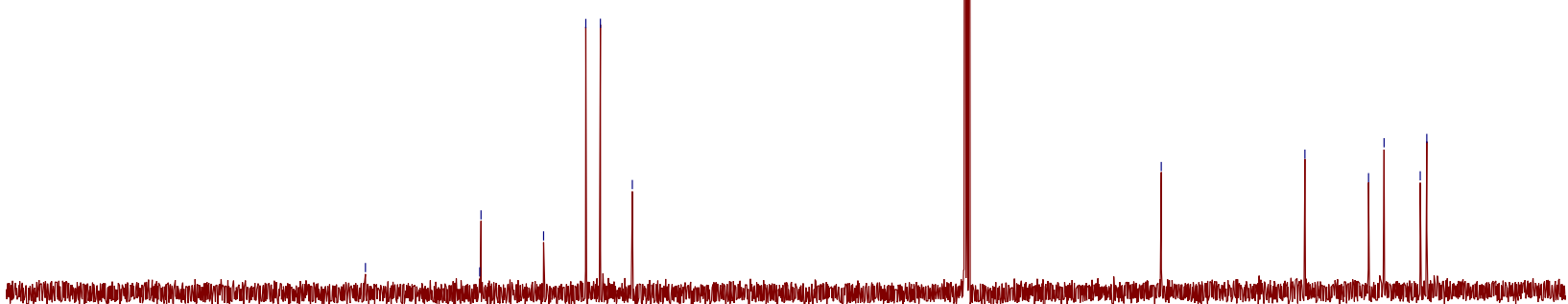


${ }^{1} \mathrm{H}$ NMR $\left(400 \mathrm{MHz}, \mathrm{CDCl}_{3}\right)$

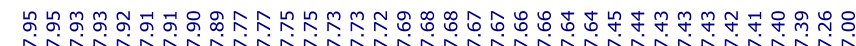

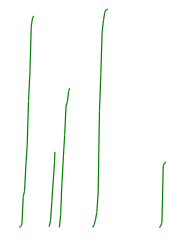

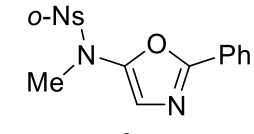

3v

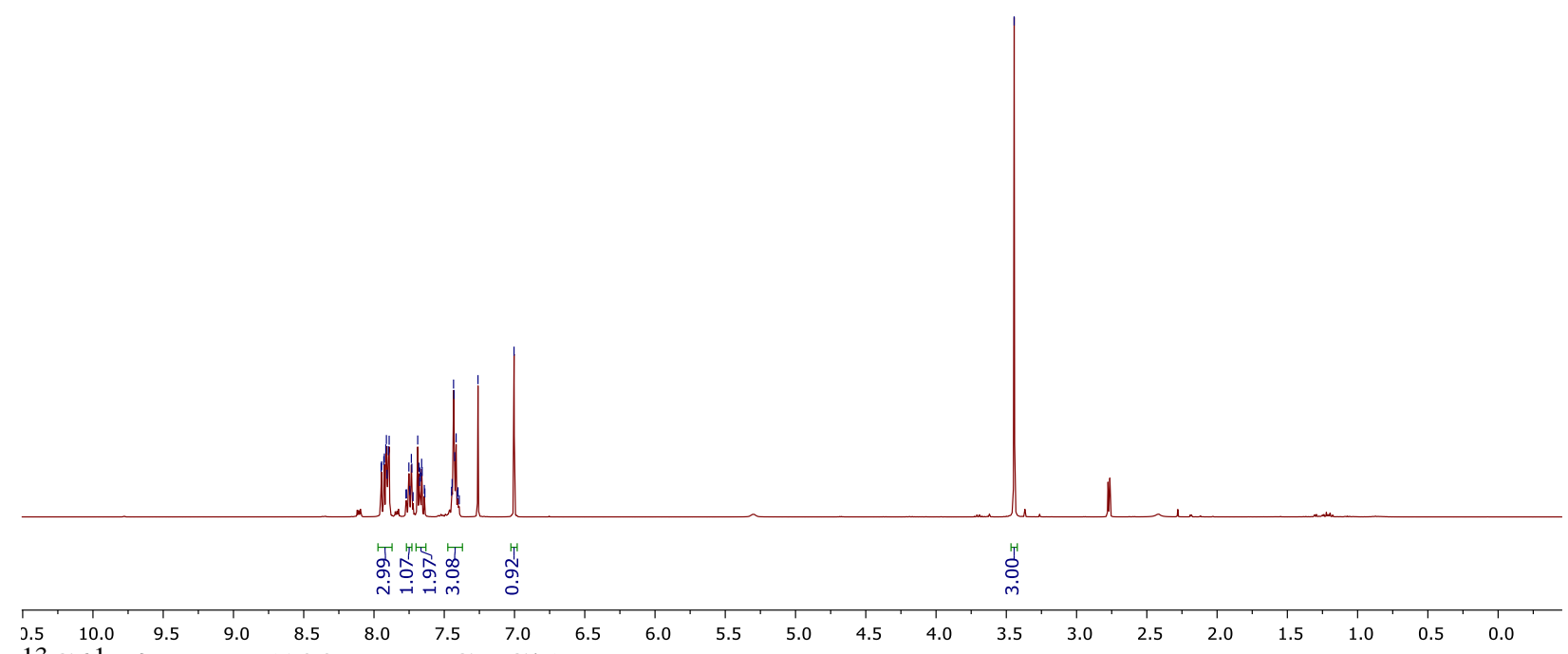
${ }^{13} \mathrm{C}\left\{{ }^{1} \mathrm{H}\right\}$ NMR $\left(100 \mathrm{MHz}, \mathrm{CDCl}_{3}\right)$

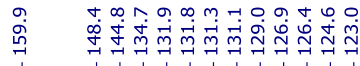

$\mathrm{Me}^{\mathrm{O}} \mathrm{Ns}_{\mathrm{N}}^{\mathrm{O}} \|^{\mathrm{Ph}}$

$3 \mathbf{v}$

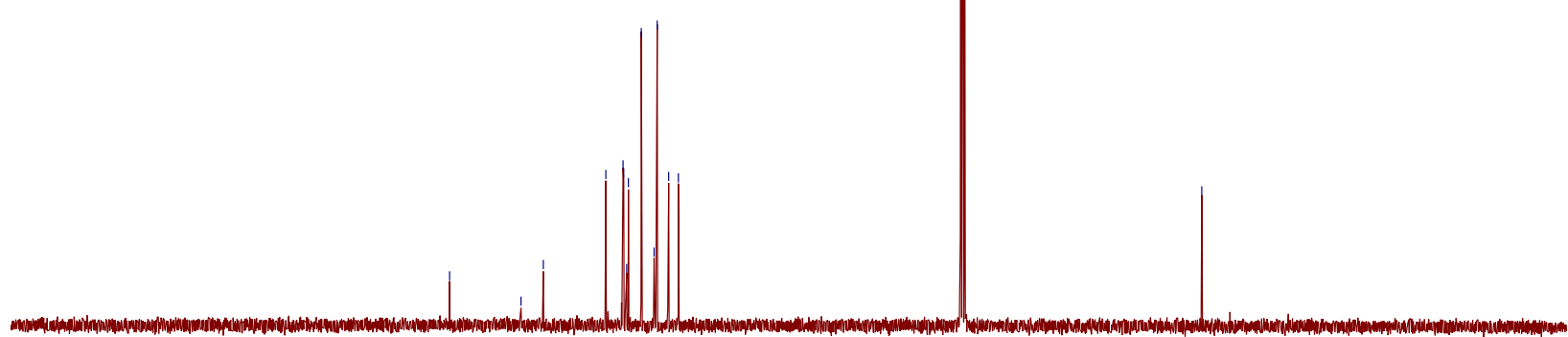

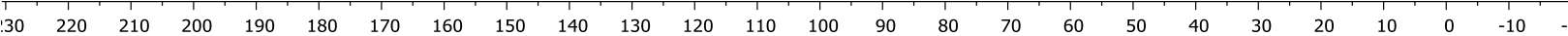


${ }^{1} \mathrm{H}$ NMR (400 MHz, $\mathrm{CDCl}_{3}$ )

管

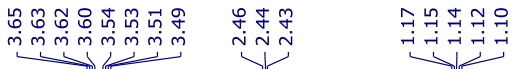
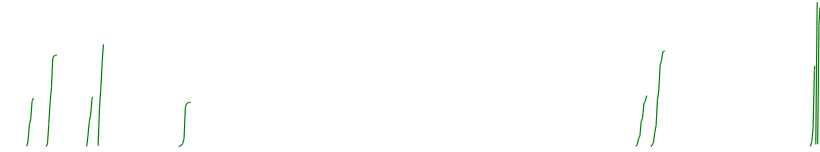

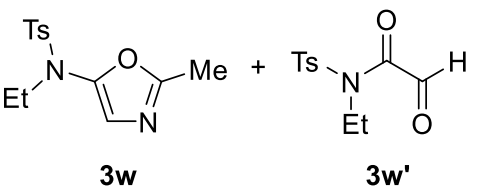

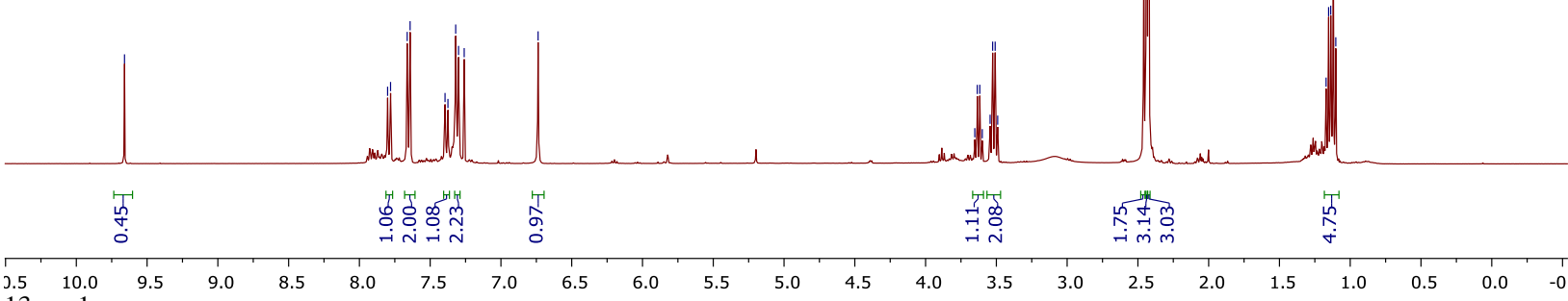

${ }^{13} \mathrm{C}\left\{{ }^{1} \mathrm{H}\right\} \mathrm{NMR}\left(100 \mathrm{MHz}, \mathrm{CDCl}_{3}\right)$

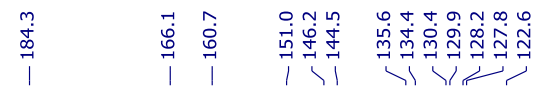

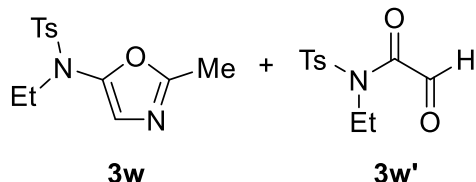

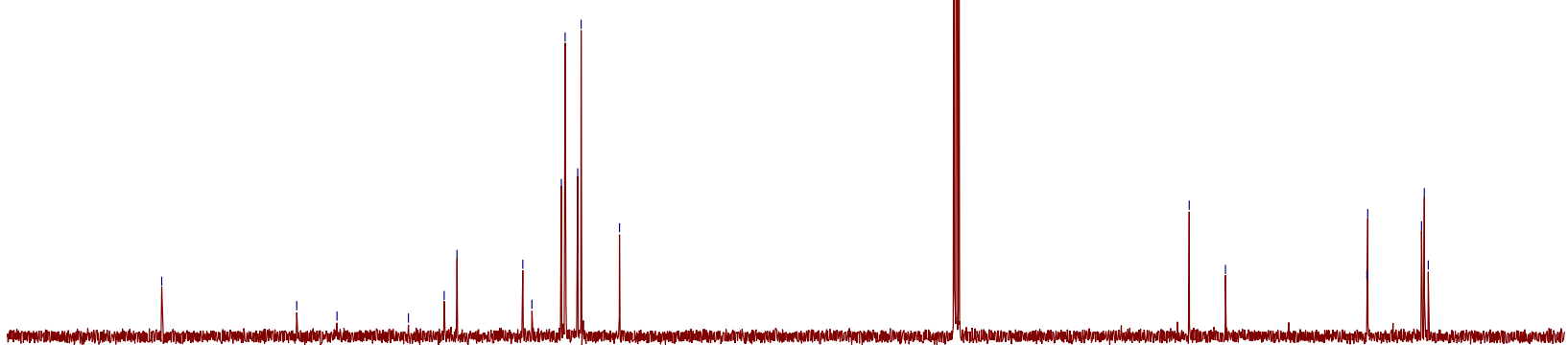

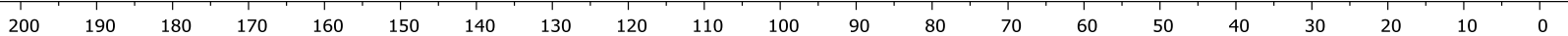


${ }^{1} \mathrm{H}$ NMR (400 MHz, $\left.\mathrm{CDCl}_{3}\right)$

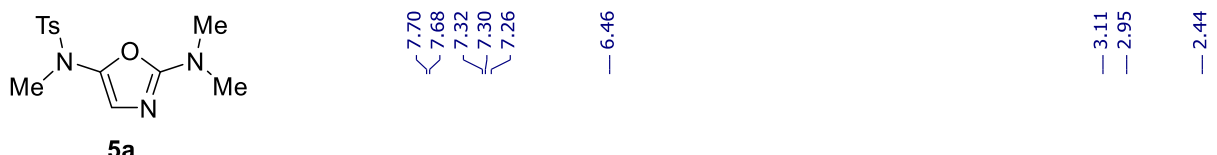

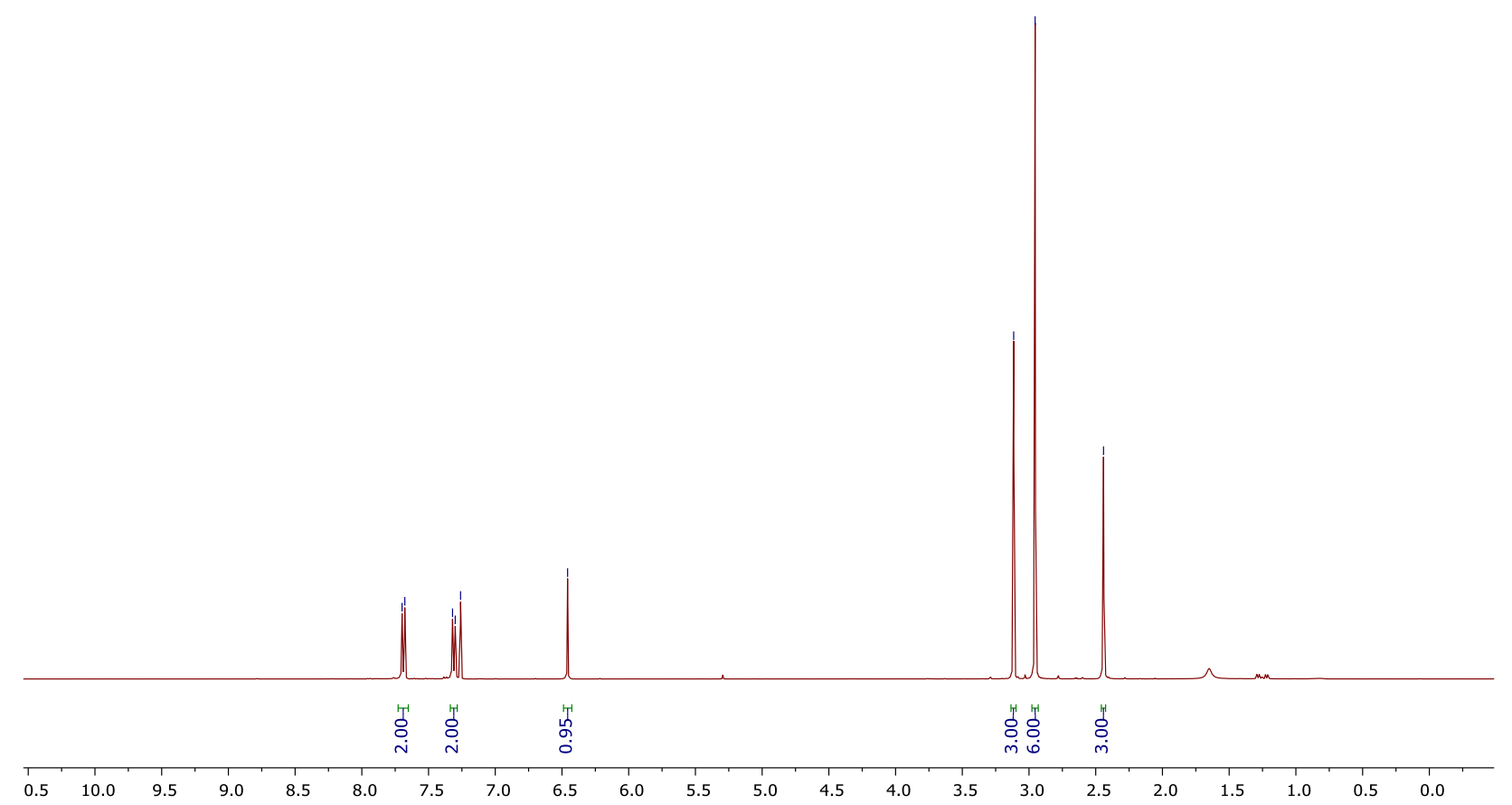

${ }^{13} \mathrm{C}\left\{{ }^{1} \mathrm{H}\right\}$ NMR $\left(100 \mathrm{MHz}, \mathrm{CDCl}_{3}\right)$

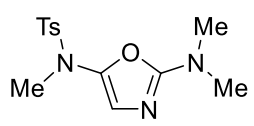

$5 a$

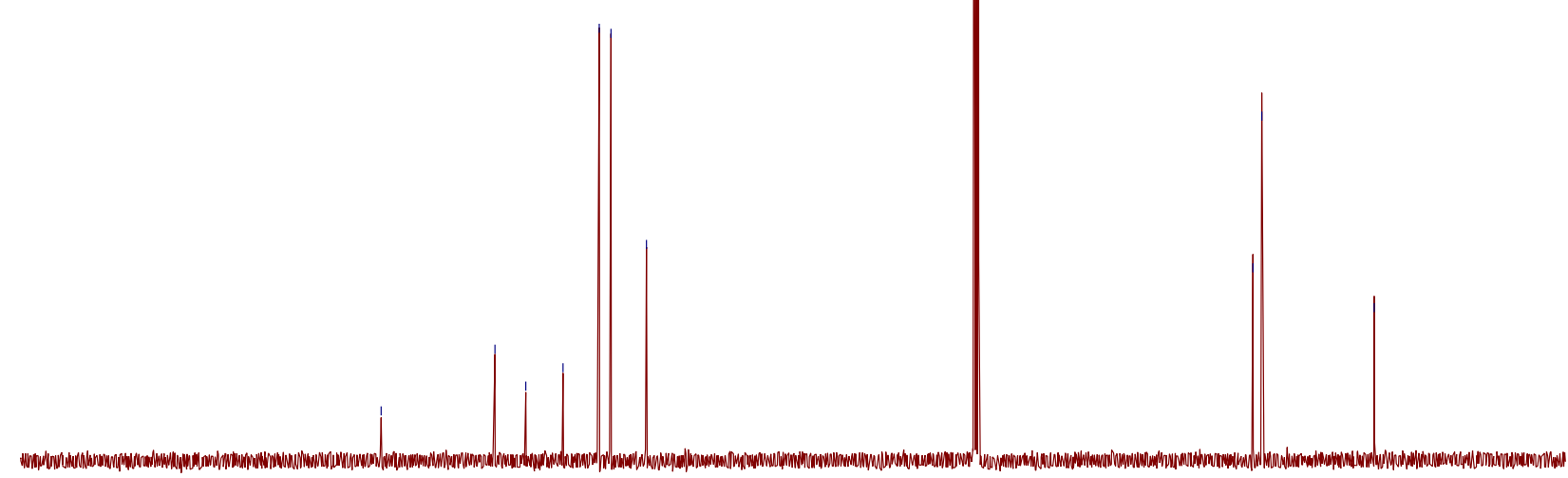

$\begin{array}{lllllllllllllllllllllllllllll}10 & 200 & 190 & 180 & 170 & 160 & 150 & 140 & 130 & 120 & 110 & 100 & 90 & 80 & 70 & 60 & 50 & 40 & 30 & 20 & 10 & 0\end{array}$ 
${ }^{1} \mathrm{H}$ NMR $\left(400 \mathrm{MHz}, \mathrm{CDCl}_{3}\right)$

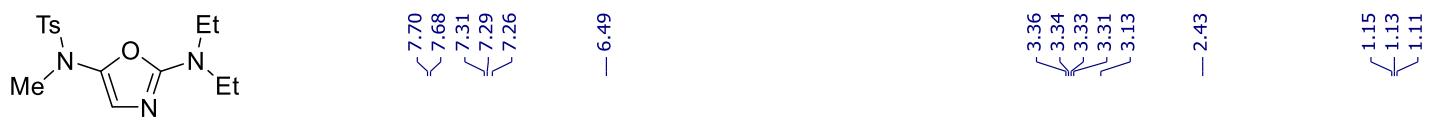

$5 b$

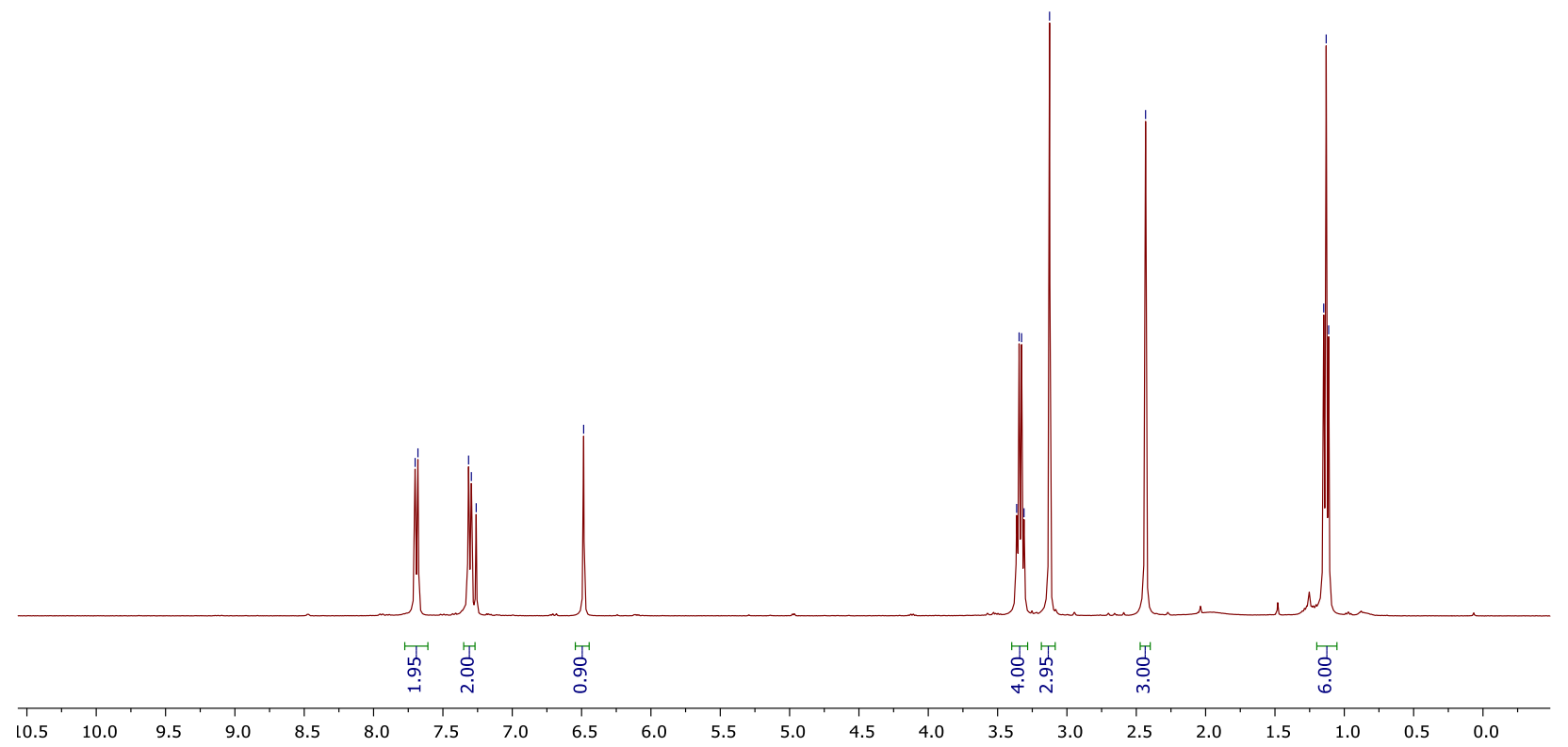

${ }^{13} \mathrm{C}\left\{{ }^{1} \mathrm{H}\right\}$ NMR $\left(100 \mathrm{MHz}, \mathrm{CDCl}_{3}\right)$

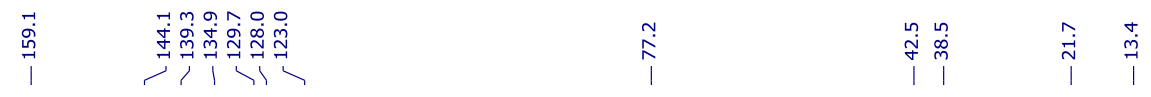

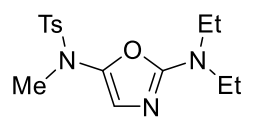

$5 b$

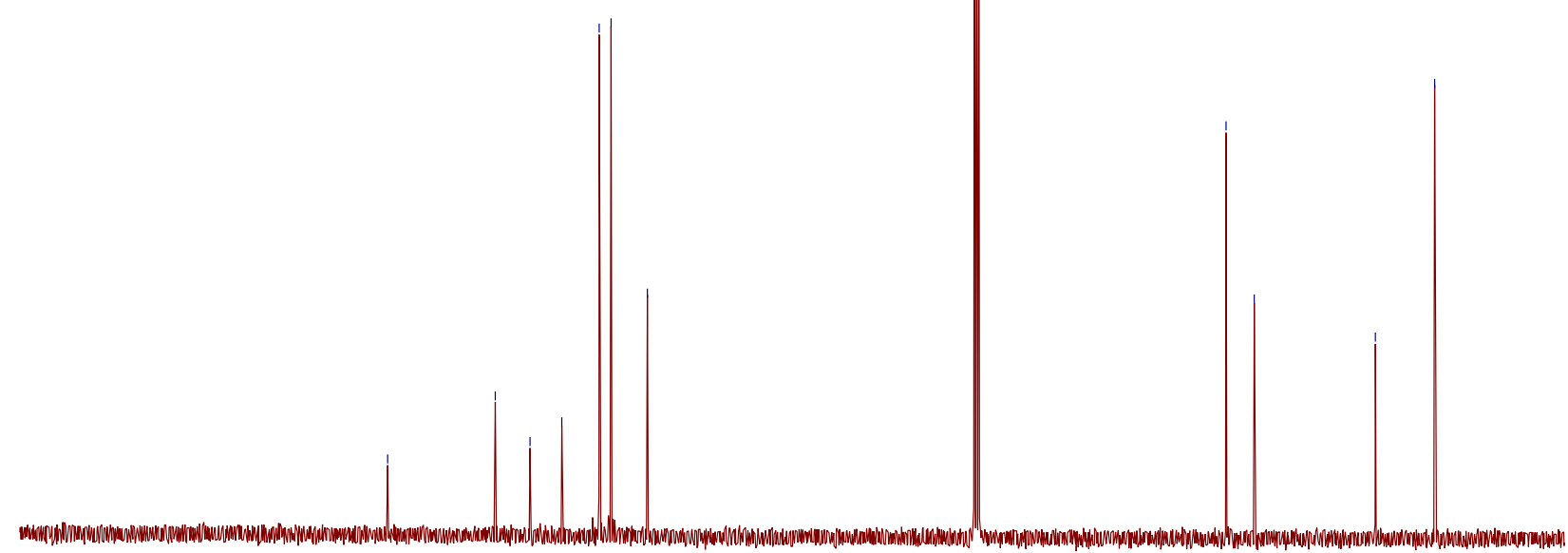

$\begin{array}{lllllllllllllllllllllll}10 & 200 & 190 & 180 & 170 & 160 & 150 & 140 & 130 & 120 & 110 & 100 & 90 & 80 & 70 & 60 & 50 & 40 & 30 & 20 & 10 & 0\end{array}$ 
${ }^{1} \mathrm{H}$ NMR $\left(400 \mathrm{MHz}, \mathrm{CDCl}_{3}\right)$

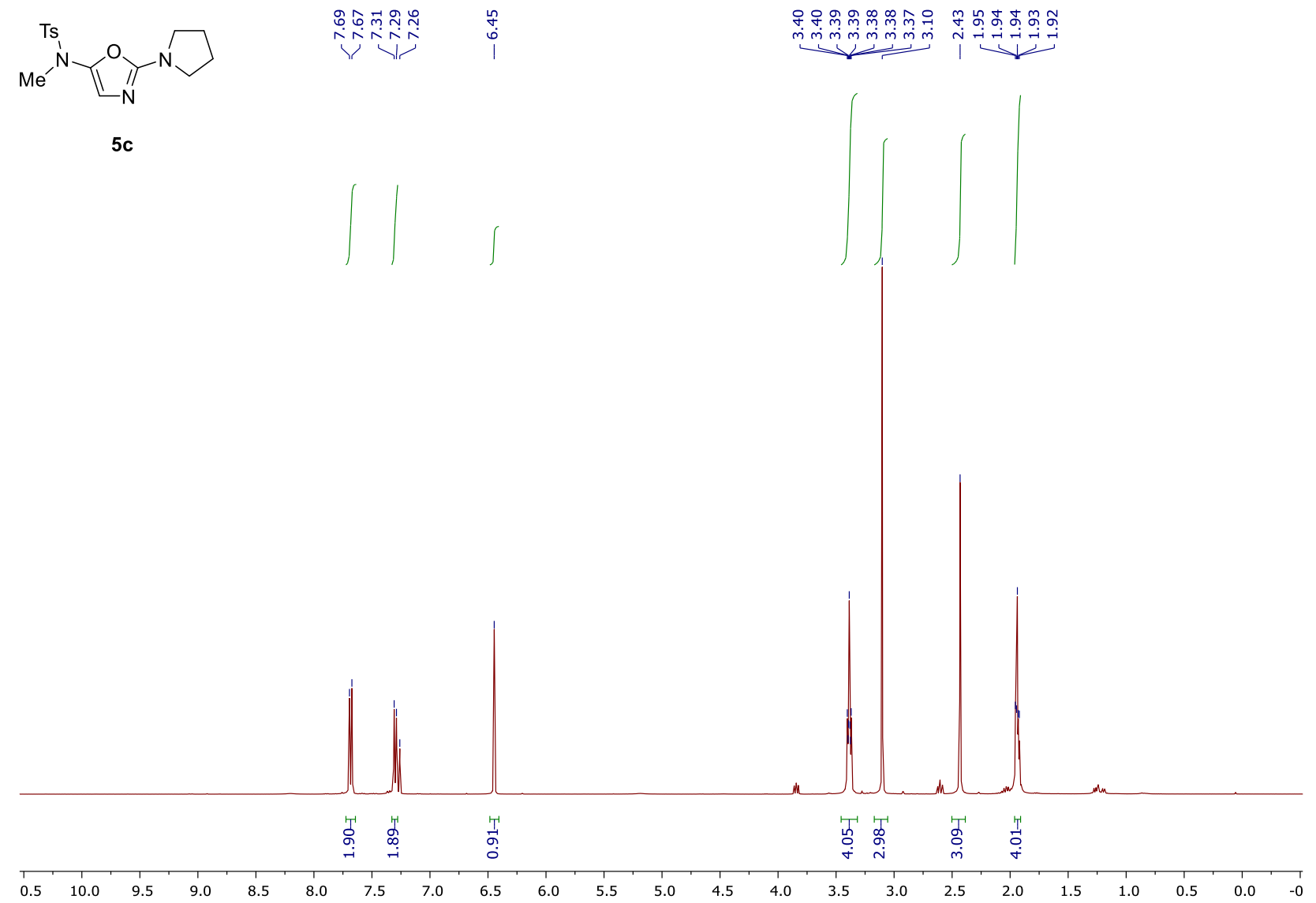

${ }^{13} \mathrm{C}\left\{{ }^{1} \mathrm{H}\right\} \mathrm{NMR}\left(100 \mathrm{MHz}, \mathrm{CDCl}_{3}\right)$

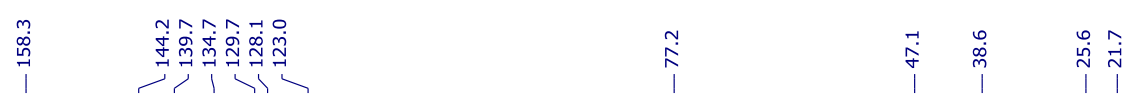

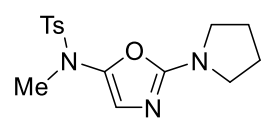

$5 c$

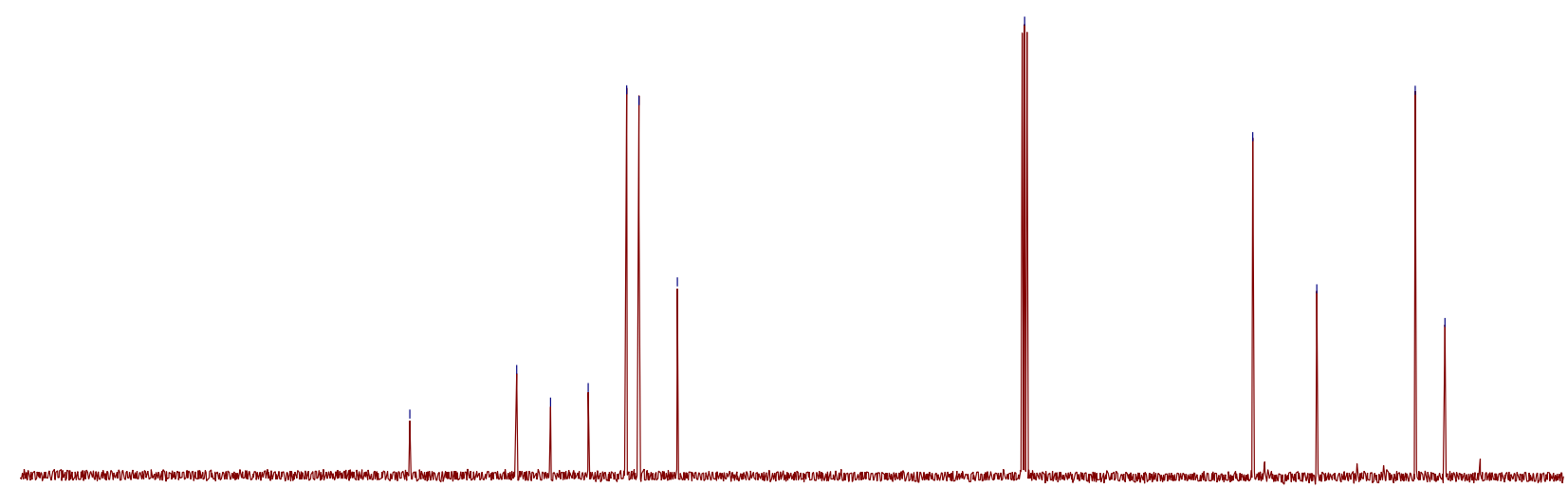

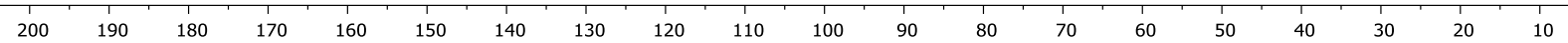


${ }^{1} \mathrm{H}$ NMR (400 MHz, $\left.\mathrm{CDCl}_{3}\right)$

$\mathrm{me}^{\mathrm{N}} \prod_{N}^{\mathrm{T}} \prod_{N}^{-N}$

$5 d$

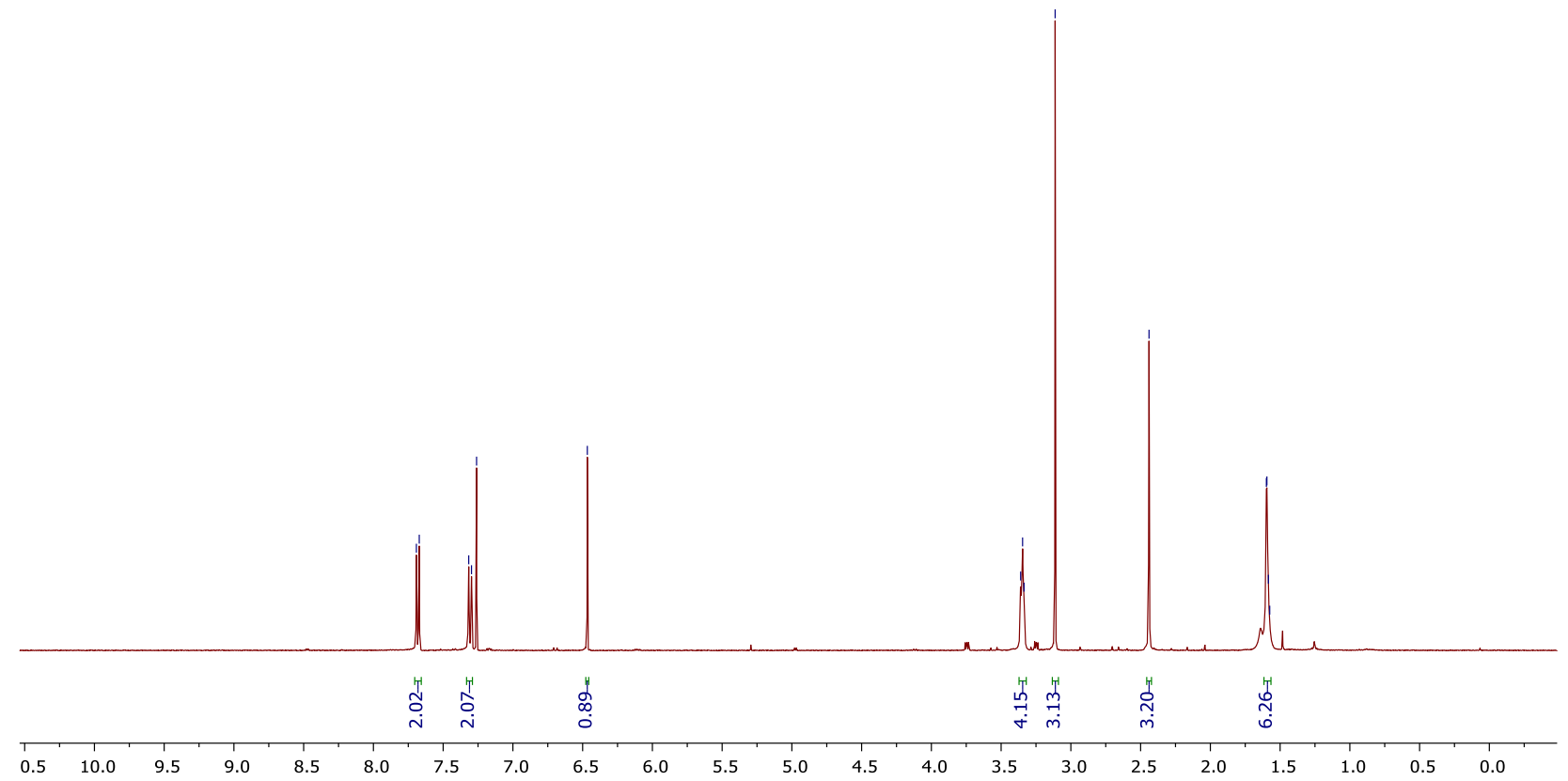

${ }^{13} \mathrm{C}\left\{{ }^{1} \mathrm{H}\right\} \mathrm{NMR}\left(100 \mathrm{MHz}, \mathrm{CDCl}_{3}\right)$

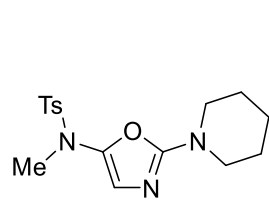

管

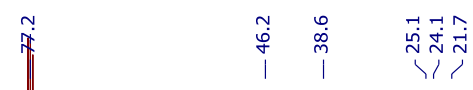

5d

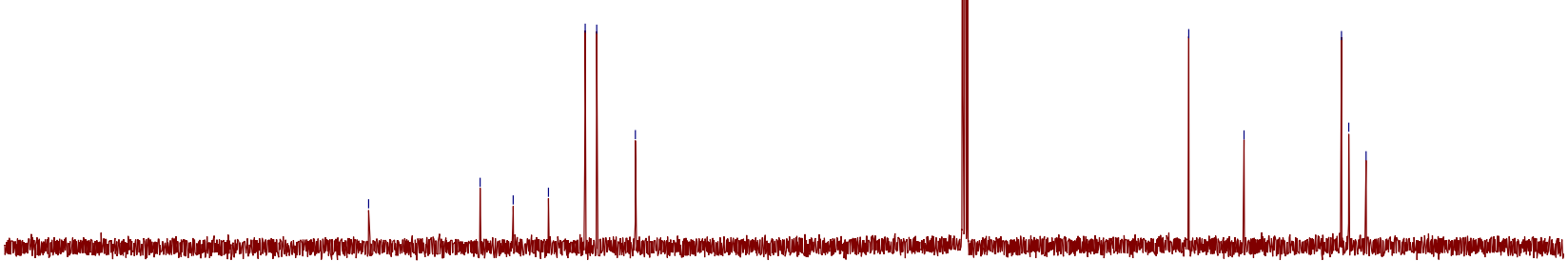


${ }^{1} \mathrm{H}$ NMR (400 MHz, $\left.\mathrm{CDCl}_{3}\right)$

în

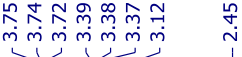

$\mathrm{Me}^{\mathrm{N}} \mathrm{L}_{\mathrm{N}}^{\mathrm{N}} \mathrm{N}^{\mathrm{N}}$

$5 e$

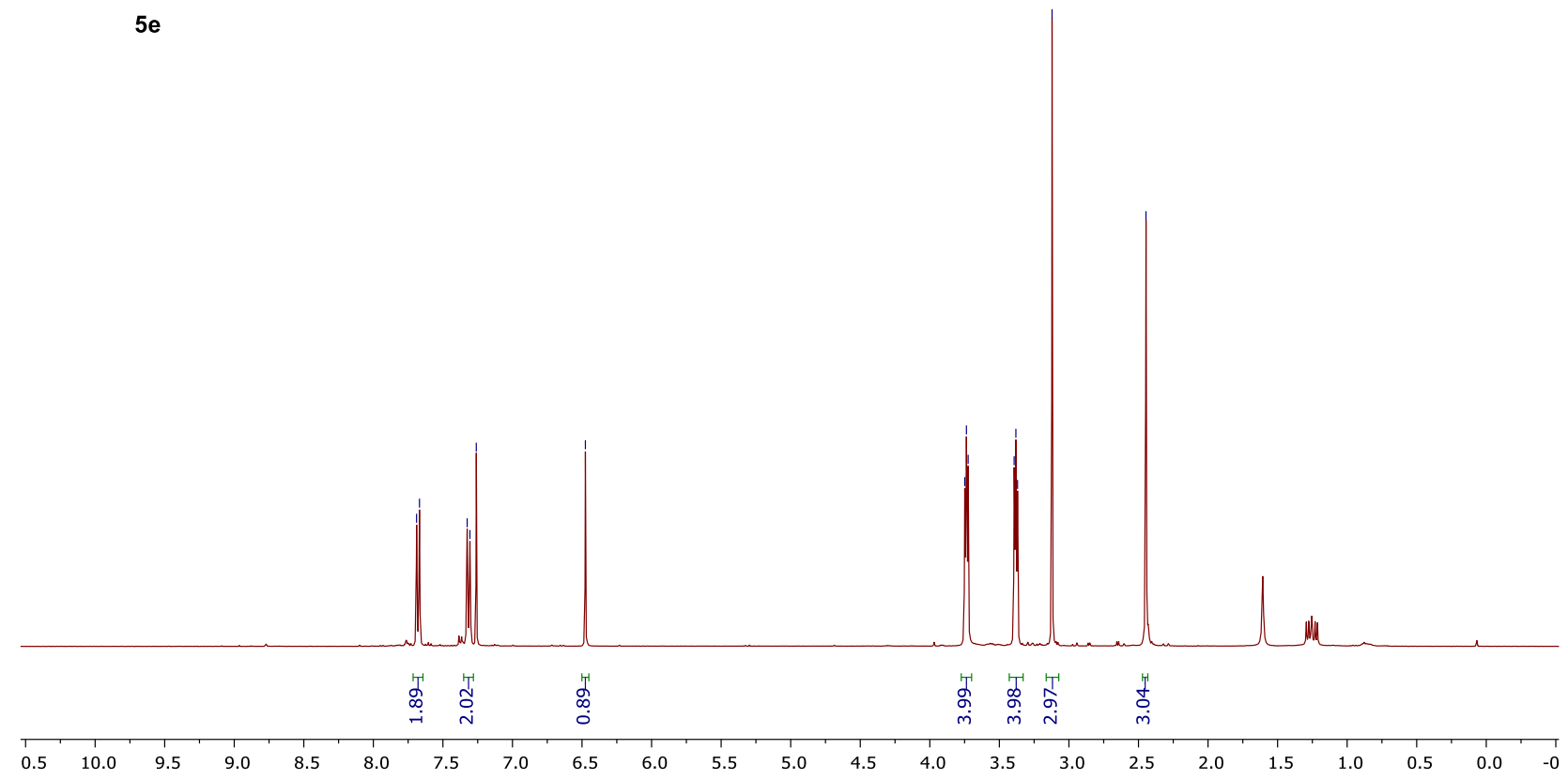

${ }^{13} \mathrm{C}\left\{{ }^{1} \mathrm{H}\right\} \mathrm{NMR}\left(100 \mathrm{MHz}, \mathrm{CDCl}_{3}\right)$

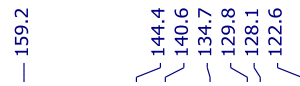

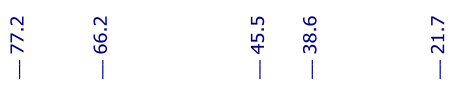

$\mathrm{Me}^{\mathrm{N}} \mathrm{T}_{\mathrm{N}}^{\mathrm{T}}$

$5 e$ 
${ }^{1} \mathrm{H}$ NMR (400 MHz, $\left.\mathrm{CDCl}_{3}\right)$

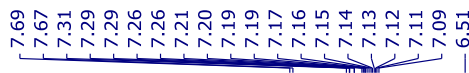

|

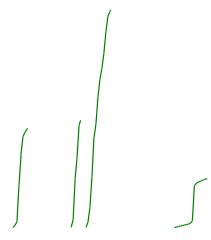

$\mathrm{Me}^{\mathrm{T}} \mathrm{N}_{\mathbf{5}}^{\mathrm{T}}$
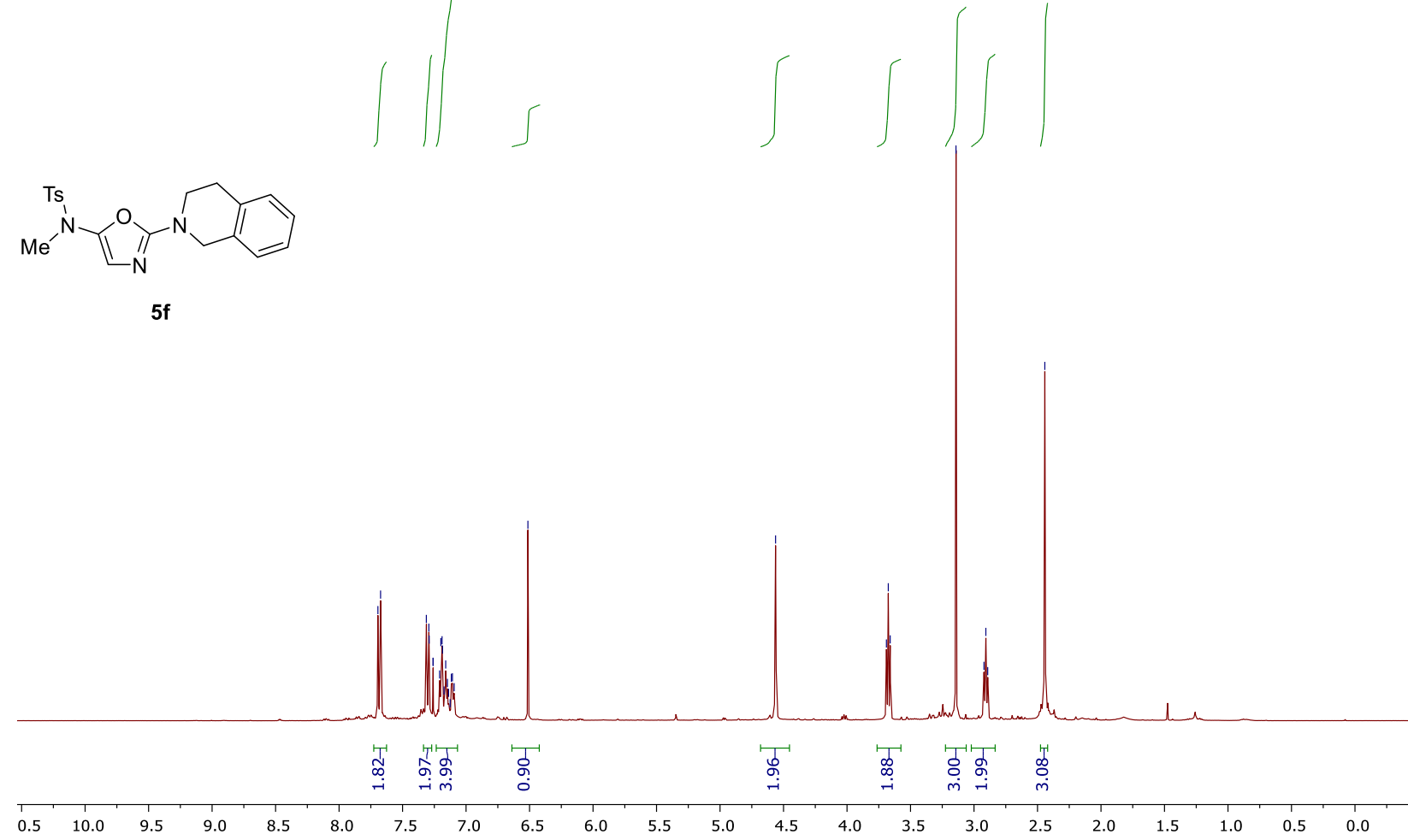

${ }^{13} \mathrm{C}\left\{{ }^{1} \mathrm{H}\right\}$ NMR $\left(100 \mathrm{MHz}, \mathrm{CDCl}_{3}\right)$
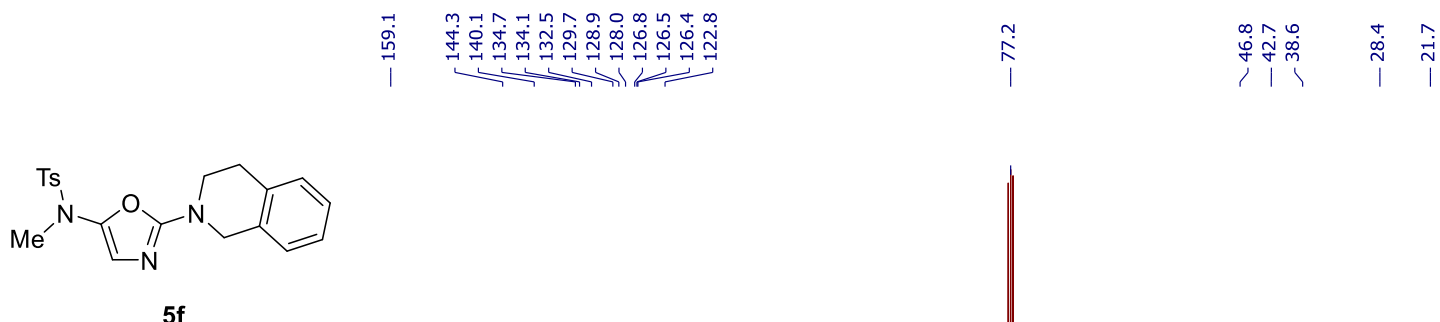

$5 f$

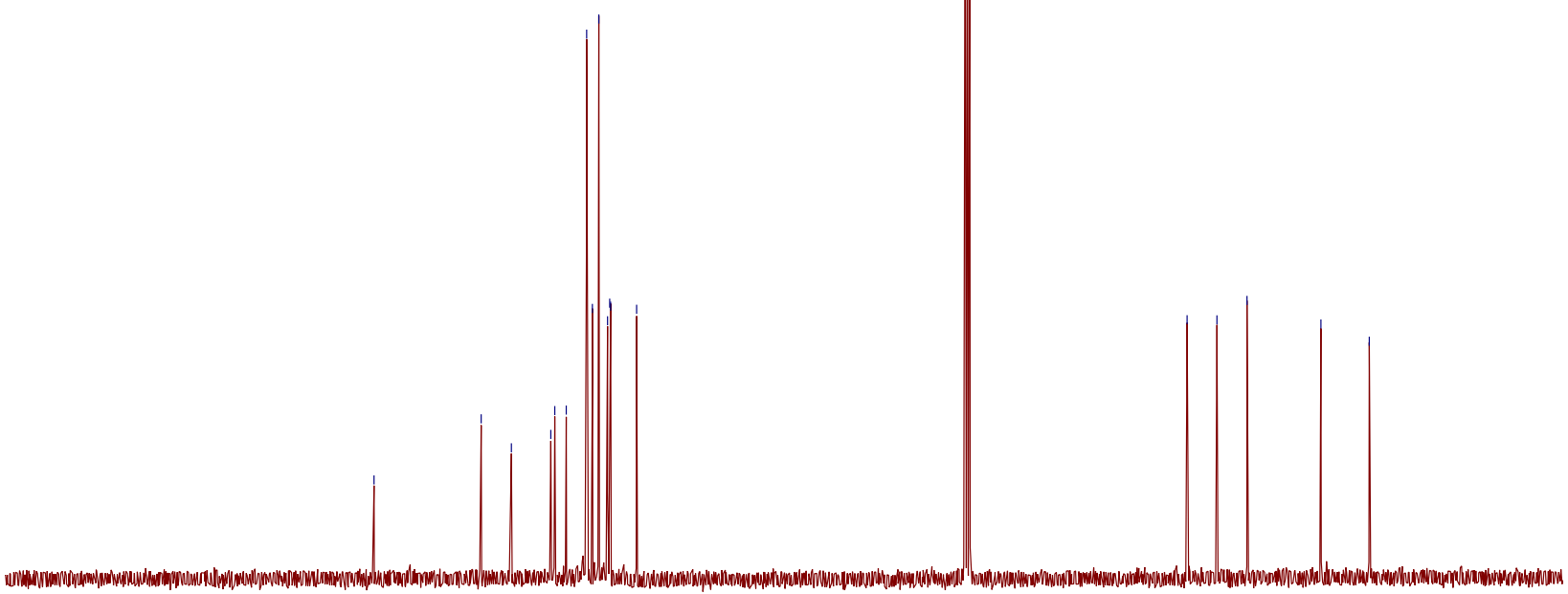


${ }^{1} \mathrm{H}$ NMR $\left(400 \mathrm{MHz}, \mathrm{CDCl}_{3}\right)$

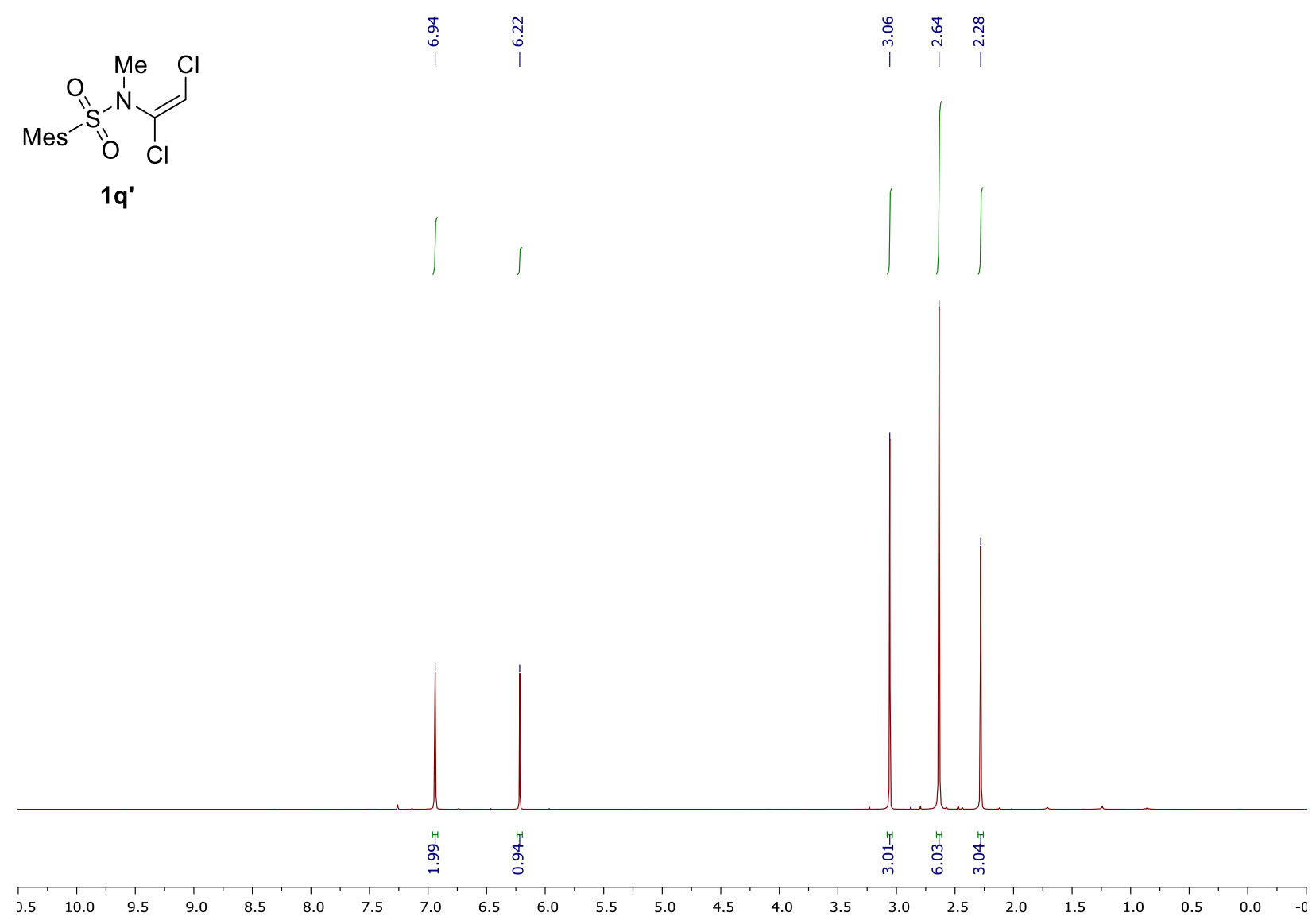

${ }^{13} \mathrm{C}\left\{{ }^{1} \mathrm{H}\right\} \mathrm{NMR}\left(100 \mathrm{MHz}, \mathrm{CDCl}_{3}\right)$

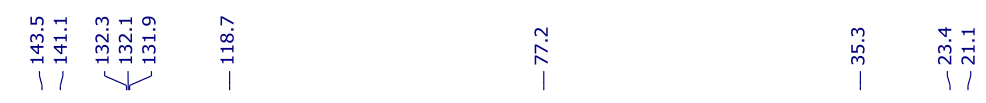

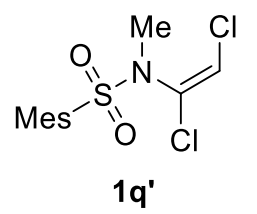

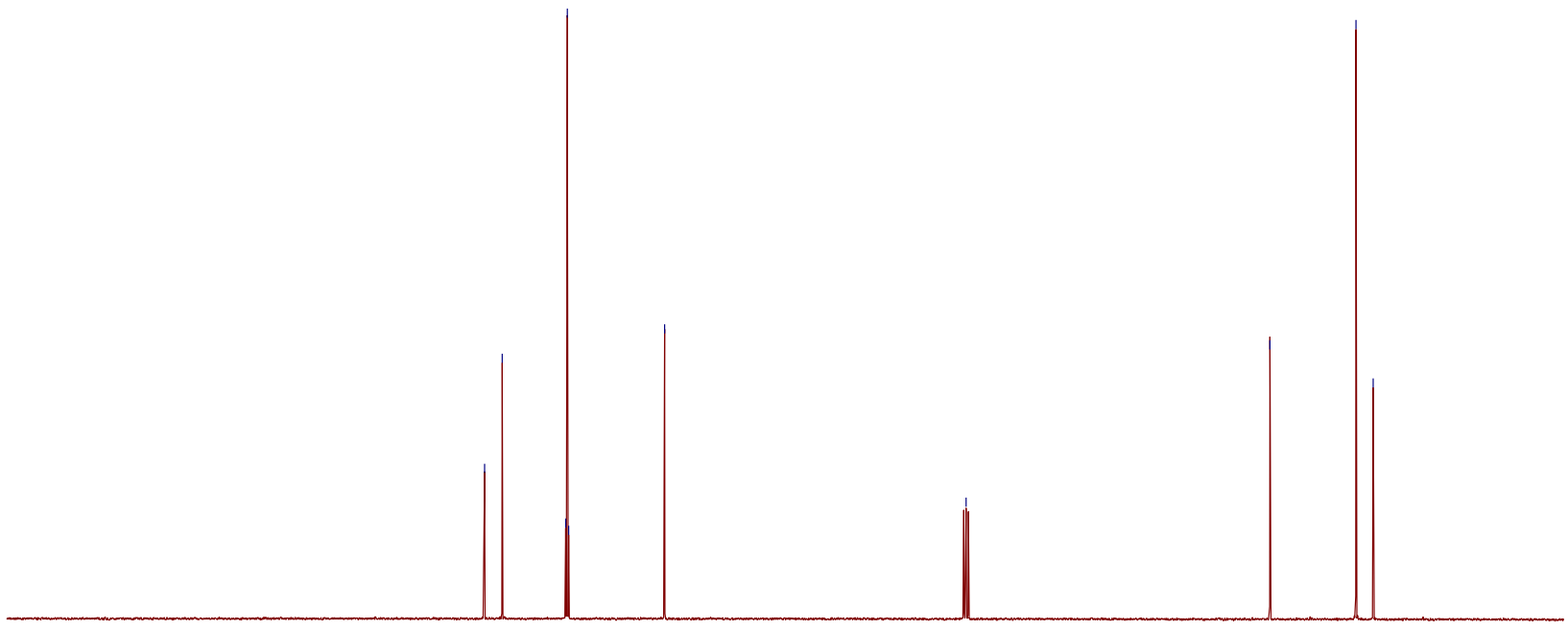

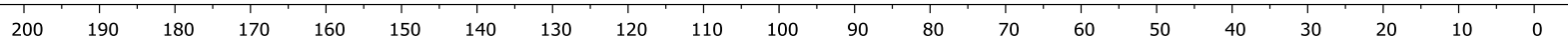


${ }^{1} \mathrm{H}$ NMR (400 MHz, $\left.\mathrm{CDCl}_{3}\right)$

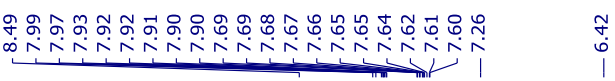

每
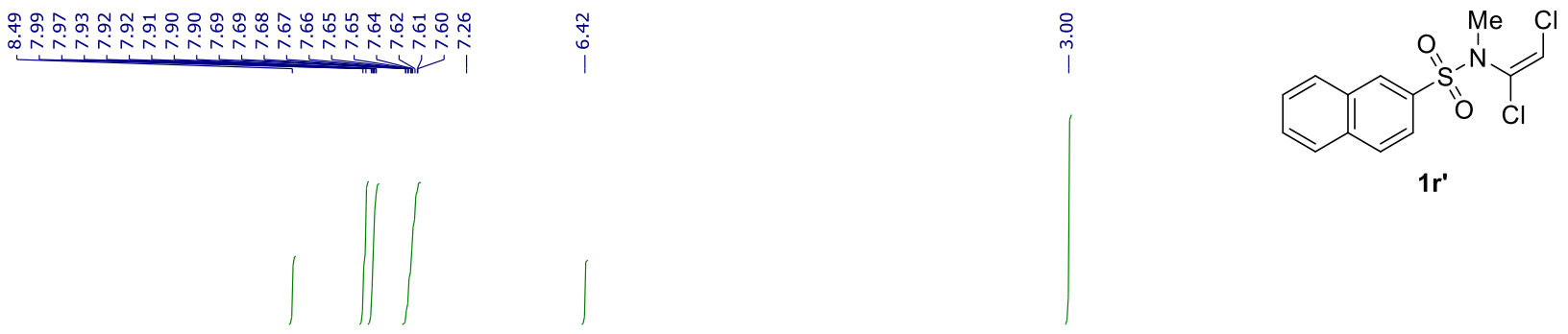

$1 r^{\prime}$

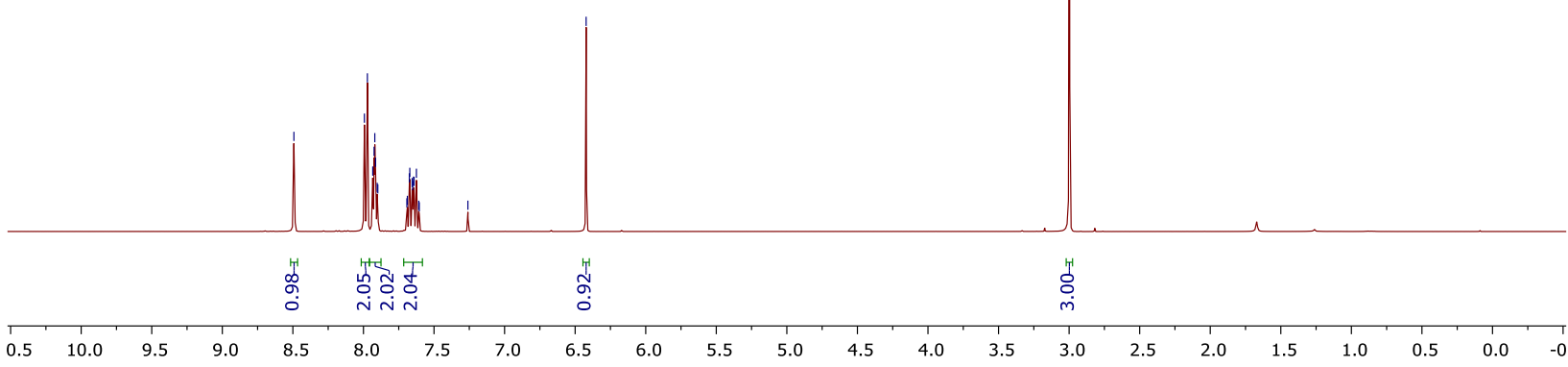

${ }^{13} \mathrm{C}\left\{{ }^{1} \mathrm{H}\right\} \mathrm{NMR}\left(100 \mathrm{MHz}, \mathrm{CDCl}_{3}\right)$

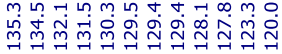
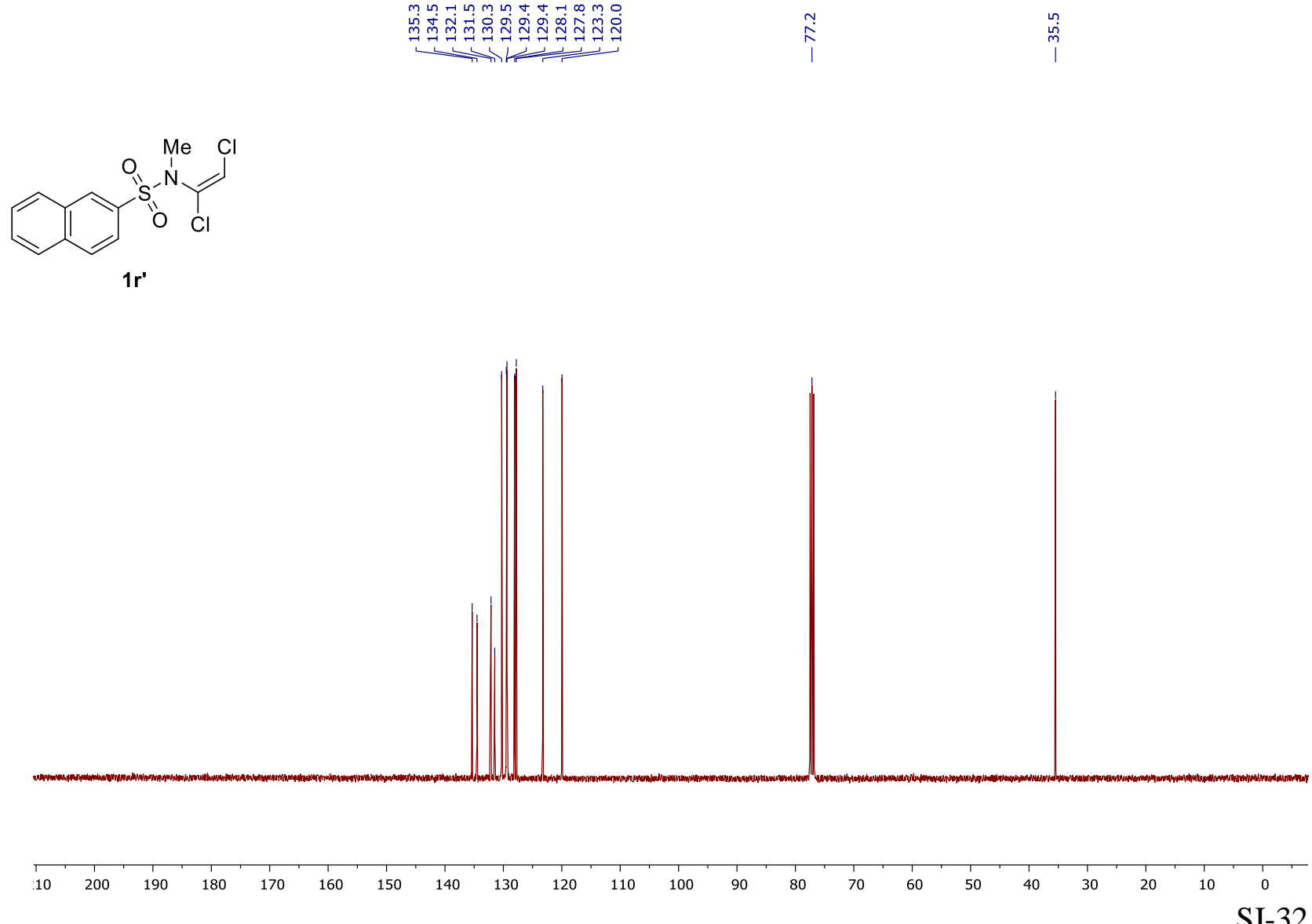
${ }^{1} \mathrm{H}$ NMR $\left(400 \mathrm{MHz}, \mathrm{CDCl}_{3}\right)$

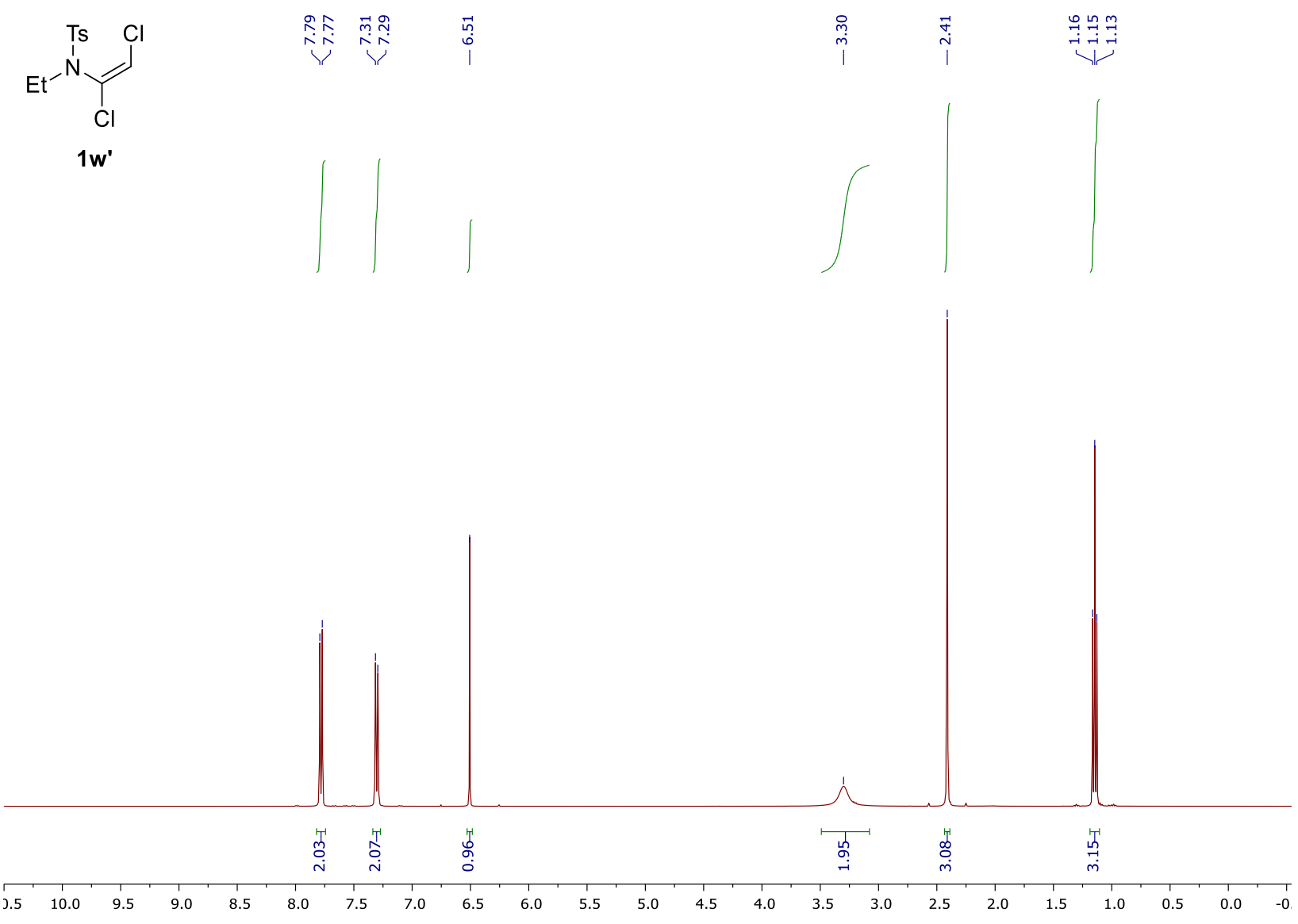

${ }^{13} \mathrm{C}\left\{{ }^{1} \mathrm{H}\right\} \mathrm{NMR}\left(100 \mathrm{MHz}, \mathrm{CDCl}_{3}\right)$

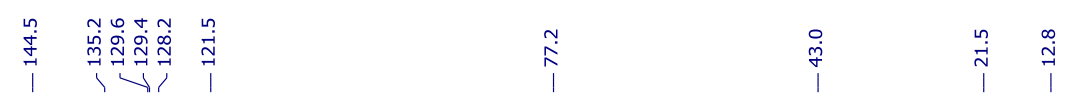

$\left.\right|_{\mathbf{C l}} ^{\mathrm{Cl}}$

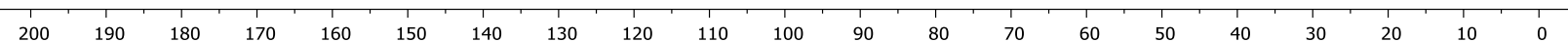


${ }^{1} \mathrm{H}$ NMR (400 MHz, $\mathrm{CDCl}_{3}$ )

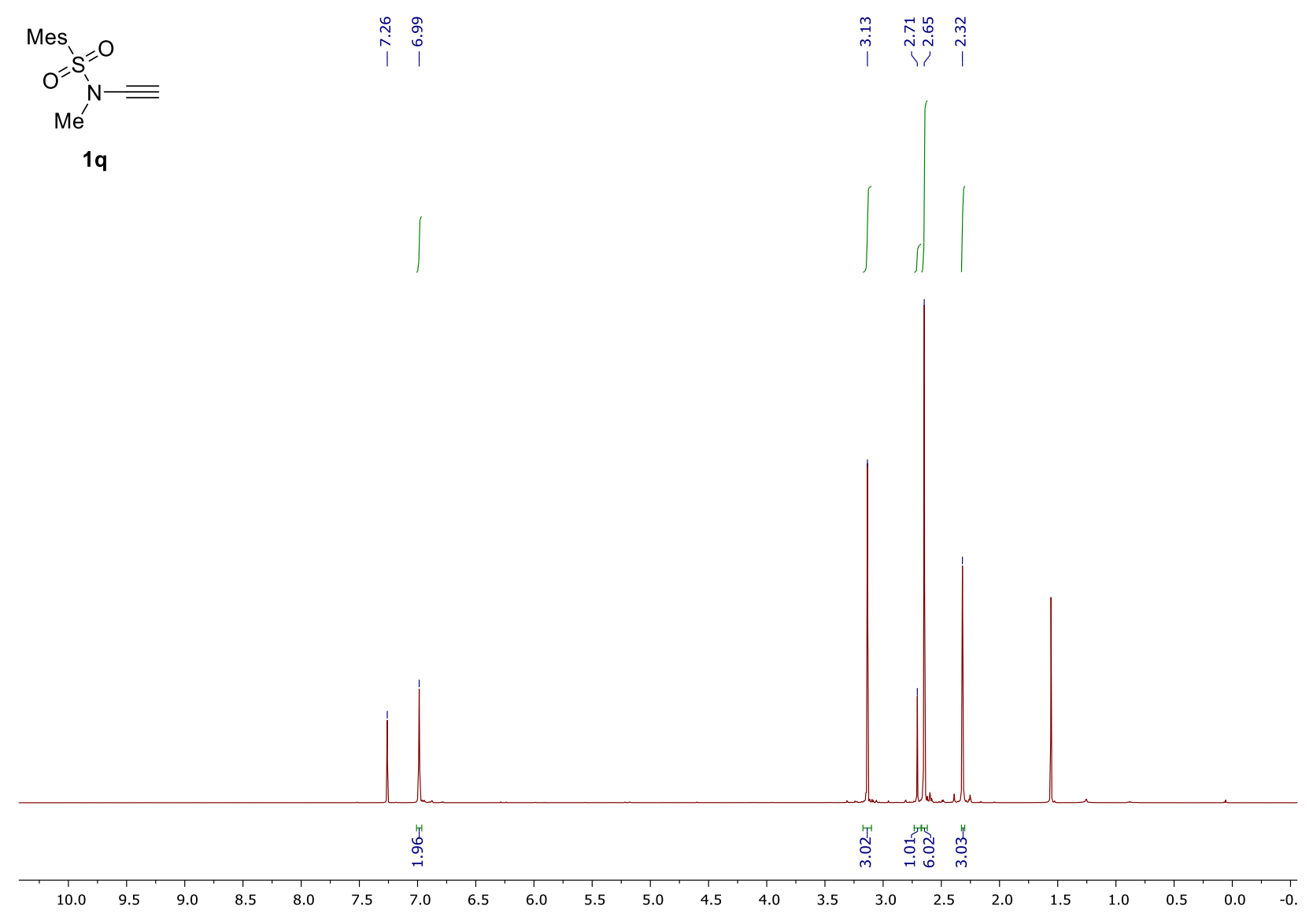

${ }^{13} \mathrm{C}\left\{{ }^{1} \mathrm{H}\right\} \mathrm{NMR}\left(100 \mathrm{MHz}, \mathrm{CDCl}_{3}\right)$

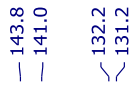

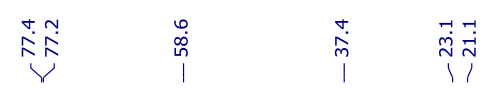

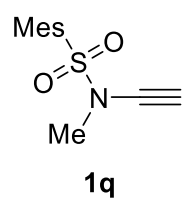

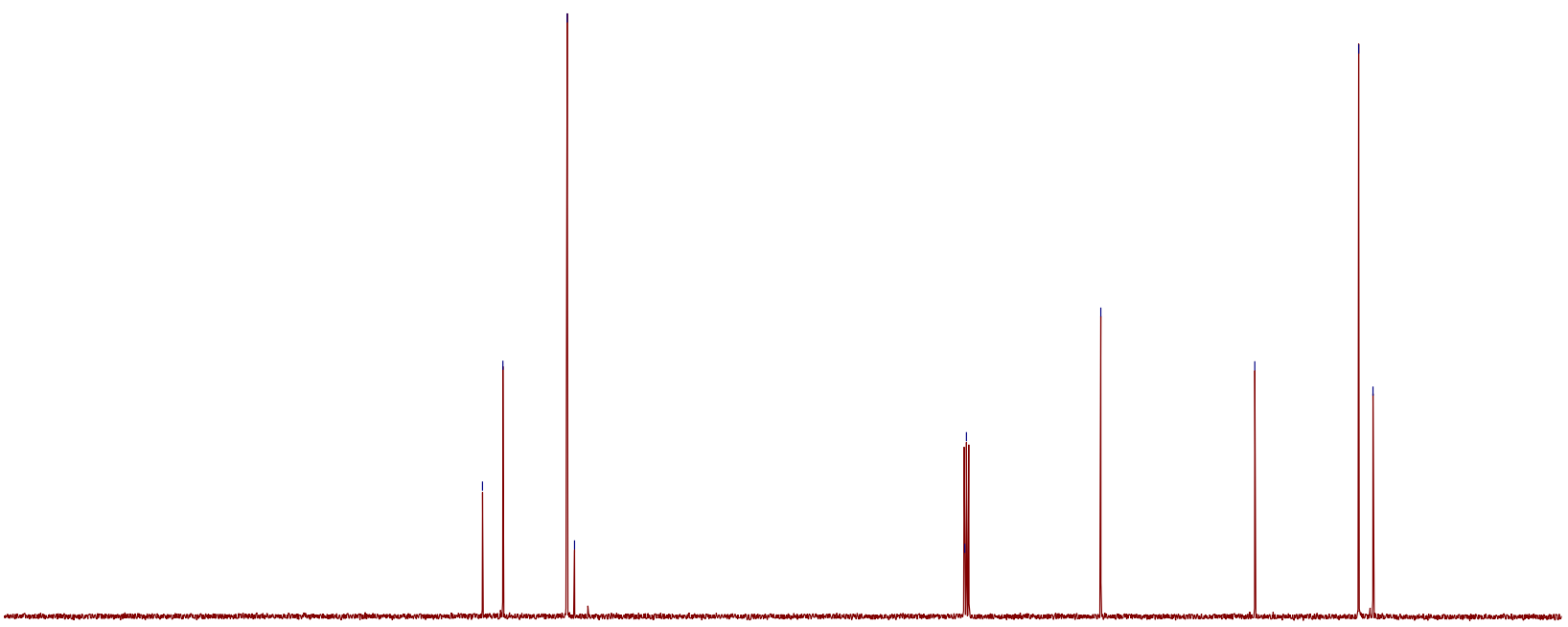

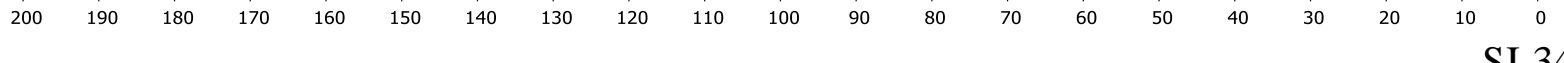


${ }^{1} \mathrm{H}$ NMR (400 MHz, $\left.\mathrm{CDCl}_{3}\right)$

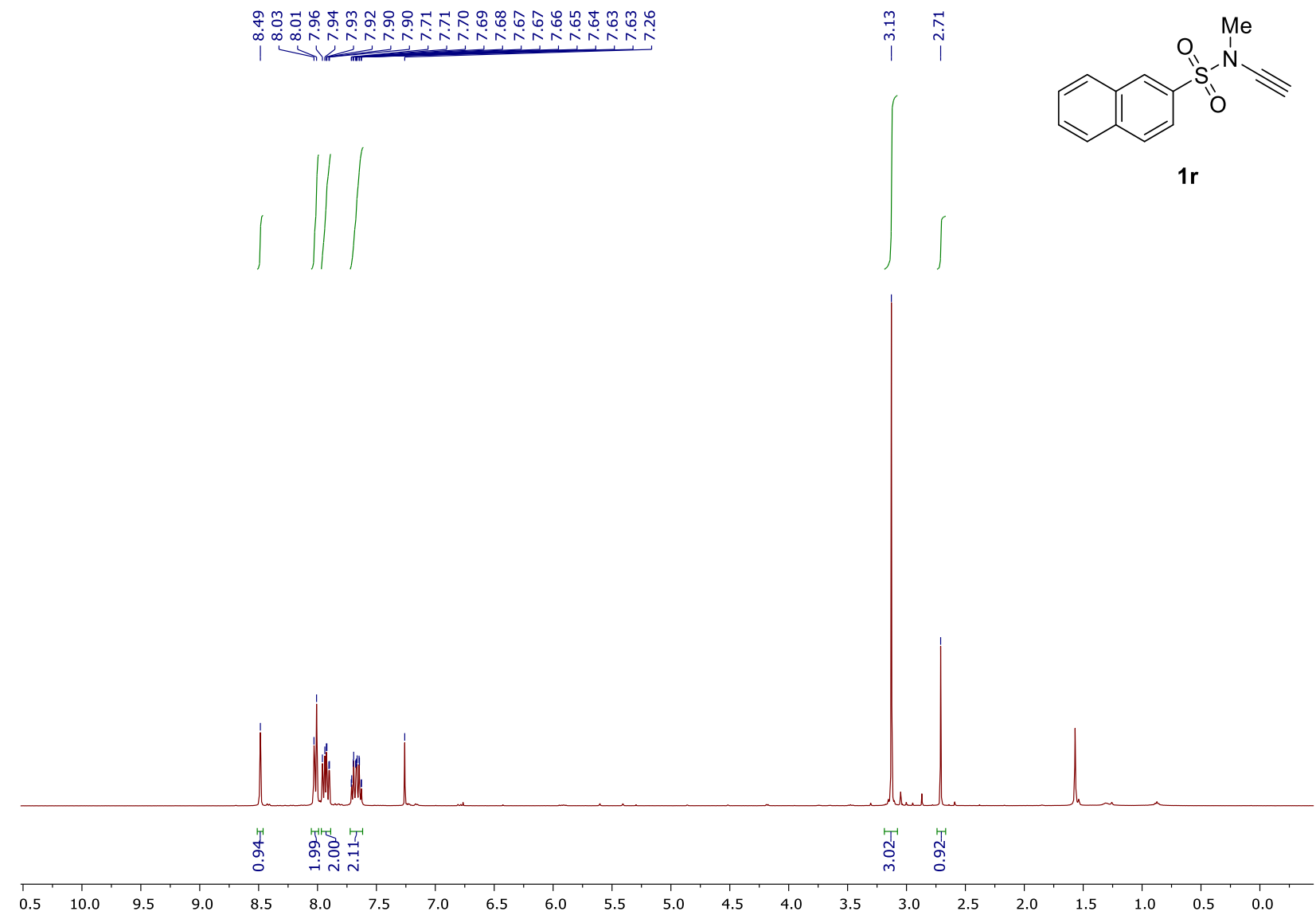

${ }^{13} \mathrm{C}\left\{{ }^{1} \mathrm{H}\right\}$ NMR $\left(100 \mathrm{MHz}, \mathrm{CDCl}_{3}\right)$
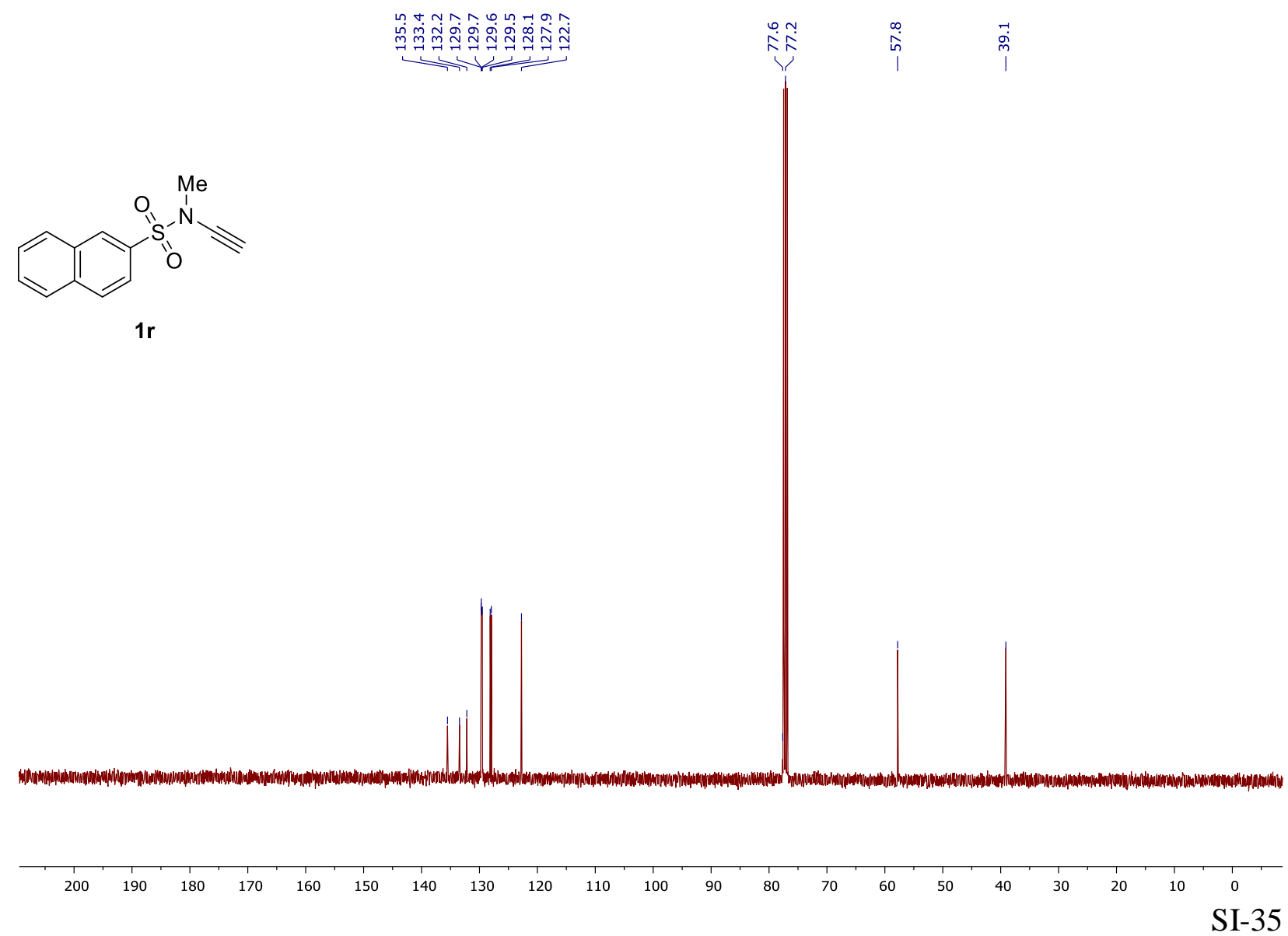
${ }^{1} \mathrm{H}$ NMR $\left(400 \mathrm{MHz}, \mathrm{CDCl}_{3}\right)$

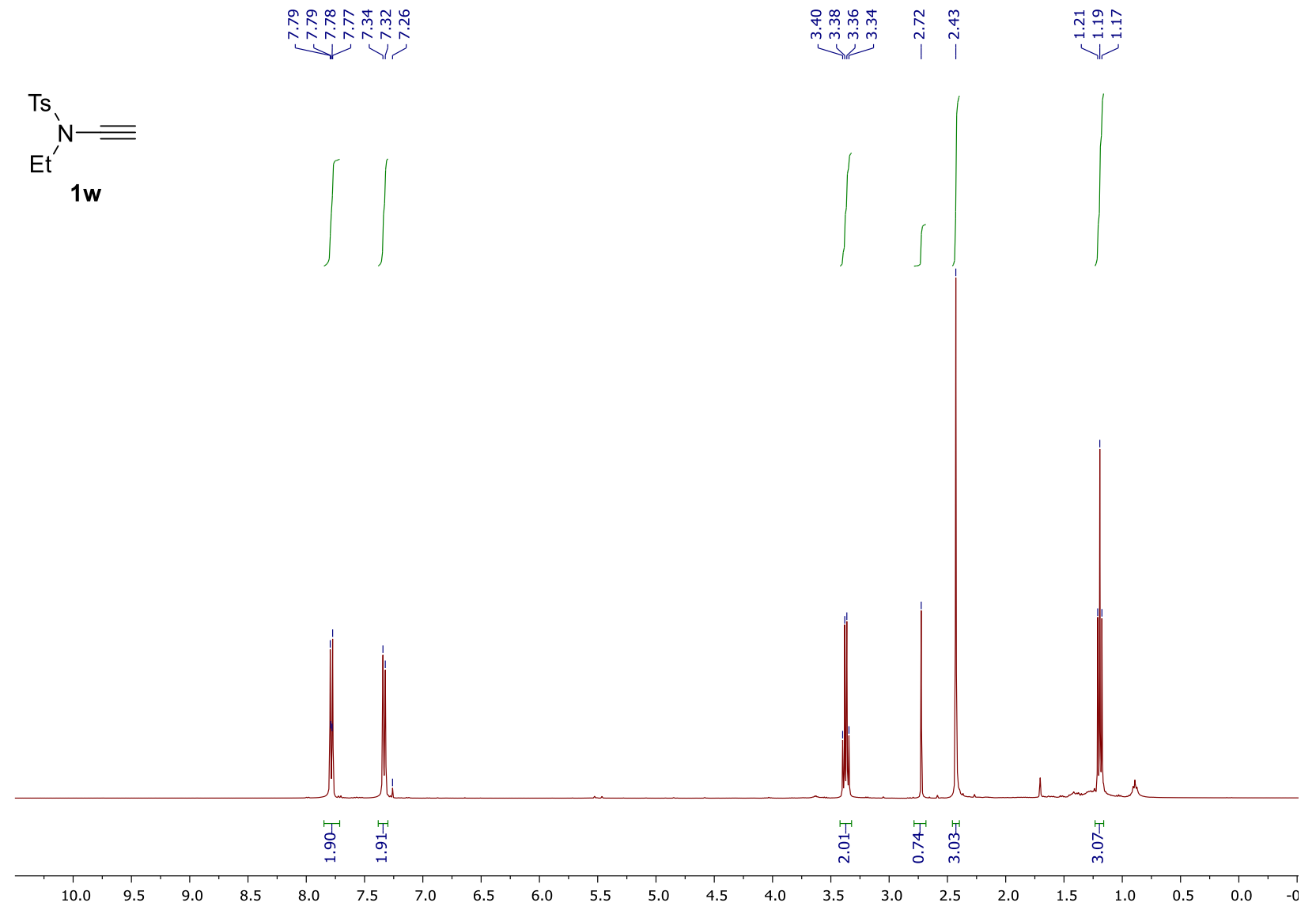

${ }^{13} \mathrm{C}\left\{{ }^{1} \mathrm{H}\right\} \mathrm{NMR}\left(100 \mathrm{MHz}, \mathrm{CDCl}_{3}\right)$

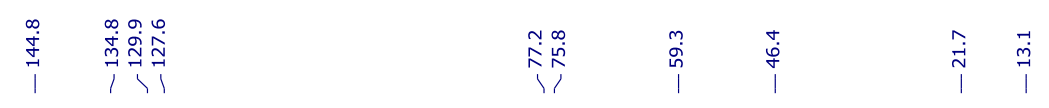
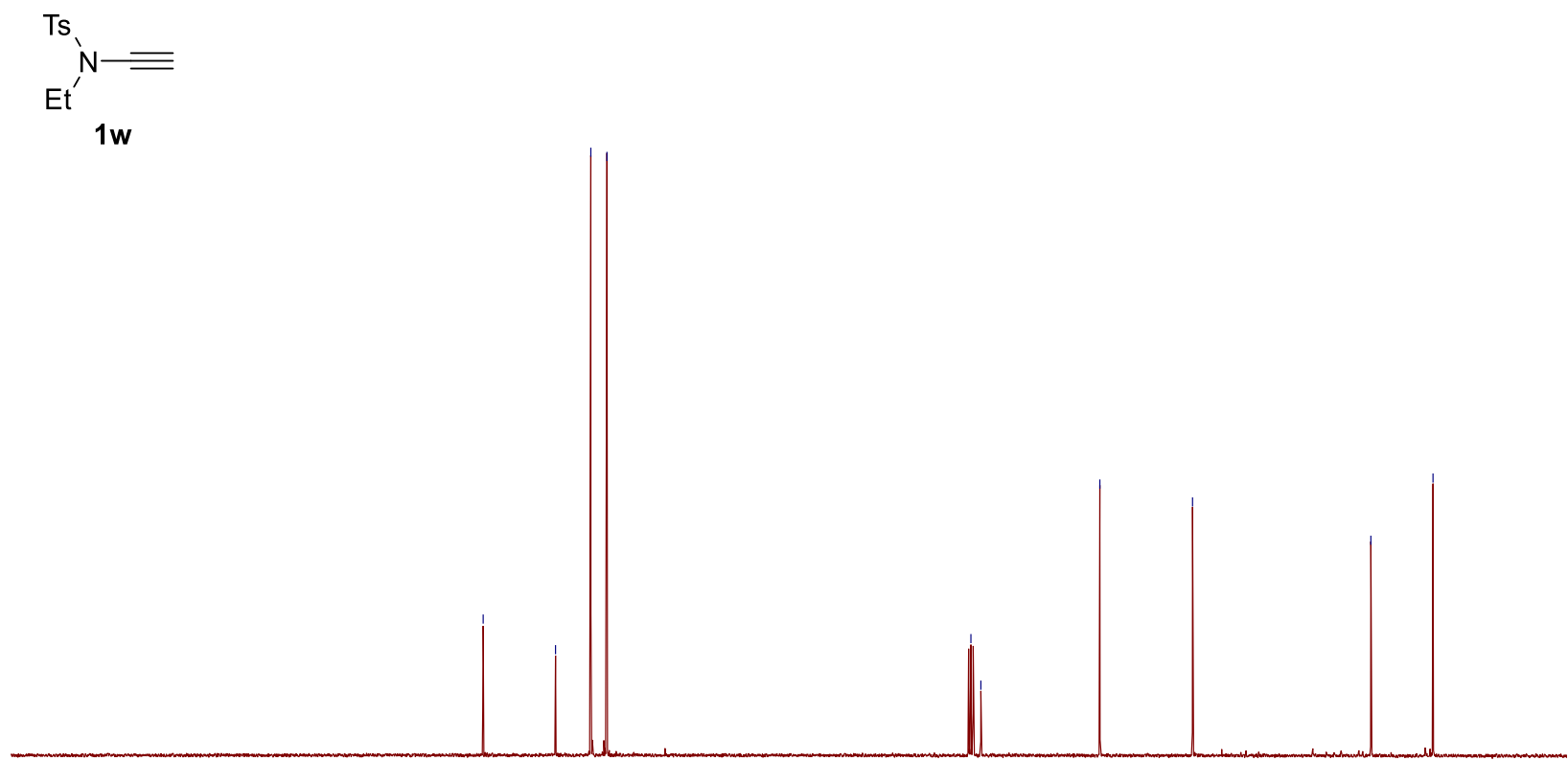

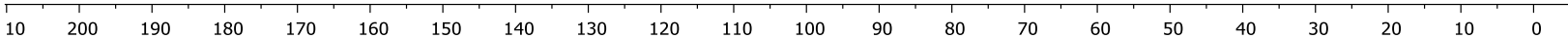


${ }^{1} \mathrm{H}$ NMR (400 MHz, $\left.\mathrm{CDCl}_{3}\right)$

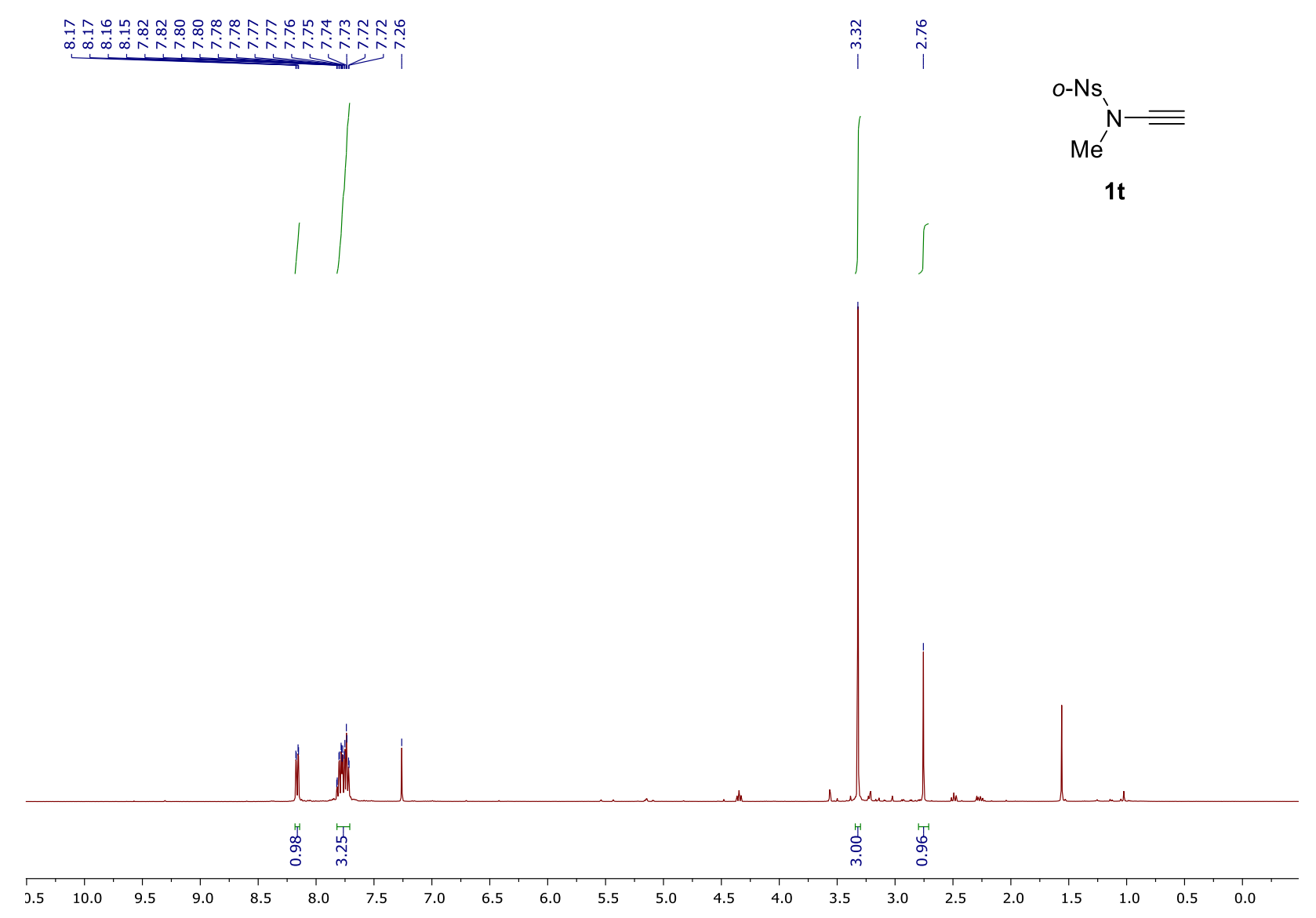

${ }^{13} \mathrm{C}\left\{{ }^{1} \mathrm{H}\right\} \mathrm{NMR}\left(100 \mathrm{MHz}, \mathrm{CDCl}_{3}\right)$

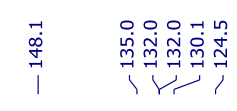

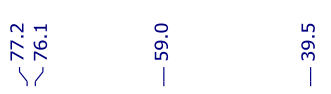

$\mathrm{Me}_{1 \mathrm{t}}^{\mathrm{O}}=$

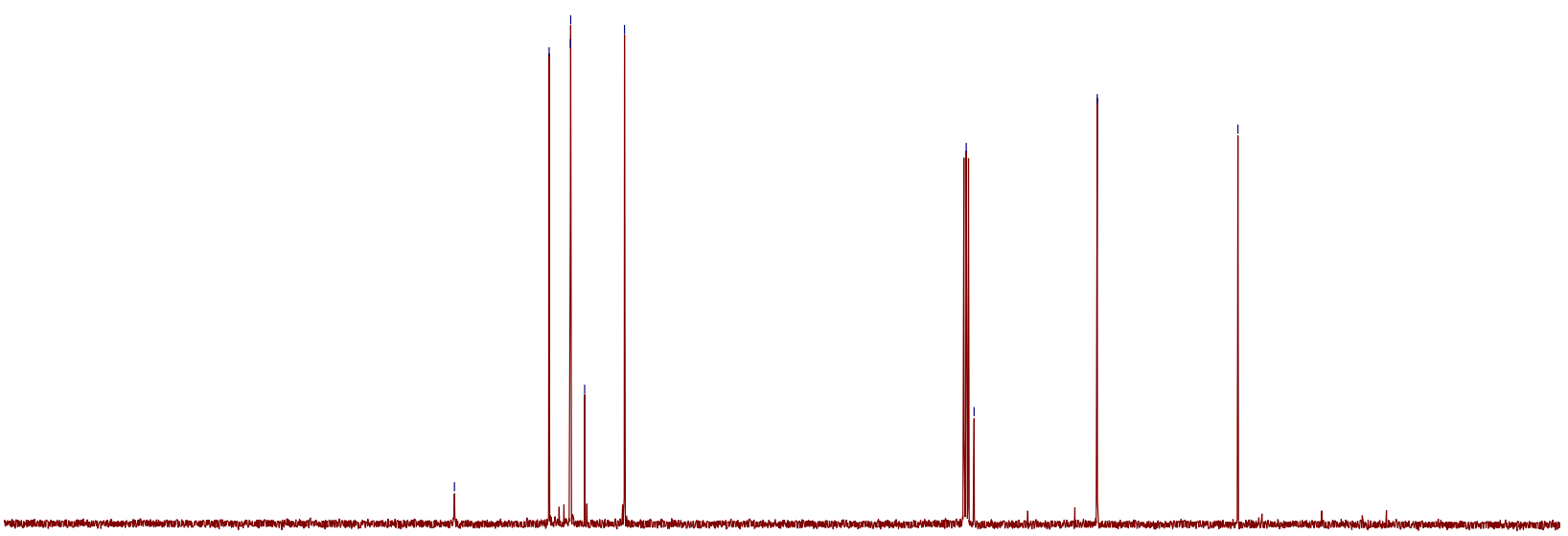

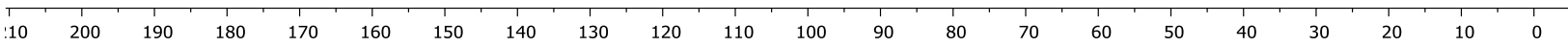




\section{XRD Single Crystal Structure of 3o:}

The crystals were prepared by slow evaporation of solution of $\mathbf{3 o}$ in $\mathrm{MeCN}$ at room temperature. For single crystal X-ray diffraction experiment the crystal was fixed on a micro mount and placed on a SuperNova, Single source at offset/far, HyPix3000 diffractometer using Mo Ka monochromated radiation. The structure has been solved by ShelXT [G. M. Sheldrick, Acta Crystallogr. Sect. A 2015, 71, 3-8] structure solution programs using Intrinsic Phasing, respectively, and refined by means of the SHELXL program [G. M. Sheldrick, Acta Crystallogr. Sect. $C$ 2015, 71, 3-8] incorporated in the OLEX2 program package [O. V. Dolomanov, L. J. Bourhis, R. J. Gildea, J. A. K. Howard, H. Puschmann, J. Appl. Cryst., 2009, 42, 339-341].

\begin{tabular}{|c|c|c|}
\hline Bond precision: & $\mathrm{C}-\mathrm{C}=0.0036 \mathrm{~A}$ & Wavelength $=1.54184$ \\
\hline Cell: & $b=9.2119(3)$ & $c=9.6426(2)$ \\
\hline & $12.537(2)$ beta $=98.770(2)$ & gamma $=110.976(2)$ \\
\hline \multicolumn{3}{|c|}{ Temperature: $100 \mathrm{~K}$} \\
\hline & Calculated & Reported \\
\hline Volume & $636.89(4)$ & $636.89(3)$ \\
\hline Space group & $\mathrm{P}-1$ & $\mathrm{P}-1$ \\
\hline Hall group & $-\mathrm{P} 1$ & $-\mathrm{P} 1$ \\
\hline Moiety formula & $\mathrm{C} 11 \mathrm{H} 11 \mathrm{Br} \mathrm{N} 2 \mathrm{O} 3 \mathrm{~S}$ & $\mathrm{C} 11 \mathrm{H} 11 \mathrm{Br}$ N2 O3 S \\
\hline Sum formula & $\mathrm{C} 11 \mathrm{H} 11 \mathrm{Br}$ N2 O3 S & C11 H11 Br N2 O3 S \\
\hline $\mathrm{Mr}$ & 331.18 & 331.19 \\
\hline Dx,g cm-3 & 1.727 & 1.727 \\
\hline $\mathrm{Z}$ & 2 & 2 \\
\hline $\mathrm{Mu}(\mathrm{mm}-1)$ & 5.974 & 5.974 \\
\hline F000 & 332.0 & 332.0 \\
\hline F000' & 332.10 & \\
\hline $\mathrm{h}, \mathrm{k}, \mathrm{lmax}$ & $10,11,11$ & $10,11,11$ \\
\hline Nref & 2414 & 2410 \\
\hline Tmin,Tmax & $0.513,0.620$ & $0.872,1.000$ \\
\hline Tmin' & 0.389 & \\
\hline \multicolumn{3}{|c|}{$\begin{array}{l}\text { Correction method }=\text { \# Reported T Limits: Tmin }=0.872 \text { Tmax }=1.000 \\
\text { AbsCorr }=\text { MULTI-SCAN }\end{array}$} \\
\hline \multicolumn{2}{|c|}{ Data completeness $=0.998$} & $=69.949$ \\
\hline \multicolumn{2}{|c|}{$\mathrm{R}($ reflections $)=0.0270(2329)$} & lections $)=0.0676(2410)$ \\
\hline$S=1.060$ & Npar $=165$ & \\
\hline
\end{tabular}<smiles>Cc1ncc(N(C)S(=O)(=O)c2ccc(Br)cc2)o1</smiles> 


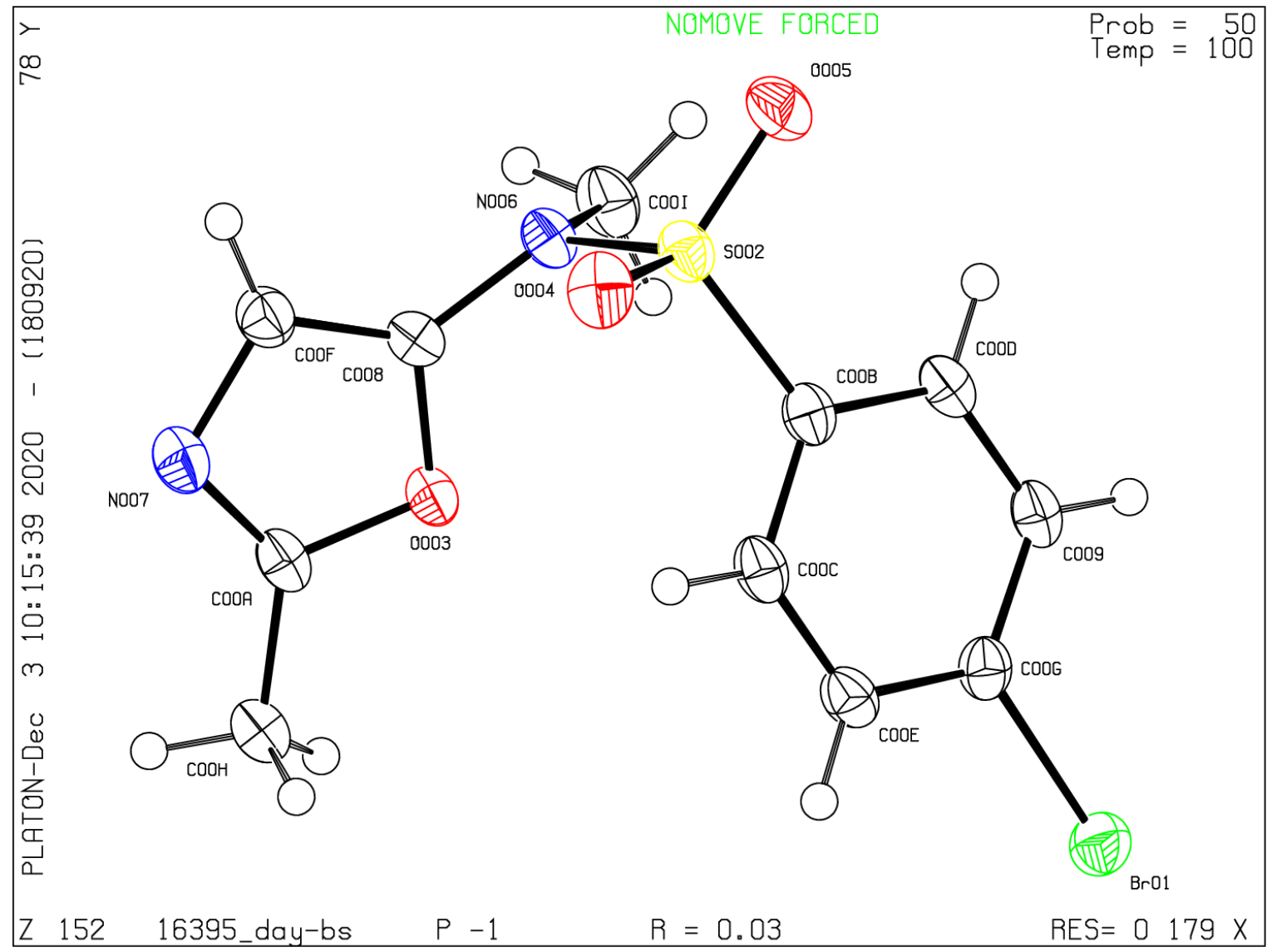

3o (50\% probability amplitude displacement ellipsoids; CCDC 2035080) 